\title{
ANÁLISES DE ROCHAS POR ESPECTROMETRIA DE EMISSÃO ATÔMICA COM PLASMA INDUZIDO EMPREGANDO SISTEMA DE INJECÃO EM FLUXO E MÉTODO GENERALIZADO DAS ADIÇÕES PADRÃO
}

MARIA FERNANDA GEORGINA GINE ROSIAS

Orientador: Prof. Dr. HENRIQUE BERGAMIN FILHO

Tese apresentada à Escola Superior de Agricultura "Luiz de Queiroz", da Universidade de São Paulo, para obtenção do título de Doutor em Agronomia. ÁREA DE CONCENTRAÇÃO: Solos $\theta \mathrm{Nu}$ trição de Plantas.

\footnotetext{
$P \mid R A C I C A B A$

Estado de São Paulo - Brasil Junho - 1986
} 
.i

Para Gastón, Daniela e Gastoncito DED ICO 


\section{* agradecimentos **}

Ao Centro de Energia Nuclear na Agricultura (CENA), a Fundaçăo de Amparo a Fiesquisa do Estado de Săo Faulo (FAFESF', ao Fundo de Incentivo á Fiesquisa (FIFEC) do Banco do Brasil, ao Conselho Nacional de Desenvolvimento Científico e Tecnolögico (CNFq) e f Financiadora de Estudas e Frojetas (FINEF').

Aos integrantes do grupo de pesquisa da sẹ̆a de Quimica Analitica do Centro de Energia Nuclear na Agricultura pela amizade e contribuicáa na minha formaça profissional.

Aos colegas do Instituto de Quimica da Universidade Estadual de Campinas, pelas sugestäes e discussàes durante a desenvalvimento deste trabalho

Aos estagiảrios e técnicos, que no exercicio de suas funçòes .sempre estiveram prontos a colaborar na pesquisa realizada.

Ao todas colaboradores que de uma forma ou de outra, me auxiliaram nos mais variados serviços possibilitando a realizaça deste trabaliho. 
INDICE

Pảgina

FESUMO. ............................ $i x$

SUMMAFY. ............................

1. INTRODUCAOA....................... 1

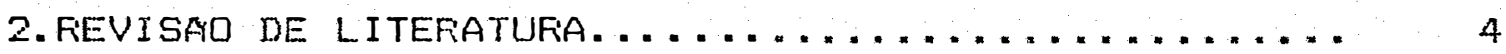

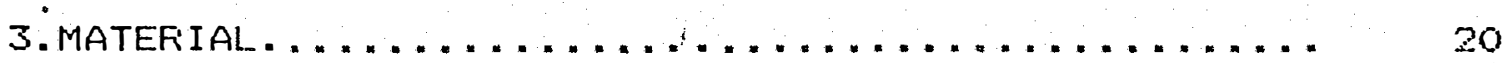

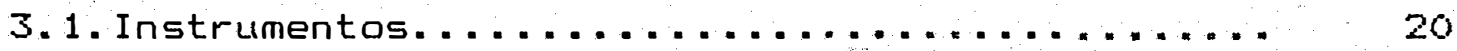

3.2. Soluçdes padrào e reagentes............. 22

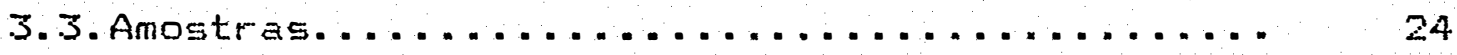

3.3.1.Amostras sinteticas............. 24

3.3.2. Amostras de rochas............. 25

3.3.3.Materiais de referencia certificados.... 26

3.4. Frogramas computacionais.............. 27

3.4.1. Operaçăo do ICF................. 27

3.4.2. Comando do sistema FIA-ICF........... 29

3.4.3.Frocessamento do SAM e GSAM.......... 29

4.METODO.............................. 31

4. 1. Métodos para contornar inteferencias........ 31

4.1.1. Analise multielementar e GSAM......... 31

4.1.2. Considerạ̧ŏes para corrẹ̣ăo das interferencias nas analises de rochas

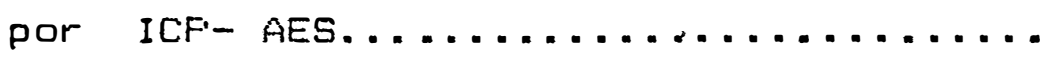




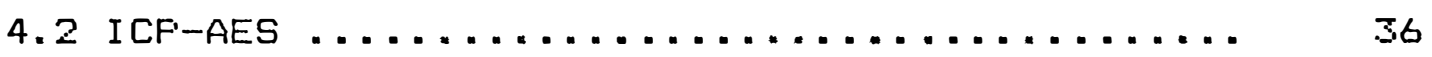

4.2.1. Condiçdes de operaçăo do ICF-AES....... 36

4.2.2. Avaliaçăo das interferencias do ICF-AES.. 37

4.2.3.Efeito matricial e deteç̧ăo de ele-

mentos traços................. $\$ 8$

4.2.4. Frocedimento para determinar as caracteristicas de deteç̧ăo dos elemen-

tos $\operatorname{tracos} . \ldots \ldots \ldots \ldots \ldots \ldots \ldots \ldots \ldots \ldots$

4.3.Sistema FIA-ICF................... 40

4.3.1. Consideraçòes sobre ó sistema........ 40

4.3.2. Frojeto do sistema.............. 40

4.3.3.Frocedimento experimental para dimensionamento do sistema acoplado FIA-ICF....

4.4. Sistema FIA para automaçào do procedimen-

to das adiçós padrăo................ 43

4.4.1.Frojeto do sistema................ 43

4.4.2. Dimensionamento dos sistemas FIA-ICF'

para efetuar as adiçöes............ 45

4.4.3.Funcionamento do sistema........... 47

4.5. O sistema proposto................ 48

5. FiESULtAdOS E DISCUSSAO................ 52

5.1. Dtimizaçào das condiçỏes de operạ̧ăo...... 52

5.2. Curvas de calibrạ̧ăo................ 53

5.3. Matriz de calibrạ̧a multielementar....... 57

5.4. Correçăo de B.G.................... 60

5.5. Efeito de matriz sobre as caracteristicas de deteç̧ăo dos elementos traços........... 


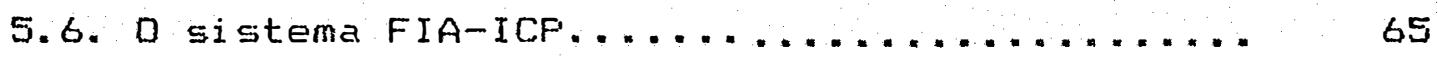

5.7. Sistema FIA para efetuar adiçesd ......... 66

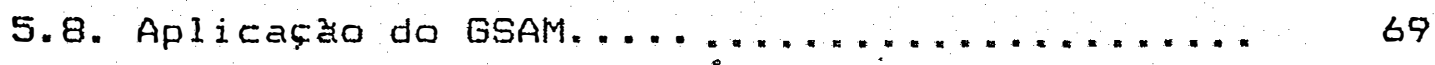

5.9. Avaliaçăo da precisăo e exatidăo dos resultados....................... 72

6. CONCLUSBES..........................

7. BIBLIOGRAFIA. .................... 84 


\section{LISTA DE TABELAS}

Tabela

Pagina

1 Caracterizaçå dos canais analiticos

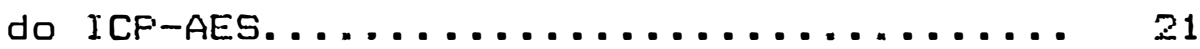

2 Soluçdes padrào estoque............... . 23

3 Composiçăo de Smacro para simulạ̧ăo de solubilizados de rochas.............. 25

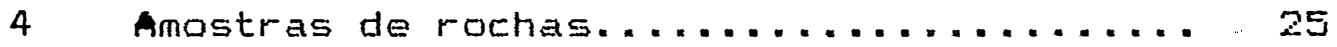

5 Materiais de referencia certificados..... 26

6 Dimensionamento do sistema proposto....... 48

$7 \quad$ Curvas de calibraçăo............... 54

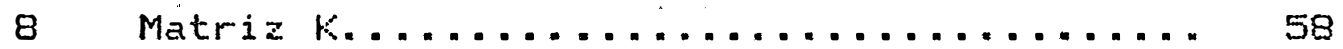

9 Avaliạ̧ăo das interferencias em \%t:ii..... 60.

10 Concentraçues aparentes e minimas detectảveis na presença de diferentes matrizes simuladas................... 64

11 Soluçŭes padråo geradas no sistema FIAICF $\ldots \ldots \ldots \ldots \ldots \ldots \ldots \ldots \ldots \ldots \ldots \ldots \ldots \ldots$

12 . Fesultados gerados pelo sistema FIA-ICF para aplicaçăo do GSAM na amostra de basalto BHVO-1................. 70

13 Comparaçåo das matrizes Kobtidas pelo GSAM para as amostras EHVO-1 e BCFi-1..... 71

14 Fiesultados parciais de amostras de rochas. 73

15 Riesultados obtidos com materiais de referencia certificados............... 76 
.vii.

Tabela

Pagina

16 Correlaçáa entre resultados obtidos e certificados..................... 78

17 Resultados totais de amostras de rachas... . 81 


\section{LISTA DE FIGURAS}

Figura

Pågina

1 Sistema FIA que utiliza injeçăo por tempo.........................

2 Sistema de amostragem na zona dispersa.... 46

3 Esquema do sistema FIA-ICF proposto....... 49

4 Efeito da potencia da fonte de radio-

frequència e da pressào de argónio na

emissào de Mn..................... 53

5 Efeito das concentraçues de Al no BEC

do As,F,Mo e de Mg no EEC do $\mathrm{Cr}, V$ e F..... 61

6 Efeito da potencia da fonte de radio-

frequencia e da pressào de argónio

sobre os valores do BEC do sensor Mn...... 62

7 Sequencia das soluçes padră geradas

pela amostragem na zona dispersa........ 67 
ANALISES DE ROCHAS POR ESPECTROMETRIA DE EMISSAO ATOMICA COM PLASMA INDUZIDO EMFREGANDO SISTEMA DE INJEÇAO EM FLUXO E METODO GENERALIZADO DAS ADIGGES PADRAO

Prof.Dr. Henrique Bergamin Filho

- Orientador -

RESUMO

As determinaçöes simultaneas e multielementares dos elementos de interesse em solubilizados de rochas, por espectrometria de emissåo atómica com plasma induzido em argönio, så afetadas por värios tipos de interfertencias. A utilizaçăo de sistemas de injeçăo em fluxio adaptados ao espectrometro permitiu avaliar as interferencias que modificam os sinais analiticos nos sensores dos elementos traços.

A caracterizaçăo de cada sensor na sua capacidade de deteç̧ăo de värios elementos, foi representada pelos coeficientes de sensibilidade, constituindo a matriz K. A forma de obtençåa da matriz K durante o processamento de diferentes amostras, foi amplamente estudada. 
0 método generalizado das adiç̧es padrăo foi considerado como o meio mais preciso e eficiente para obtença da matriz $K$, uma vez que cada elemento desta matriz provém de um processo de regressào linear. A aplicaçăo deste método foi facilitada, após a desenvolvimento de um sistema por injȩ̣ăo em fluxo para automaçà̆ das adiçđes padr สัด.

A velocidade analitica para determinar 20 elementos em uma amostra, considerando-se três niveis de adiçăo por elemento, foi de aproximadamente 120 determinaçus por hora.

Os elementos $\mathrm{Ba}, \mathrm{Ni}$, Sr, Cd e Zr, que ocorrem em baixas concentraçós nos solubilizados de rochas podem ser determinados no ICF-AES na forma convencional, o que aumenta a frequencia analitica para aproximadamente 160 determinaçes por hora.

A exatidăo do método foi comprovada utilizando-se materiais de referencia certificados de diferentes tipos de rochas de diversas procedencias.

- desvio padrào relativo das medidas sucessivas de uma mesma amostra, em geral foi menor que $2 \%$ para os elementos que se encontram na faixa de concentraçóes de 1 a $10 \mathrm{mg} / 1$ no solubilizado. 
INTERFEFENCE COMPENSATIONS IN ICF-AES ROCK ANALYSIS USING FLOW INJECTION AND THE GENERALIZED STANDARD ADDITION METHOD

Maria Fernanda Georgina Giné Rosias

Prof.Dr. Henrique Bergamin Filho

- Adviser -

SUMMARY

The aim of this study was to evaluate and correct the spectral interferences for the determination of trace elements in rock: samples by inductively coupled plasma atomic esmission spectrometry (ICF-AES).

The interelement effects were evaluated by using a matrix simulator flow system coupled to the spectrometer. A multianalyte calibration matrix (K matrix), including the sensitivity coefficients of all analytes at all sensors, was obtained by using the Generalized standard Addition Method (GSAM). This method uses the response variations related to the incremental quantities added to the samples with further calculations of the $K$ matrix regardless of background problems. The 
.xii.

behaviour of the $k$ matrix when different samples are processed under the same experimental conditions was investigated.

A flow injection system with zone sampling was designed in order to perform, in an automated form, the additions required for the application of the GSAl. The suggested analytical procedure permits an analytical frequency of up to 120 determinations per hour, including a complete GSAM application.

The accuracy was assessed after the analysis of standard certified reference materials of rock samples. The precision, evaluated after replicated measurements of typical samples, in the range of 1,0 to $10,0 \mathrm{mg} / 1$, in the rock: solutions, was characterized by a relative standard deviation lower than $2 \%$. 


\section{INTRODUÇAO}

Em ICF-AES*, as interferencias espectrais causadas pela coincidencia de linhas de emissäo ou pela lua difun.. sa, constituem um serrio problema analitico nas determinaçdes de elementos que se encontram em baikas concentraçâs em solubilizados de rochas.

Nestas analises, a luz difusa de devida, principalmente, á emissào intensa dos elementos maiores da matriz. Esta interferencia pode ser quantificada através da mediçào da intensidade da radiaçào de fundo, ou BG*⿻丷木, nas imediaçoes das linhas de emissato.

As interferencias espectrais causadas pela superposiçăo de linhas de emissào, podem ser contornadas utilizando-se a anßalise multicomponente. A anảlise multicomponente, procura quantificar as interaçes na deteç̣̂ă dos elementos da amostra, atraves da determinaça dos coeficientes de sensibilidade com que cada elemento é detectado em cada sensor. O Metado Generalizado das Adiçbes Fadrato (GSAM***), é um tipo de analise multicomponente, * ICF-AES - do ingles "Inductively Coupled Filasma Atomic Emission Spectrometry ** BG - do ingles "Backiground" ** GSAM - do ingles "Generalized Standard Addition Method" 
onde os coeficientes de sensibilidade săo determinados pela regressăo linear da variaçăo das réspostas em cada sensor, apỏs o processamento de vârios niveis de ad̀ calo para cada elemento da amostra. A precisào dos resultados obtidos por este método depende principalmente do número de adiços efetuadas para cada elemento e dos niveis. de concentraçues adicionados. A aplicafảo do GSAM exige um nümero muito grande de manipulaças dias soluçues, sendo portanto aconselhảvel a sua automaçăo.

A automaçäo do procedimentio das adicobes padráa tem sido desenvolvida utilizando sistemas de anảlise por injeçăo em fluko, FIA*. Estes sistemas utilizam a introduçăo reprodutivel de amostras en um fluido que a transporta em direçăo ao detector. Durante o transporte, a amostra sofre um processo continuo de dispersăo, constituindo-se em uma zona de distribuiçă, onde os gradientes de concentraça estabelecidos săo inerentes á dimensionamenta do sistema e ás concentraçues envolvidas. A exploraçăo dos gradientes de concentraçă, empregando uma unidade de comutaçăo controlada eletronicamente, possibilitou a automaçăo do procedimento das adiçăes padrä̌o. O objetivo principal do presente trabaliho consiste em contornar, de forma automatizada, as intereferências que se apresentam nas analises de solubilizados de rochas por ICF-AES.

Para a automaçơo das adiçües, foi desenvolvido um sistema FIA-ICF, que utiliza reamostragem na zona dis* FIA - do ingles "Flow Injection Analysis" 
persa do padrăo, para gerar soluçes de diferentes concentraçdes. Ds métodos jả existentes na literatura for am considerados inadequados, seja por nåo serem adaptảveis ao ICF, nåo apresentarem grau de automaçăo suficiente ou mesmo por nå corresponderem ás caracterlsticas de precisáa e velocidade analitica desejadas. 


\section{REVISAOD DE LITERATURA}

A estabilizaçăo de uma descarga de plasma induzido, operando á pressảo atmosfärica e com gases fluindo por um tubo aberto, foi conseguida pela primeira vez por Reed (1961). Este autor patenteou a configuraçąo do plasma induzido (ICF) que era inicialmente utilizada como fonte de ions para crescimento de cristais. Fosteriormente, Reed em 1967 citado por Barnes (1978): sugeriu a utilizacáo da descarga do ICF como fonte para espectroscopia: A partir desse trabalho, surgiram dois grupos de pesquisa desenvolvendo independentemente a utilizaçăo do ICP na Quimica Analitica. Assim, Greenfield em 1964 e Wendt e Fassel em 1965 publicaram seus trabalihos sobre o potencial analitico do ICF. Greenfield em 1968, patenteou o arranjo contendo o nebulizador e tubo central para formaça do plasma conduzindo o aerosol da amostra para a chama. Dickinson e Fassel (1969), formularam um arranjo experimental que forçava o aerosol da amostra na linha central, ocorrendo nessa etapa a desolvatạ̧ăo antes de atingir a tocha. 
Fosteriormente, Fassel e Kiniseley (1974-a) e Greenfield et alii (1975), desenvolveram a configuraçăo que permitiu o desenvolvimento da Espectrometria de Emissăo Atomica com plasma induzido (ICF-AES) como têcnica analitica empregando-a nas mais diferentes aplica5. des.

No que se refere aos problemas de interferencias, os primeiros trabalhos mostravam-se otimistas. Segundo Fassel e Kniseley (1974-b), as altas temperaturas atingidas na fonte de plasma eram responsáveis por uma atomizaça mais completa que nas chamas convencionais, o que, junto com a utilizaçăo de um gảs inerte como carregador da amostra, fizeram com que o plasma apresentasse reduçăo das interferencias geralmente associadas as tecnicas que utilizavam chamas de combustáo.

Em 1982 fiybarczyk et alii, mostraram que as altas temperaturas do ICF năo permitiam a formaçà̀o de compostos refratarios, os quais constituem a principal interferencia quimica nas chamas por combustå.

$$
\text { Um estudo realizado por Mermet (1975) a Larson }
$$

et alii (1975), mostrou a relaça existente entre as condiças de operaçăo e a ocorrencia de interferencias espectrais. Larson et alii em 1976, descreveram o problema de interferencia devido a emissào intensa produida por alguns elementos e que atinge outros detectores afetando o nivel de radiaça de fundo (EG). Isto foi descrito principalmente para analises de elementos traços. Boumans $e$ de Boer em 1976, reali- 
zaram um estudo comparativo do efeito da nebulizạ̧ăo na magnitude das interferencias. Estes autores concluiram que os efeitos interferentes variavam com os parâmetros de operaçăo tais como potencia da radiofrequencia, forma do plasma, razăo dos fluxos, altura de observạ̧ăo da emissăo e tipo de nebulizạ̧ăo. Segundo Kornblum e de Galan (1977), no caso do ICF as expectativas de fonte livre de interferencias eram baseadas na extrapolaça para altas temperaturas dos valores reportados pela fisica de plasma e na possibilidade de suprimir ionizạ̧des através do emprego de "buffers" adequados. Esses autores estudaram os efeitos de interferencias produzidos pela adiça de elementos de baixo potencial de ionizaçåa.

Berman e McLaren en 1978, estabeleceram as condiçáes de compromisso para processamento de anảlises simultaneas multielementares no ICF. Os principais parametros que produziam maior interferencia afetando também os limites de deteç̣ăo eram : a altura de observaça, a energia da fonte de radiofrequencia, a vazăo e a pressào do argonio utilizado para nebulizaçăo. Fosteriormente, Mclaren et alii (1981), utilizaram diferentes recursos para contornar interferencias na analise simultanea de elementos maiores, menores e tracos em sedimentos marinhos. Empregaram correça de $\mathrm{GG}$ para determinar B, Ca, Fe, Mg, Na, Ti, As, $\mathrm{Cr}, \mathrm{Cu}, \mathrm{Mo}, \mathrm{Ni}, \mathrm{F}$ e $\mathrm{F}^{\prime} b$, fatores de correçào para Al,Mn,V e Zn e ambos os 
recursos para Ele, Cd e Co. Estes autores justificaram a ccorrencia de interferencias pelas diferenças existentes entre as matrizes da amostra e dos padröes. Também classificaram as intereferencias nas anklises por ICF en : espectroscỏpicas, devidas a luz direta e superposiçăo de linhas, e nåo espectroscópicas, devidas a problemas de nebulizaçào ou ionizaçào.

Em 1981, Schrader et alii descreveram as interfertencias espectrais devidas a llu difusa, a superposiफ̧ào de linhas vizinhas e a emissào e absorçào de bandas moleculares de $\mathrm{OH}_{3} \mathrm{NO}_{3}$ radicais $\mathrm{N}_{2}^{+}$ou devidas ao argonio. Observaram que as I inhas de enissäo do Al apresentavam um efeito de al argamento ao aumentar a concentraçăo, e isto podia causar interferencias. As concentraçes elevadas de All, eram também responsäveis por urn "continuum", nà regižlo do espectro correspondente ao ultra violeta entre 190 a $212 \mathrm{~nm}$.

Estes autores, definiram o BEC* ou BG expresso em unidades de concentraçăo e estudaram as vạriaçŏes deste sob diferentes condiçŏes de operaçăo.

Schmidt e Slavin (1982) propuseram a utilizaç⿳亠丷厂े० de padra $0^{\circ}$ interno para compensar os efeitos das interferencias nào espectroscopicas. Nesse trabalho, mostraram - aumento da precisào e exatidăo quando se utilizava Sc como padrảo interno na determinaçà̃o de Mn em soluçto de NaCl. Apontaram as dificuldades experimentais que

*EEC - do ingles Eackiground Equivalent Concentration. 
apareciams tais como o "continuum" que pode ser superado através de técnicas de correçáa do EG, probìmas de eficiencia da nebulizaçăo que foram superados utili-zando padrào interno e por ultimo, mudanças da matriz, as quais provavelmente tamben afetavam a nebulizaça s o transporte e a volatilizaça no ICF" . Fara minimizar estes problemas as autores recomenciaram a prepara de soluçaes padrào parecidas com as matrizes das amostras.

Larsen et alii (1973) utilizaram o metodo däs adiçes padráa para contornar os problemas de diferença de matriz entre a amostra e as soluçes padräa. Esse método sỏ e aplicável na regiăo onde a resposta do sensor apresenta-se linear ou pode ser lineariaada.

Zscheile et alii (1962) para analises multielementares aplicaram a regressáa linear utilizando o ma-todo dos quadrados minimos para estimar as concentraçes de cada componente na amostra. Estes autores efetuaram analise espectrofotométrica do sistema de 4 componentes formado por acidos constituintes da molecula de FiNA. Estabeleceram melaçoses 1ineares entre as curvas de absorfaro, usando 36 comprimentos de onda entre 220 e $290 \mathrm{~nm}$. Neste madelo consideraram que a resposta correspondente ao espectro de absorçáa da mistura era funçăo somente dos componentes conhecidos. Analizaram a estabilidade do sistema baseanda-se no desvio padräa dos valores abtidos para cada componente. 
Brown et alii (1982) apresentaram a ảlgebra

matricial envolvida na regressa linear do sistema multicomponente utilizando o metodo dos quadrados mànimos.

Warner et alii em 1977 observaram que a utilizaçăo do modelo linear multicomponente aplicado s analise de uma amostra complexa pode ter sua estabilidade afetada por nä́o considerar todos os componentes da amostra, sejam interferidos ou interferentes.

Fara os sistemas analiticos multielementares onde apresentam-se simultaneamente interferencias, efeito ma-tricial e mudangas do BG foi proposta a aplicaça do metodo generalizado das adiç̧es padraxo (GSAM) por Saxberg e Kowalski (1979). Este metodo combina a analise multicomponerte com o SAM*; permitindo a calibraça de uma maneira geral, ao promover adiçes de todos os elementos da amostra que sào interferentes e interferidos. Entretanto, apresenta as restriços de aplicaçăa correspondentes ao método dos quadrados minimos apresentadas por Phillips e Eyring (1.983), assim como as consideraçbes para aplicaça do SAM antes mencionadas.

Saxberg e Kowalski definiram a matriz K que corresponde aos coeficientes de sensibilidade de todos os sensores obtidos a partir da adiça de todos os elementos presentes na amostra. Fara processamento do GSAM afirmavam ser necessärio que o nủmero de sensores e o *SAM - do inglés "Standard Addition Method" 
numero de adiçōes sejam maiores ou iguais ào de analitos.*. A matria k era calculada atraves da relaçăo entre a matria das diferenças entre as respostas, antes e após a adiça, $e$ a matriz das concentraços adicionadas.

Jochum et alii (1981), estudaram o problema da amplificaça do erro quando este se propaga ate o resultado final nas analise multicomponentes utilizandose GSAM. A enfase desse trabalha foi dada 卢 influencia do projeto experimental sobre exatidáa da matriz $K$ e da concentraçăo do analito. A propagaçàio dos erros ocorre na determinaçăo da matriz do problema dos quadrados minimos e no calculo da matriz $K$ para determinar as concentraçes dos analitos. Nesse trabalho, a sureptibilidade da soluça numerica aos erros, ou em outias palavras, o fator de amplificaça do erro foi denominada condicäo do problema.

A metodologia do GSAM foi ampliada por Kalivas e Kowalski en 1982, de forma a permitir a deteç̧ăo e correçà̃o de mudanças graduais devidas a fenomeno deterministico ("drift"), que ocorrem no decurso da anklise.

Kalivas (1983) utilizou as dados obtidos por Zscheile et alii (1962), e simulou trés niveis de adiçàंo para cada um dos quatro componentes do sistema de forma a possibilitar a aplicaçà do GSAM. Fara a simulą̧ăa, foi aplicado o método de Monte Carlo * analito do ingles analyte. 
introduzindo um erro a acaso nas respostas iniciais corrigidas e nas diferencas entre as respostas finais e iniciais. A melhor exatida e precisalo foi conseguida quando os 36 sensorés foram utilizados e isto foi avaliado a partir da condiço de Ke Segundo o autor a condiçăo de $K$ pode ser utilizada como indicaçăo da estabilidade do sistema e ao mesmo tempo serve de medida

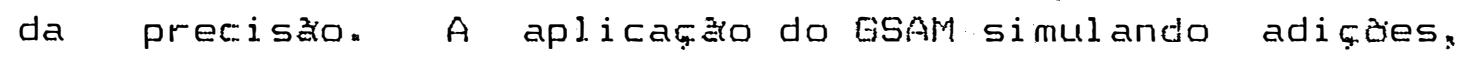
apresentou resultados mais estảveis que as obtidos pela analise multicomponente sẹm adiçßes.

- Frank et alii (1983) apresentaram o algoritmo dos quadrados minimos parciais fls * para análises multicomponentes. O FLS, substitui a regressa linear do GSAM e năo apresenta as restriçaes com relaça ao número de sensores, analitos e adicoes. Este metodo utiliza a transformaçăo das variaveis independentes originais em outras ortogonais as quais sảo combinaçęes lineares das variáveis independentes. Desde que as variaveis dependentes sà̃o também combinaçues lineares das ortogonais, entao, os coeficientes de regressä do novo sistema de equacotes servem para calcular os coeficientes das variáveis originais. Este notodo leva a lima reducto de variáveis o que permite filtrar ruido presente nos dados. Lma vantagem do fls a que funciona em sistemas subdeterminados, ou seja, a matriz $K$ pode ser calculada mesmo quando o numero de adiços è menor que $o$ de analitos e as concentrabes corrigidas * Fils do inglés Fartial Least Square. 
podem ser estimadas mesmo quando se tern menos sensores que analit.tos

Osten e Kowalski (1985) propuseram um modelo para detectir e corrigir o EG em anjise multi... componente: supondo que a amostra tem analitos conhecidos e outros interferentes dos quaj.s nồo se conhece a concentraça nem o espectro. Entretanto seu efeito sobre a resposta do sensor n-3simo pode ser defirida como o BG deperidente da concentraça. Eso. Este modelo presupóse que cada semsor responde linearmente a todos os componentes na faixa de concentraço de interesse e que nào ocorre $E G$ instrumental.

Lorber et alii (1985) apresentaram um método para correçaio do EG em anzilise multielementar. Trata-se de obter um vetor correspondente a EG e posteriormente minimizar o seu efeito atraves de un processo de ortogo nalizaçăo. Aplicaram este procedimento par"a anjlise de traços de $U$ em ácido fosforico por ICF-AEs. reportando interferencia significativa do Cr,Fe, Mg, V e CN. Vandeginste et alii (1983): propuseram o método GSAM iterativo, no qual, apos cada adifäo, calculam o grau de precisào e efetuam mais adiçues até atingir - grau de precisáo previamente estipulado. Isto foi conseguido por realimentaģo da resposta obtida apds cada adi tâto avaliando a linearidade e decidindo pela necessidade de novo passo. 0 GSAl originalmente propunha igual nimero de adifbes para todos os analitos, o que acarretava nivel de 'precisaio diferente 
para cada elemento. Com esse metodo o: autores procuraram corrigir a falha do GSAM original que nao dava informaçues a respeito do valor dos incrementos a adicionar e nå testava a linearidade.

Lingane citado por Fiatzlaff (1979) propos eretuar incrementos que levassem a obtengazo do dabro da resposta obtida inicialmente. Franke et alii (1978) Fiatzlaff (1979) estudaram o efeito do tamanho do incremento na precisàa dos resultados quando era aplicado - metodo das adiços padräa. a valor do incremento era determinado apes a primeira mediça de forma a que a resposta permanecesse na faika linear. Estes autores propuseram também luma base para determinar o numero b̀timo de adiç̧es padräo a efetuar.

Segundo Larsen et alii (1973), as procedimentos manuais para efetuar adiçes padräa sào demorados e sujeitos a contaminaşăo.

Leiritie e Mattsson en 1970 descreveram a automaçà̃o do procedimento de adiçăa padrăo para a determinaçăa de Mg, Ca, Ti, Mn, Cr e V por AAS*. Utilizaram um capilar em forma de $Y$ para aspirar a soluça padrăo simultaneamente com a amostra de forma que fossem introduzidos juntos na chama. Estes autores desenvolveram as equaçies corresponderites ao SAM, aplicando correça de volumes. Atraves do dimensionamento dos capilares, conseguiram um sistema com vazbes de $70 \%$ para amostra e $30 \%$ para a sol luça ào padrăo. *AAS do inglés Atamic Absorption Spectrametry 
Em 1975, Ruzicka e Hansen propuseram a analise por injeçà en fluko (FIA), a qual utiliza a injeçäo de volumes reprodutiveis da amostra em lum filuido que a transportal, sob condiçöes de fluxo laminar. No transporte da amostra, ocorre um processo continuo de dispersảo o qual permite a interaçăo da amostra como fluido carregador, estabelecendo-se uma zona onde ambos apresentan gradientes de concentraçă *ara caracterizar a dispersào definiram o coeficiente de dispersăo como sendo a relaçăo entre a coneentraçăo obtida no sistema por injeça e a concentraço correspondente a configuraçąo em volume infinito (Kmugy 1984). A zona dispersa da amostra, segundo aqueles autores, depende das caracteristicas das especcies quimicas envolvidas, do volume injetado, da vazào do carregador, do percurso analitico ate a deteç̧ăo, diaxmetro interno das tubulaçues e tipo de reator empregado.

Vanderslice et alii (1981), descreveram as rela5. Cues entre os fatores hidrodinamicos e geometricos que afetam a dispersào em um sistema FIA e os parametros da representaçäo grafica correspondente, tais como inicio, altura e largura da zoria da amostra. Painton e Mottola (1581), pesquisaram o efeito da ocorrencia de reaçào quimica, na distribuiçào das especies na zona da amostra. Em um trabalho posterior (1984), os mesmos autores modificaram a equaça geral que rege o transporte por conveçăo-difusào adicionando um termo que inclue a a influència da 
cinética quimica.

A propriedade dos sistemas FIA, dél estabejecer uma zona dispersa bem definida e reprodutivel, constituju a chave para automaça de värios procedimentos anal1ticos. Assimy Bergamin et alii em 1978 propuseram um sistema FIA com zonas coalescentes, onde tanto a amostra como o reagente formam zonas dispersas que coalescem; adicionando-se a conseguindo desta forma otimizar o consumo de reagentes. Em 1981, Jacintho et alii utilizaram o principio das zonas coalesicentes para diluifa de amostras em sistema FIÁ acoplado ao ICF.

Tyson e Idris (1981), desenvolveram um sistema FIA em linha ùnica para efetuar adiçes padrăa. A amostra era bombeada continuamente no nebulizador do AAS E as diferentes soluçes padrao eram injetadas. Os sinais transientes obtidos apresentavam-se positivos quando a concentraça do padrazo era maior que - da amostra e vice-versa.

Fosteriormente, Zagatto et alii (1983), efetuaram o método das adiços padrăo utilizando o sistema fIA com zonas coalescentes, para contornar problemas de interferecias nas analises por ICF-AES de $\mathrm{Zn}, \mathrm{Ni}$ e $\mathrm{Cu}$ em ligas. Neste sistema, ambas a amostra e a soluçăo padrăo, eram injetadas simul taneamente em suas respectivas solucbes carregadoras, sendo transportados para um ponto de confluencia onde ocorria a adiçà, formando uma zona ünica. 
.16 .

Com o advento da unidade de comutaço com controle de tempo programavel proposta por Bergamin et alii (1980), viabilizou-se o procedimento de retirar da zona dispersa da amostia, aliquotas reprodutiveis. As concentracodes dessas aliquotas eram determinadas pelo intervalo de tempo entre as comutaços como descrito por Reis et alii (1981). O sistema permitill a amostragem na zona disperse, onde ocorre gradiente de concentrạ̧a, e a injeçăo da porţăo selecionada em outro fluxo carregador. Esse sistema foi Proposto para efetuar diluiçues programảveis nas determinaçes de Fotassio por AAS.

Baseado nos principios de amostragem na zona dispersa e no de zonas coalescentes, foi possivel a exploraçào do gradiente de concentraçăo da zona da amostra nos sistemas FIA, para fins de automaçăo do procedimento de adiçăo padrăo (Ginè et alii, 1983). Nesse trabalho foi utilizado o sistema de amostragem na zona dispersa de uma ànica soluçào padräio de forma a gerar diferentes soluçoes padräo diluidas. 0 método das adi-cổes padråo foi empregado para contornar efeito matricial na determinaçăo espectrofotbmetrica de nitrato em material vegetal.

Kalivas e Kowalski em 1983 apresentaram um instrumento automatico para implementar o GSAM sob controle computacional. Fara isto, a amostra foi bom-beada em forma continua simultaneamente para a célula de fluxo de um espectrofotometro e para o 
sistema de adiços. As adiçues eram avaliadas por pesagem em balança. Efetuaram trés ndveis de adiçáa dos tres elementos analisadgs y utilizando válvulas de tres pasos com comutạ̧ăo preumatica para efetuar a entrada das soluçües. Um microprocessador comandava o sistema, ligando a bomba, ativando os solenoides. de comutaça, efetuando a leitura da balanga e controlando o espectrimetro. A tara da balança era efetuada com a amostra e depois da adiça efetuava-se nova pesagem. Fosteriormente agitava-se a mistura das soluçâs e finalmente a soluçă era dirigida para medi

Tyson et alii (1984), propuseram um sistema FIA para efetuar adiçes padräo com a amostra fluindo continuamente e diferentes volumes de uma ênica soluçă padräo sendo injetados em fluxos carregadores também variảveis. Os cảlculos levavam em consideraçăo as diluiçes do padră injetado e do interferente no carregador. Este prosedimento exigia um teste preliminar para se determinar a razao entre o interferente e 0 analito.

Israel e Barnes (1984), propuseram um metodo FIA inverso, onde o analito a ser determinado era bombeado continuamente para o nebulizador do ICF. Volumes discretos de ågua destilada ou outro solvente eram injetados no fluxo do analito e em seguidia, o mesmo volume de uma soluçăo padrăo era injetada. Este 
.18 .

modelo foi aplicado na determinaçăo de silicio em ảcido fosforico concentrado por ICF: utilizando o mécodo das adiçes padrăo para compensar efeitos de matriz.

Araujo et alii (1985), desenvolverim um sistema FIA para efetuar adiçes baseado na exploraço do gradiente de concentraçå da zona dispersa. o sistema utilizava duas unidades de comutạ̧ăo sendo uma destinada a entrada de água ou amostra e a outra, permitia a injeça da soluçăo padrăo que era adicionacia por confluencia. A correspondencia da funçăo concentraçäo-tempo obtida em ambas situaçdes permitia determinar as concentraçdes adicionadas e as respostas após adiça.

Zagatto et alii (1985), propuseram um sistema FIA com injeçäes sequenciais onde volumes de um mesmo padrac eram injetados em um mesmo fluido carregador. 0 sistema gerava a partir de uma solufäo concentrada diferentes zonas dispersas as quais se interpenetravam. A passagem destas pelo detector produzia maximos correspondentes ás regides mais concentradas e minimos correspondentes a concentraçăo na regiăo de interpenetraçăo das zonas. Os autores mostraram qué estes maximos e minimos apresentavam maior reprodutibilidade do que a conseguida nas regides onde os gradientes de concentraço era mais pronunciado. o processamento das adiçes padrao foi conseguido utilizando um sistema em confluencia. Este sistema permitia efetuar tres ou cinconiveis de adiça sem afetar sensivelmente a velocidade analitica 
caracteristica dos sistemas FIA e na requerendo controle de tempo. Este sistema foi utilizado para contornar efeito matricial nas analise de Cu por AAS em amostras contendo teores variakeis de etanol.

Bysouth e Tyson (1985), desenvalveram um sistema FIA-AAS com duas bombas peristalticas, uma delas de rotaça fixa para manter constante a vazăo de entrada no nebulizador e a outra de velocidade variavel controlada por computador. a processo baseava-se na substituiça de parte do diluente que vai para o nebulizador por uma soluçăo padrảo, 0 padrảa, desta forma, era adicionado continuamente por confluencia sobre a amostra.

Hirai e Tomokuni (1985) utilizaram um sistema FIA onde a concentraçăo aparente da amostra era medida duas vezes. A primeira medida era efetuada ap̉s a injeça sucessiva de padrues e amostras com uma soluçăo confluente de solvente. A segunda medida era efetuada pelo mesmo procedimento mas com adiça confluente de soluça padrăo que apresentasse uma leitura apropriada. O fator correspondente ao efeito matricial era calculado pela diferença entre os sinais em ambas situaçoes.

Harrow e Janata (1985), projetaram um sistema FIA com cinco vảvulas para efetuar as adiçoses padră. A amostra era injetada e o padrăo adicionado por confluencia durante um periodo de tempo variável. 


\section{MATERIAL}

\subsection{Instrumentos}

Foi utilizado um espectrometro de emissåo atomica com plasma induzido em argónio, Jarrell-Ash modelo 975 AtomComp, constituido pelos seguintes mádulas:

-um gerador de radiofrequencia capaz de fornecer potencia de ate $2 \mathrm{~kW}$ e frequencia de $27,13 \mathrm{HHz}$ a uma bobina de induça de cobre, onde se forma um campo magnetico oscilante responsavel pela sustenta5\%ัด do plasma:

-um conjunto nebulizador-catmara de condensạ̧à̆o-"tocha" de quartzo, atraves da qual a amostra e conduzida ao plasma. Foi utilizado nebulizador ajustảvel com fluxo cruzado:

-um espectrometro com montagem fiowland, equipado com 40 canais analiticos. No presente trabalho, foram utilizados 20 canais analiticos cujos comprimentos de onda sảo apresentados na Tabela 1 :

- un sistema otico para corresăo de BG que utiliza placa refratora para deslocamento do comprimento de onda.

- LIm computador FDF-E usado para processamento do sinal 
de salda do espectrometro. Este computador constitui um sistema dedicado com "hardware" e "software" especificos, para comando das atividades de padronizaça e de medicao do instrumento

-uma impressora Teletype:

Tabela 1. Caracterizaçăo dos canais analiticos do ICF-AES

\begin{tabular}{llll} 
Especie & $\lambda(\mathrm{nm})$ & Especcie & $\lambda(\mathrm{mm})$ \\
\hline Al I & 308,21 & Mn I I & 257,60 \\
As I & 193,60 & Mo I & 202,00 \\
Ba I & 455,40 & Ni I & 231,60 \\
Ca I & 317,90 & F I & 214,90 \\
Cd I & 228,80 & Fb I & 220,30 \\
Co I & 228,60 & Ti I I & 334,90 \\
Cr I & 267,70 & Sr I & 421,50 \\
Cu I & 324,70 & V I I & 292,46 \\
Fe I & 259,90 & Zn I & 213,80 \\
Mg II & 279,07 & Zr I I & 339,10
\end{tabular}

* Sào apresentados os comprimentos de ondad(nm) para cada linha de emissào I atomica ou II iónica.

Nos experimentos realizados com sistemas de analise por injeça em fluxo, foram ltilizados:

- Lima bomba peristaltica marca Ismatec modelo mp13-GJ4 equipada com 13 canais de bombeamento e 10 velocidades de rotacasos

-tubas de bombeamento de "Tygon" de diferentes diametros internos:

-tubos de polietileno com $0,86 \mathrm{~mm}$ de diametro interno para as linhas de transmissäo e reatores helifoidais; -conectores em forma de Y para adiça de fluxos con- 
fluentes construldos em acrilicos

-unidade de comutaçăo construida em acrilico, comandada. eletronicamente;

-regj.strador marca fiadiometer modelo FiECb1, equipado cem unidade de alta sensibilidade FEA101:

- espectrofotometro marca Eleckman modelo 23. provido de cubeta de fluxo Hellma-178 com volume interno de 80 fil e passo bitico de $10 \mathrm{~mm}$.

Alem dos instrumentas mencionados, empregou-se um microcomputador SACI (Sistema Automatico para Controle Instrumental), baseado no microprocessador 8085 da Intel, como unidade de comando para a comutaçăo do siste-ma de fluxo e iniciaşa do ICF.

Para tratamento dos dados foi utilizado um computador Erasiom modelo BFiloooM, equipado com impressora Elebra, monitor de video e sistema operacional F-80 para operar com Fortran.

Fara solubilizaça das amostras foi utilizado um bloco de aquecimento marca Sarge, com capacidade para 15 "bombas" de teflon, equipado com unidade de controle de temperatura e fabricado conforme prototipo da Seçà de Quimica Analitica do CENA.

\subsection{Soluçăes padrào e reagentes}

Para o preparo de todas as soluçes foi lutilizada sempre agua destilada e deionizada.

As soluçaes padräomestoque foram preparadas a par- 
tir de substencias espectrograficamente puras, provenientes da Johnson \& Matthey Chenical sa Limited. A Tabela 2 apresenta as concentraçues das soluçes estoque preparadas e a substancia utili iada para sua preparacán.

Tabela 2. Soluçes padra-estoque.

\begin{tabular}{|c|c|c|}
\hline El emento & Concentraçäo (mg/1) & Substancia \\
\hline$A 1$ & 10.000 & A1C13. $6 H_{20}$ \\
\hline As & 1.000 & As20S \\
\hline $\mathrm{Ba}$ & 1.000 & Ba $(N O S) 2$ \\
\hline $\mathrm{Ca}$ & 10.000 & $\mathrm{CsCOS}$ \\
\hline Cd & 1.000 & $\operatorname{CoO}$ \\
\hline Co & 1.000 & $\mathrm{CoSO4.5H20}$ \\
\hline $\mathrm{Cr}^{-}$ & 1. .000 & Cr metalico \\
\hline $\mathrm{CH}$ & 1.000 & CusO4. 5420 \\
\hline $\mathrm{Fe}$ & 10.000 & Fe2O \\
\hline 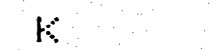 & 1. 000 & $\mathrm{KCl}$ \\
\hline $\mathrm{Mg}$ & 10.000 & MgO \\
\hline Mo & 1.000 & $(\mathrm{NH} 4)_{6107024.4120}$ \\
\hline $\mathrm{Na}$ & 10.000 & NaCl \\
\hline $\mathrm{Nb}$ & 1.000 & $\mathrm{NB} 205$ \\
\hline $\mathrm{Ni}$ & 1.000 & $\mathrm{MiO}$ \\
\hline $\mathrm{F}$ & 1.000 & $\mathrm{H}_{2} \mathrm{FO} 4$ \\
\hline $\mathrm{Fb}$ & 1.000 & F'b $(N O S) Z$ \\
\hline $5 r$ & 1.000 & $5 r(N O S) 2$ \\
\hline $\mathrm{Ti}$ & 1.000 & TiO2 \\
\hline v & 1.000 & NHAVOS \\
\hline $\mathrm{Zn}$ & 1.000 & ZnSOA. 7420 \\
\hline $\mathrm{Zr}^{-}$ & 1.000 & $\mathrm{ZrOCl} 2 . \mathrm{H} \mathrm{HO}$ \\
\hline
\end{tabular}

Foram utilizados acido cloridrico $\$ 8 \% \mathrm{~m} / \mathrm{V}(d \infty 1,19)$, fluoridrico $40 \% \mathrm{~m} / \mathrm{v}(d \sim 1,13), \quad n i \operatorname{tric0} 65 \% \mathrm{~m} / \mathrm{v}(d \sim 1,40)$ sulfarico $(d \sim 1,84)$ e perclarico $70 \% \mathrm{~m} / \mathrm{v} \quad(d \sim 1,67)$, de qualidade p.a. da Mercl: para a solubilizaça do algumas substancias espectrograficas: para a decomposiçáa das amostras e para avaliaçào das provas em "branco". Freparou-se agua regia misturando-se HCI e HNOS na proporço de $\Xi$ : 1 empregada para o ataque inicial 
das romens

soluca de verde de bromaresol de $00 \mathrm{mg} / \mathrm{l}$ prepar rada em tetraborato de sodio o, M empregada para ajuste do sistema de adisos.

Argondo liquido de gusidade prem, fornecido pela oxigenio do Erasily fot utilizado no refocomo gas de trangorte e rebulizacro da amosta e para retriga racta da "tocha".

\subsection{Amostras}

\section{3 .1 Amostras sinteticas}

Foram simuladas amostras sintelcas a partir das

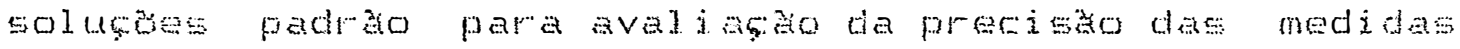

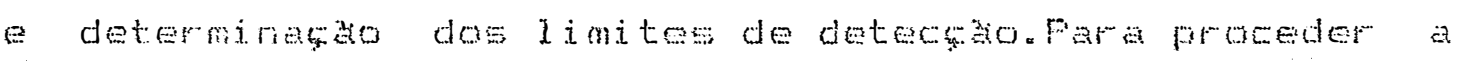
simulabang foram preparadas solucose contendo diferentes concentratos dos elementos Al, Cang e Fe os quats. pelas suas concentrages de ocomencia nos solubilizados de rowas sazo considerados tomo elementos maiores. As solusoses contendo estes elementos for am denominades Smatro. 0 silicjo näo roj contemplado porque o método de decomposiça uto ulizado leva a eliminaço deste elemento.

As concentracoes das solucjes simuladas representando diferentes tipos de rochas foram determinadas com base gm dados compilados por Pinta (1990). A Tabela 3 mostra a composiczo dos elementos matores nos solubilizados simulados de rochas, supondo que as 
anostras rosesen decompostas com ataque deido com bas en $250 \mathrm{mg}$ de roma e o volue completado para 25 m. . Esses teores levan en considerara, o fator de diluiforo a que sera subnetidos no sistema simudar.

Tabela I. Composica (mg/l) de Smaro e Smaro para simulaga de solubilizados de roches

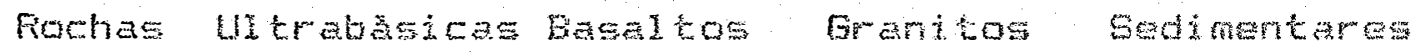

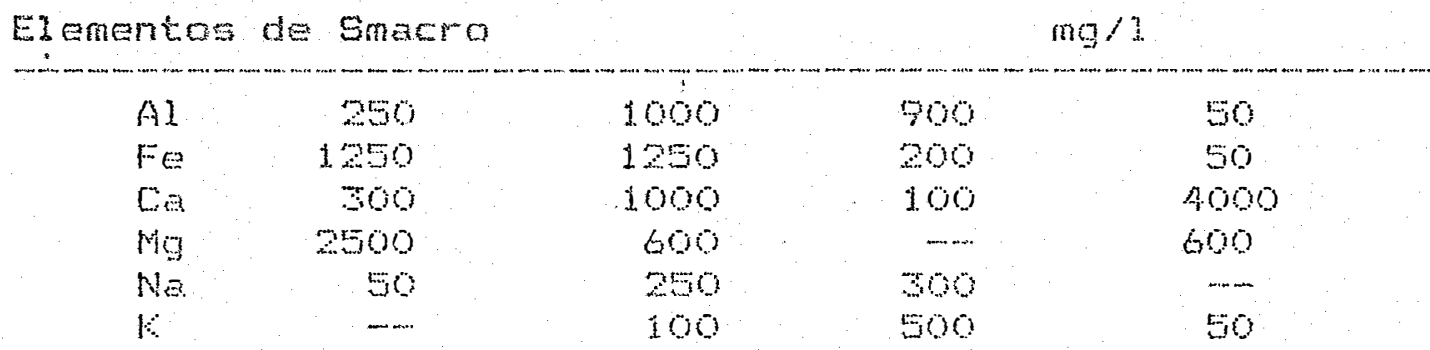

Soluches Smicro contendo os elementos: As, Ba

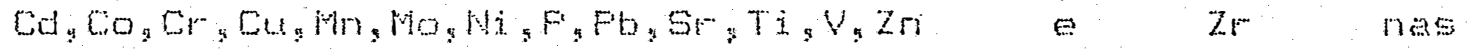
ententemoses de: $50,0-250-10,0-5,0-2,5-1,0-$ $0,5-0,25$ e $0.1 \mathrm{mg} / \mathrm{l}$

\subsubsection{Anostras de rochas}

Foram empregadis roches cedidas por diverses Instituiços conforme apresentado na Tabela 4 .

Tabela 4. Amostras de rochas

\begin{tabular}{lll} 
& \\
Amostra & siala & Froredencia \\
\hline basato & BE-1 & CEFED \\
granito & GE-1 & CEFED \\
granito & GIGC & IG-UNTCAMF \\
granito & GUWO & UWO
\end{tabular}

CEFED Centro de Fesquisas e Desenvol vimento-Bahja IG-UNJCANF Instituto Geociencias. Universidade Estadual de Campinas Uwo Depto. Geologia Universidade de Western Oritariomcanadz 


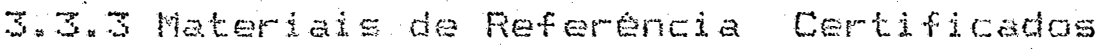

Foram utilizados materiads de referancia certificados de roches de diferentes procedonom, atim de aveLiar a exatideo do metodo proposto A Tabeta 5

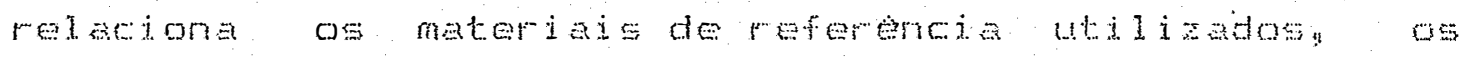
valores cortificados para os elementos de interesese a entidade fornecedora.

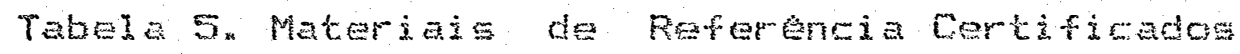

\begin{tabular}{|c|c|c|c|c|c|c|c|}
\hline & $\begin{array}{l}\text { SARH-! } \\
\text { granito } \\
\text { SAES }\end{array}$ & $\begin{array}{l}\text { SAmb-? } \\
\text { sinnito } \\
\text { shas }\end{array}$ & $\begin{array}{l}\text { SARH-3 } \\
\text { lujaur = } \\
\text { SABS }\end{array}$ & $\begin{array}{l}\text { SAMn-4 } \\
\text { narito } \\
\text { ShEs }\end{array}$ & $\begin{array}{l}\text { BCf-1 } \\
\text { bosalto } \\
\text { uses }\end{array}$ & $\begin{array}{l}\text { BHW-1 } \\
\text { bs } 2 \text { alto } \\
\text { Usos }\end{array}$ & $\begin{array}{l}\text { fon-1 } \\
\text { riolito } \\
\text { USG }\end{array}$ \\
\hline \multicolumn{8}{|c|}{ OXPEC- - } \\
\hline $5 i 0 ?$ & 75,70 & $43 ; 63$ & 52,30 & 52,64 & 54,53 & 49,90 & 73,40 \\
\hline 01203 & 12,68 & 17,34 & 13,64 & 16,50 & 13,72 & 13,70 & 13,80 \\
\hline$F=203$ & 2,01 & 1,50 & 9,91 & 0,97 & $13, i_{1}^{3}$ & 12,00 & 1,90 \\
\hline Ca! & 0,70 & $0_{8} 68$ & 3,22 & 11,50 & 6,87 & 11,30 & 1,17 \\
\hline Mg̣n & 0,06 & 0,46 & 0,20 & 7,50 & $3 ; 48$ & 7,20 & 0,28 \\
\hline $\mathrm{H} 20$ & 3,36 & 0,43 & 6,37 & 2,46 & 3,30 & 2,30 & 4,10 \\
\hline$k 20$ & 4,89 & $15 ; 35$ & 5,51 & 0,25 & 1,70 & 0,53 & 4,30 \\
\hline $\sin 0$ & 1606 & Bot & 0,77 & 0,19 & 0,18 & 0,17 & 0,08 \\
\hline 1102 & $580 x$ & $265 \%$ & 0,40 & 0,20 & 2,26 & 2,70 & 0,27 \\
\hline \multicolumn{8}{|c|}{ ELEHENTOS - D.- } \\
\hline A 5 & $\mathrm{kLC}$ & $N E$ & $\mathrm{NC}$ & $\mathrm{NC}$ &.$\overline{8}$ & 拉 & $\mathrm{HC}$ \\
\hline Ea & $1208:$ & 2418 & 450 & 102 & 660 & $130)$ & $760=\frac{15 x}{2}$ \\
\hline $\mathrm{Cd}$ & $N C$ & $\mathrm{NC}$ & NC & $M$ & 900 & $\mathrm{NC}$ & 师 \\
\hline Eo & $\mathrm{HC}$ & 了程 & $\mathrm{NC}$ & 58 & $3 \frac{1}{6}$ & $47 x$ & $3 \neq x$ \\
\hline $\mathrm{Cr}$ & 12 & 12 & $10 \%$ & 34 & 15 & 3200 & 3 \\
\hline $\mathrm{Cu}$ & 12 & 14 & 13 & 14 & 16 & 135 & $\{1[E \mathbb{R}$ \\
\hline ho & $\mathrm{NC}$ & $\mathrm{MC}$ & NC & NC & 1.55 & $\mathrm{NC}$ & HC \\
\hline $\mathrm{Hi}$ & $6 x^{3}$ & $T$ & $N \Gamma_{1}$ & 120 & 10 & 1460 & $62 x$ \\
\hline$P$ & NC & 524 & 260 & $130: 2$ & 1571 & 1397 & 218 \\
\hline $\mathrm{Pb}$ & 40 & $5 n$ & 43 & $N C$ & 14 & b菩妾 & $21 * *$ \\
\hline $5 r$ & 10 & 2 & 9587 & 260 & 330 & $326 x=\frac{z}{5}$ & $100 \times \frac{2}{n}$ \\
\hline$v$ & $2 \pi$ & 10 & 81 & 220 & 420 & 296 & $15:$ \\
\hline $2 \pi$ & 50 & $103 *$ & 395 & 68 & 125 & 179 & $22 \%$ \\
\hline $\mathrm{Zr}$ & 300 & 33 & 11031 & $23 \div$ & 165 & 203 & $280 \div$ \\
\hline
\end{tabular}

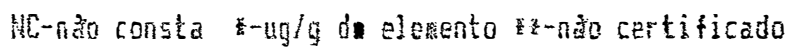

SRES- South African Dureau of Standards

USES-United States feologital Survey 
A solutilizaso des amotras desortas nas tabelas 4 a fol eretuada de maneira semenhate ao procedinento descrito por Langmyne Paus (1960) "

a) Fesarames 250 o no de amostra de rocha ou

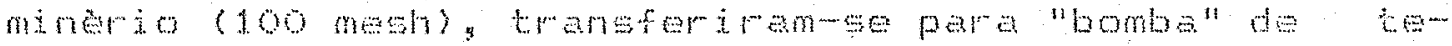

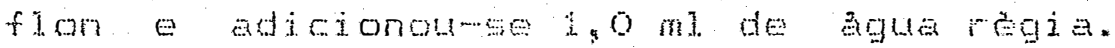

b) Apos deixar a mistur an repouso por 1 hor com a "bonba" aberta, for"an adioionados 5,o ma de acido filow ridrion.

c) As "bomban" fom fen fechade Jevadas para o bloco da aquecinento, rom a temperatura ajustada para 140 C, onde permanemeram por 2 horas

d) En segutal as "bombas" forka retiradas do bloco e restriadas com agua cormerte.

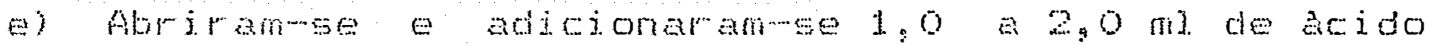
perclorico a ajutoumse a temperatura do bloco de aquewimento a $210 \%$

f) Apde quase securag a anostra foi retomada com 25 m de $\mathrm{HCl} 0.5 \mathrm{M}$

9) Cada grupo de emostras solubijizadas, foj acompamiraco da prova en "branco" "contendo somente os acidos.

\subsection{Frogramas Computacionals}

\section{4 .1 Dperagado do ICF}

Fina o PDF-8E foi utilizado o "softwere" basico implantado no espectrometro pelo fabricante. Os dados de controle do programa sao definjdos em uma matriz 


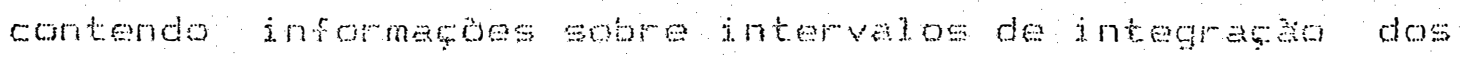

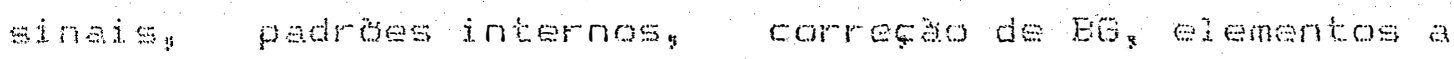

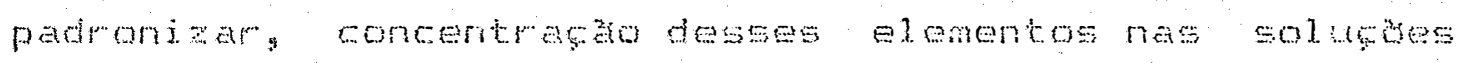

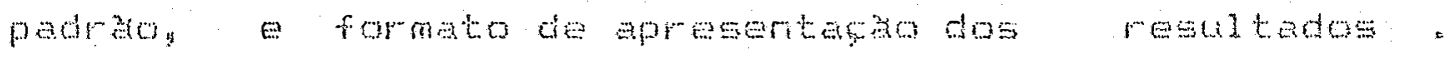

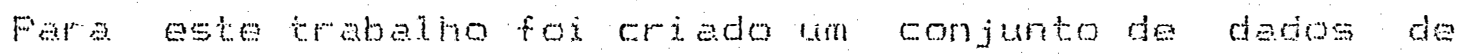
Eontroje formano a matriz MAgE (Material geologitol"

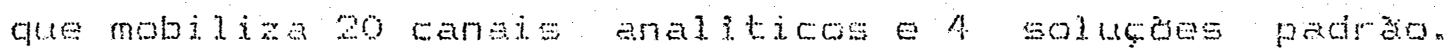

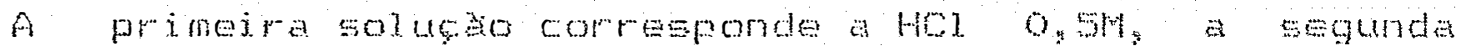

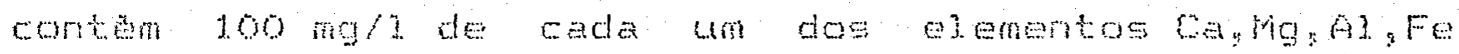

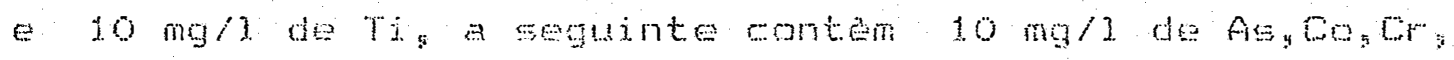

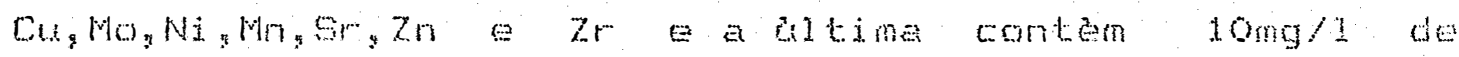

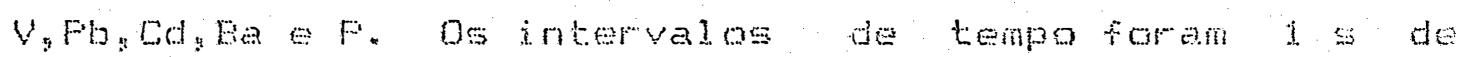

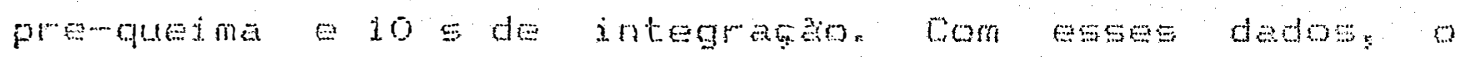

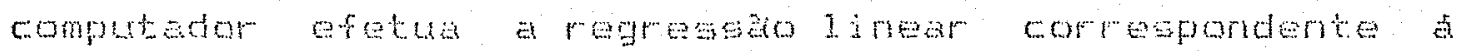
rel mo ajuste da reta descrita pola equagno

$$
0+0 \mathrm{O}+\mathrm{O}
$$

$$
\text { ... } 1
$$

orida:"

C - concentratas

F - reago entre as intensidadas do sensor considerado

e do padroto interno,

6 -... ganho ou coeficiente de geneibia islade

0 - rator de ajuste da reta dorigem ("offset").

Fara o jevantamento das inteferencias, foi utilizado o conjunto de ladoe de controle rornecidos pelo fabricante denominada matria WATF e que inelui todos os 


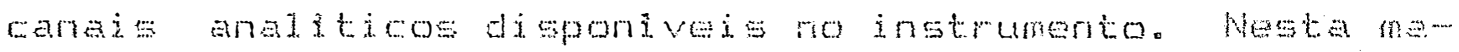
triz os intervalos de tempo form de $1=$ de prem queime e 10 s de integrason

\section{4 .2 Comando do sistema FIA-TCF}

Foi desenvolvido pare este trabalmo, um programa que permite a SACT controlar a unidade de combega e a

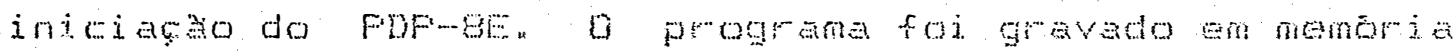
permanente de forma que o operador do sisteme Fuft ICF coloque na memoria do usurmio apenas os parametros de controje $0 \mathrm{~s}$ tempos de comutace do injetor e de

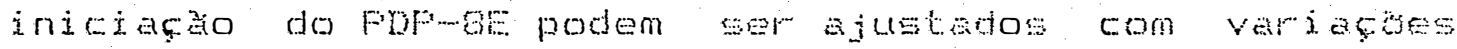
de ate 1 dowmo de segundo. o flugorat do programe os prosmetros de controle aso descritos no ppendioe.

\subsubsection{Processamento do GAm e Gom}

0 programa 659 modificado pare analises de roches foi desenvolvido a partur do progreme original da Infometrix. Foj empregada uma versabosorita em For tran para computador de 8 bits e b4 bbyces de memoria (sistema operacional CF/M) " o programa esta dimensionado para tratar ate 20 anditos envolvendo 100 adicoes. Fara um nemero major de adjeges ou de arad itos, sto necesserrias mudangas nas dimenedes das variaveis do comendo MAIN. Fara facilitar a util iacko do netado como instrumento de calibrapaso, o programa gera um arquivo que

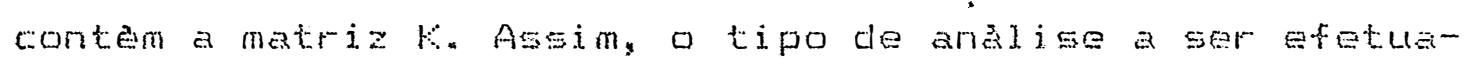


da e determinada pelo valor de Mood fs variaveis envolvidas e as opges de eseolha de noun enconiram se trabeladas no Apsndice. 
4. METODO

4.1 Métodos para contomar inter rerencias.

4.1.1 Analise miltielementen e GoAv.

0 modejo matenatico da andise mulicomomerto considera que alguns sensores sao afecados pelas contribuicases de outros elementos na anotra assin y a resposta obtida no sersor a pode ser expresen peja equas?o 2, a 5 equin:

$$
R_{i}=\sum_{j=3}^{n} k_{i j} c_{j}+E_{i}
$$

onde:

$$
\begin{aligned}
& R_{i} \text { - resposta obtida no sensor } i \\
& k_{i j}-\text { constante de sensibilidade do andito j no } \\
& \text { sensor i ( j variando de } 1 \text { ate } 20 \text { ) } \\
& c_{j}-\text { concentraga do amajito j } \\
& E_{i} \text { - ruido medido no sensor j. } \\
& \text { o modelo do ben utiliza adisos de concentraçes }
\end{aligned}
$$
conhecidas, dos elementos de interesse e dos elementos interferentes. Este metodo baseia-se na regressado i inear entre as variafedes das respostas devidas as adjobes e as 


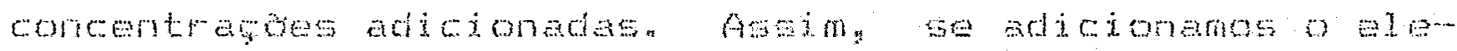
mento $1_{y}$ a monse na resposta de deserita peia equacto 3 a segur.

$$
k=\sum_{j=i}^{n} k_{i j} c_{i}+k_{i} c_{i}+k_{i}
$$

onde:

$$
\begin{aligned}
& R_{i}-\text { resposta apos a adisto }
\end{aligned}
$$

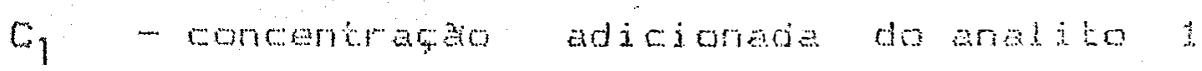

$$
\begin{aligned}
& \text { ki - constente de ensibilidede do anelixo } \\
& \text { no sensor i }
\end{aligned}
$$

0 conjunto das constantes de senesibidiade kij detinem a matoliz $k$.

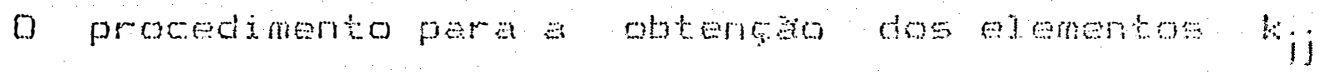
assin como o calculo da concentrata corrigia dos ele mentos na amostra e mostrada a continuara.

Ne andise muticomponente as mespestes obtidas, somente com as solucbes padra preper ades ma diferentes nivejes de concentraga, individuelmente pera cada elemento de interesse, "resulta en una calibrabo geral. Far cata sensor, o processo de regressalo linear conduz a uma relapao entre as concentrabos de todos os elementos que contribuen para a resposta. o sjstema de equagesa correspondente a varios sensores, pode ser expresso em notagao matricial como se segue:

$$
[R]=[K][\mathrm{C}]
$$




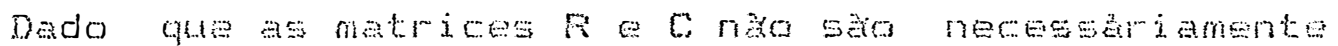
quadradas " a obtanca da matry $K$ e conseguida

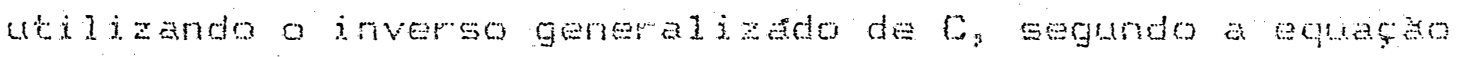
5

$$
[K]=\left(\left[C^{T}[C]\right)^{M 1}\left[C^{T}\right][R]\right.
$$$$
\text { *.*. }
$$

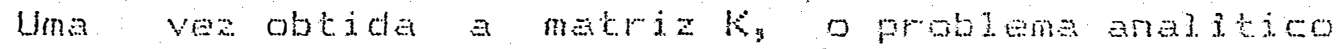

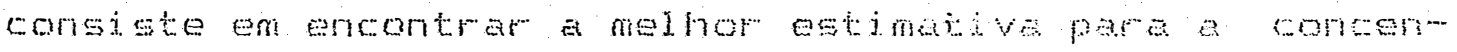
tracko de cada elementos a partir das respostes j. rijeiajs.

Neste casos a matriz Ka carator betion do conjunto de sensores e des condicose experinertads e independe da composicio da amostax

Guando os coeficientes de sensibilidade dependem da

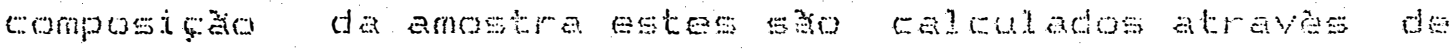
adicoses padra de todos os elementos de interessez aplicando o Matodo Eeneralizado das Adicases Forron

Considerando r analitos, p eensores e a tondita de contorno $p \geqslant r$, o metodo requer um nomero de adiçoses $n$, $r$. Desta forma a matriz de resposas $\mathrm{R}$ apresenta dimensobs de $(n+1) \times p$, considerando a resposta inicial e as respostas apes as $n$ adicoes. A matriz $C$ tem dimensbes de $(n+1) \times r$ a matriz $K$ de rkp: mostrando a contribuifa de cada un dos r analitos em Eada um dos p sensures, para uma composiça do amostra especifican

Para o calculo da matriz K no GSAls utilizam-ses 


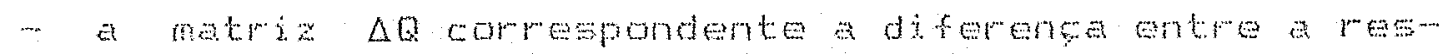

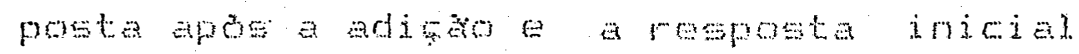

- a matriz $\triangle N$ indjoando as quatiodes totads and

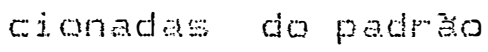

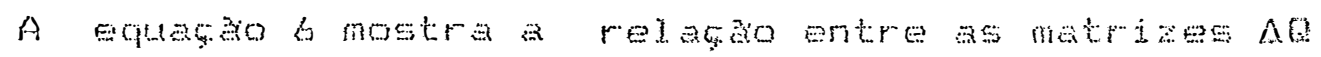
$\Delta N=K$.

\section{$[\triangle Q]=\left[\begin{array}{lllll}\mathrm{A} & \mathrm{N}\end{array}\right]$}

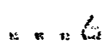

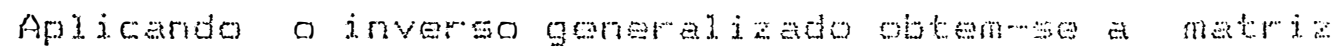
16

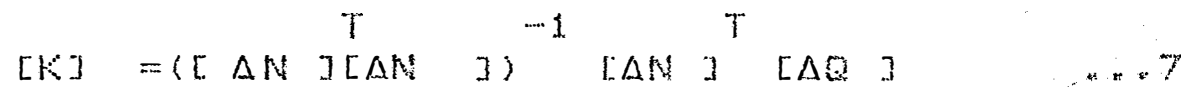

As quatidados iniciajs dos dementos na anos

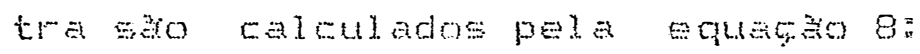

$$
n o=90[x]^{-1}
$$

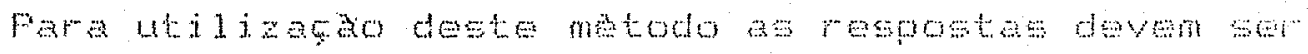

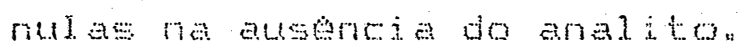

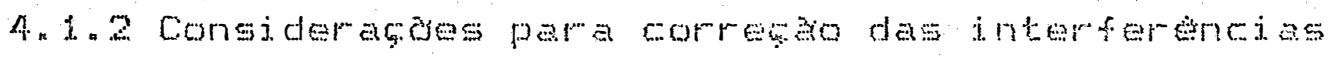
กRE malises de rechas por ICF-AES

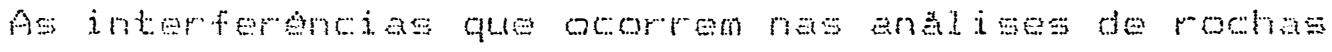

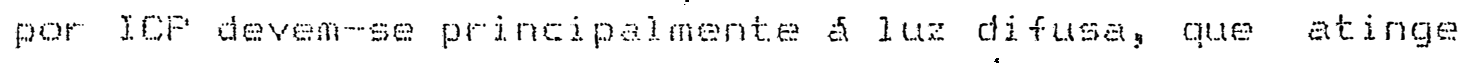

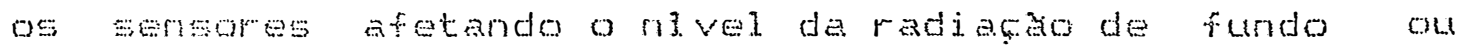
EE*

Qutro tipo de interferencia espectrals mas diriail

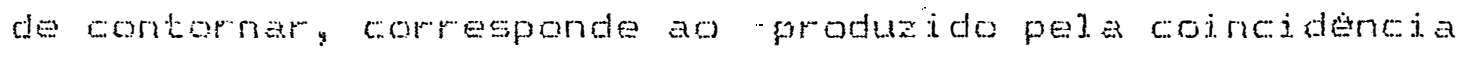




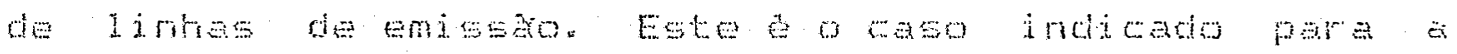
Lti]izaso do

0 SsAn foi aplicado principanente como remantrat

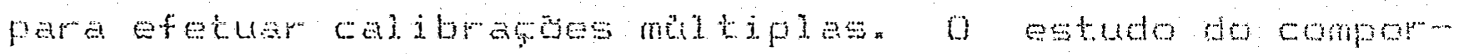
Lamento dos toeficientse de metriz to quamo anostas

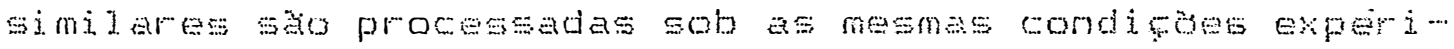

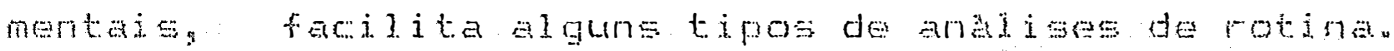

Fara tacilitar o menusedo dos componantes da natraz

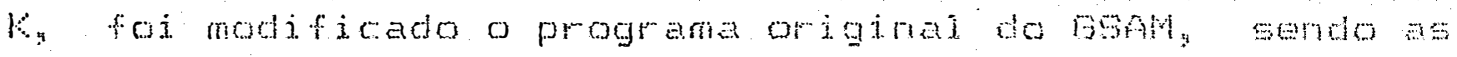
seguntes opobes contampladas;"

- utilizacaro de uma mesma metriz amostras

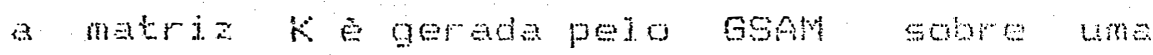
mostra repregented ivan Wors $=1$.

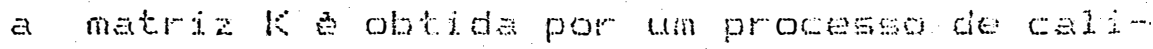

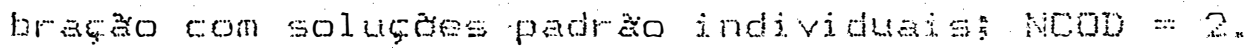

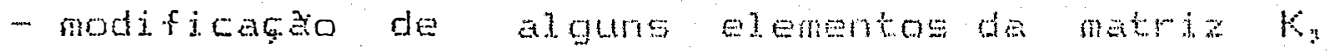
por serem afetados pela matmiz da amostra

- inserczo de uma nova matriz 6

todos os elementos sat novos: Nond = 4

alguns elementos sato novos" NoOD $=5$

- andise complata do osAm original: WoOD $=6$

Una vez obtida a matriz $K$, as concentraçes dos elementas na aruosta sao deterininados a partir da

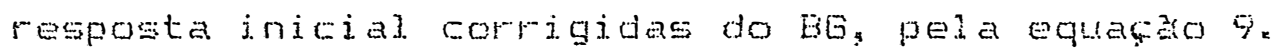

$$
\text { no }=(90-\operatorname{sg}\rangle)[K]
$$


seja arnazenada num diswo megnetion, para uso posterior Desta forma foi possivel formar um banoo de dados das

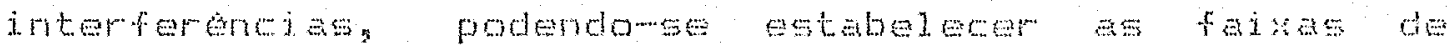
variages ocomides durante un perado e tanom para avaliar as condicose opepacionas do espectrometro.

\subsection{ICF-AES}

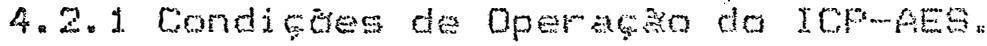

0 ajuste des condicoes de operaso do popmes roi

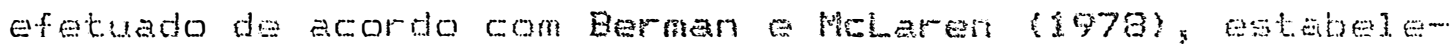

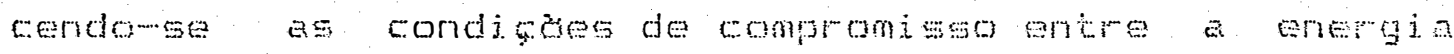

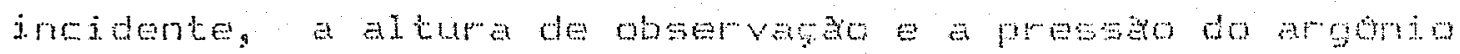
no nebulizador" para obtenca das intersidades mais favor avej

A varredura dos partmetros fod real inda na sequencia antes mencionada. A potencia da ronte de retri

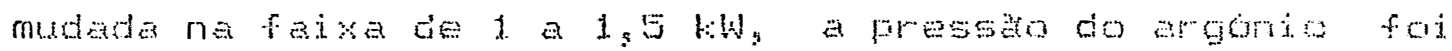
variada entre 15 e 30 ib/pol e as alturas de observaco foram de 10,15 e 20 nm. A vaza do argonio empregado para refrigeracá da toche foi mantida constante em 19 Jinin. A 1argura da fenda de entrada no espectrometro foi de 25 Hm. Fara efetuar o alinhamento otico laterals empregouse luma lampada de Ho como fonte de lus e um mitometro com 1200 divisoes. no qual rada 4 divisges comresponden an deslocamento de i $4 \mathrm{~m}$.

Segundo os autores antes citados, as linhas de emisw sao atomicas e ionitas apresentam diferentes comportamen- 
tos com wespeito a ajuste da alture de obervala As

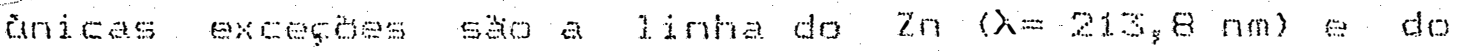

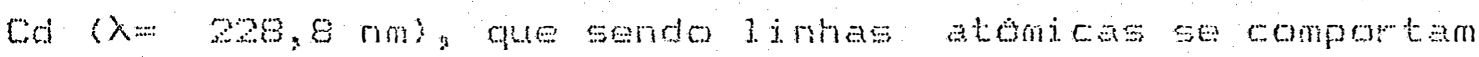

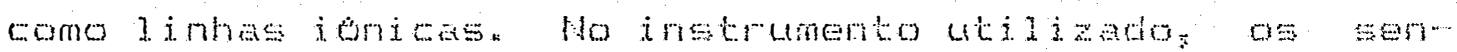

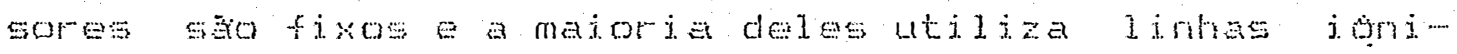

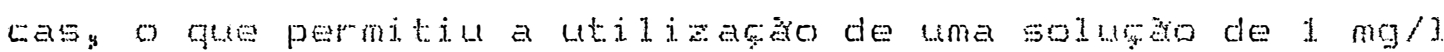
de Mn para efetuar o ajugte.

\subsubsection{Avaliaga das interfereneias no IOF aEs}

Afim de quatificar as inter ferencias nos direrentes sensomes "foi projetade un sistena didudor ern fluno. Trata se de un sistend com bombemento continuo das solu

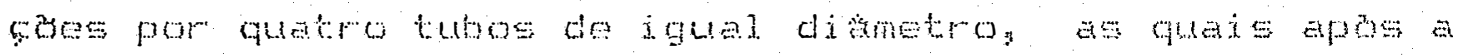

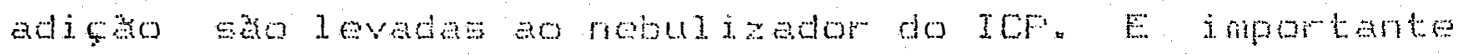

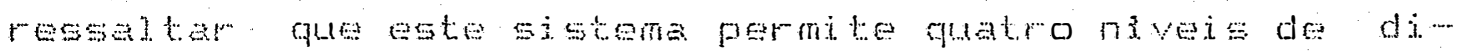

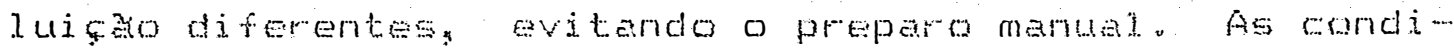
ches de mistura foram avaliadas atraves da reprodutibilidade das medidas.

A geraczo de diferentes solugdes padro permitiu determinar a faixa lit de operago do scp para cada elemento. Utilizaram-se solucóes padrace individuais de 5000,1000 e $500 \mathrm{mg} / 1$ de Ca, Mg, Al, Na, Ke Fe de 500 mgll para os demais elementos com excepa do ż para o qual se utilizou $100 \mathrm{mg} / 1$. Como diluente empregou-se HCl $0,5 M$

Fara cada padraco gerado, obtiveram-se as respostas correspondentes a todos os sensores, permitindo determi-- 


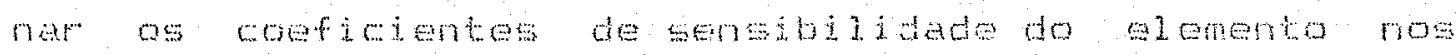
diferentes comprimentos de onde atraves de un processes de regressa hinear. Este proctimento ieva a dotenga da matriz K. As medides for an eretudas antriplickta be

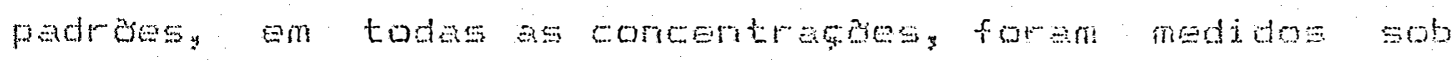

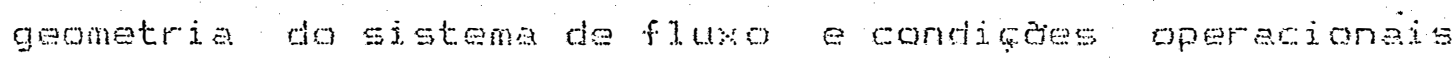
do epectrometro constantes. Este levantamento fot repew tido utilizandome o corretor de Ee de forma a identifi-

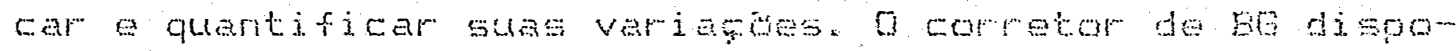

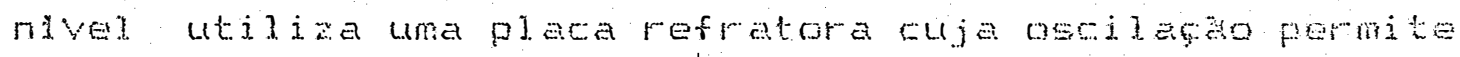
registrar separadanente o sjnal espectraj do analito sm $(\lambda) \quad 0$ sinal ajaconte m $(\lambda+\Delta \lambda)$. Fara cada cidos envia duas veres o einel cormesondente a nompimento de onda ( $\lambda$ ) do sensor e lime vez squle desiocado em ( $\Delta x$ ). For outro lado, o "softure" do computador acsodado a instrumento controla a aliemancia destes sinais e prow cede s substraço do sinel do BG de forma a formecer como resultado o simal I

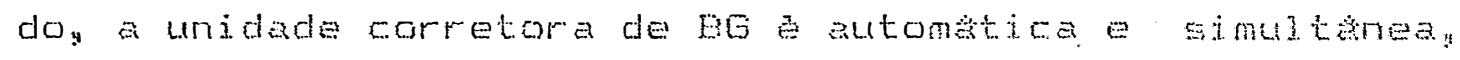
de forma que ocomre deslocamento do comprimento ie onda para todos as sensores no sentido de ( $\lambda$ ) crescente.

\subsubsection{Efeito matricial e detecto de elementas trafos}

Foram afetuados testes iniciais simulando solubilizados de amostras de rochas, para se avaliar o efejto da matriz na determinaso dos elementos que se apresentain en bajkas concentrabes.

A simulaço dos soluoilazados de rochas foi realiza- 
day utilizando um sistema de fuxo continuo constitudo

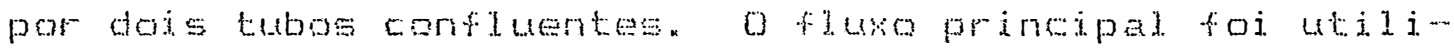
zado para as solucose smacro e o flumo confluente para a

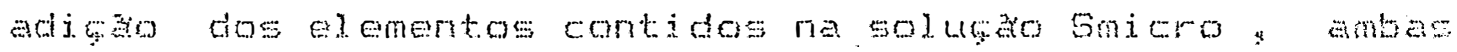
descrites na Tabala 3 As varbes foram de 1,2 as ml/min para o fiuko principal e de adicko, reepectivamen te. A raza entre os fluos foi escohida de forme a

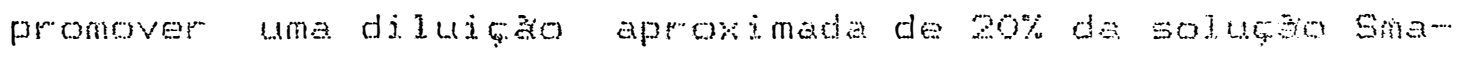
$\cos \cos ^{2}$

4.2.4 Frocedimento para deteminar as caracterigti-m cas de deteckato des el comentos trapos

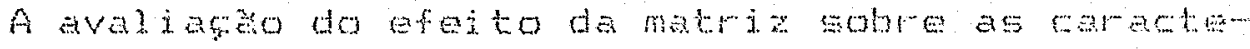

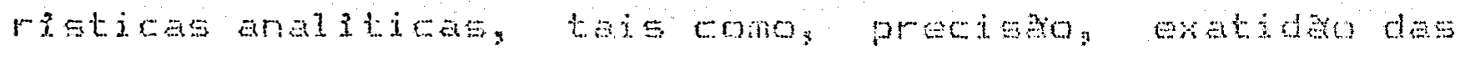
medides e concentrapos nonimas detertzveis nos solubj 3. 2 ados de rochas, fod efetuada polo procedimento desori to a seguir.

Inicialnentes Lma soluga de HCJ O, Gy foi bombeada peio sistema. En continuagas solugres snicro ress concentrabos de 50,0-25,0-10,0-5,0-2,5 - - $1,0 \ldots-0,5$ - 0,25. e $0,10 \mathrm{mg} / 1$ for an bombedas no cand confluente. Deve-se observar que a sistema pronove una diluifas de cinco vezes destas solusbes. Fosteriormente, a solucao Smacto foi bombeada no tluko prineipal e por confluencia recebia as solucbes smiaro nas concentragos descritas. Este procedinento foi repetido utilizando o corretor de EG. 


\subsection{Sistema FAMTCP}

\section{1 Considerabes sobre o Ei stema}

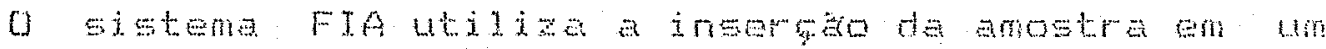
fluddo que a transporta dispersando-a e formando uma zona de amostra que frui pera a detecezo, produzindo un sinal transiente (Furicka e Hansen, 1975). A dispersao da anowtra è dependente do fluo de massa do procerso de difusa. sendo desta forme : controtada pelo dimensjonamento do sistema pelas carectemisteas dos fluidos (Applaton et alid, 1989).

Na utilizaca do ICF como analisador simultaneos a sinal. malitico e produto de integragen wequndais. Assim sendo o controle do intervajo de tempo entre a entrafa da amoetra no sistema o o inicio da betectao e

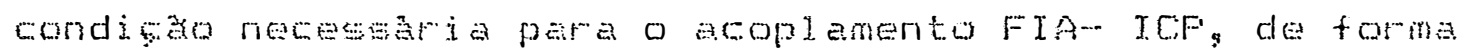
a efetuar medidas reprodutzveis na zona da amostra.

Neste sisteme a raza sinal-rido e funcăo do volume injetado, da vaza da soluca áo carregadora da amostras do efeito des diluiço dos fluxos confluentes; do comprimento da bobina de dispersán a da aquisiczo do sinal na regiazo mais adequeda da zona da amostra, alem dos parametros de operasao do ICF. (Jacintho et alis,1981).

\subsubsection{Frojeto do sistema}

Para projetar o sistema FIA ICF, foi necessario o ajuste das veriaveis controlabeis, que conduzem a pesposta mais sensivel e preaisa. Numa tentativa de reduça do 


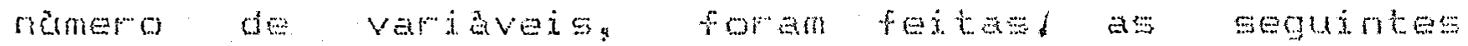
considerateses:

-a vaza de bombemento para entrade dos 1 a quidos no nebulizador foi definda en 1,5 mism, a qual 2 I igeiramente superior d de aspiracto nominal do instrum mento.

- o tempo de integraga do minel pelo rof rod de

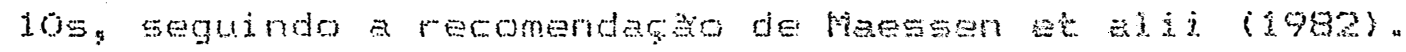

- com referenoja ao volume injetedo de amostira este deve ser suficientemente grande para minimisar a dispersa no sistama FIA e produzir un pioo cuja larguma media (medida na netace da altura da zone disperea da amostra se ajuste an tempo de integraca do sinel de forma a obter a melhor melaco simel/rido. Entretantos naco deve comprometer a velocidade anditicis

Fara a determinaceno do volume de amotra injetado foi lutilizada a injegán por tempo deserita por Jorgengen et ali (1985). Neste procedimento a amostra bombeada continuamente, durante um intervalo de tempo, que derine assims a quantidade de anostra que entra no sistema. Nesta fase foi utilizada uma unidade de comutacto com controle de tempo programavel.

A Iinha de acoplamento do comutador ao nebulizador foi dimensionada täo curta quanto posisivel, desde que em sistemas em confluencia a misture é facilitada alem de haver um nebuli zador no sisteman 
4.3.3 Procedinento experimental para dimensionamento do sistana acoplado FIA-ICP

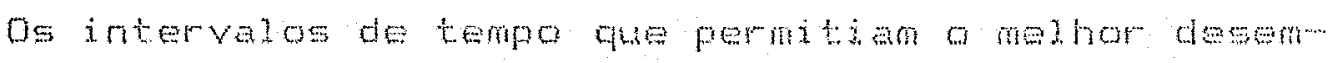

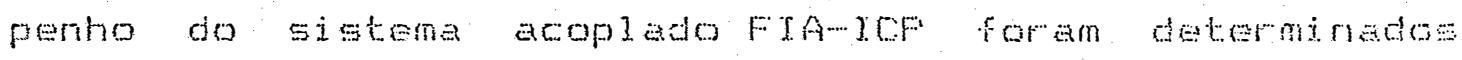
ativando-se no espetrometron somente: o sensor do rn es Utilizando o sistema FIA mptementado ne Figura 1. Neste sisteme as vanges dos fludos $c$ o for fom de

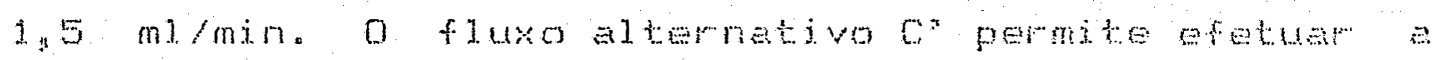
injecia da anostra por tempon Para etetuar a Yarredura do volume de amostra injetado, fol elabomado um porograma que incrementa o tempo de permanencia do comutador na posindo

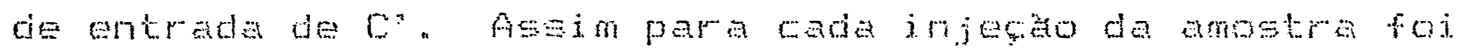
obtido o regietro do pico; cuje larguta media proporcional ao volume injetado enquato nâ atinge a comoga

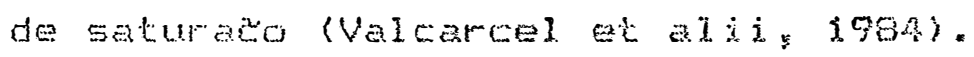




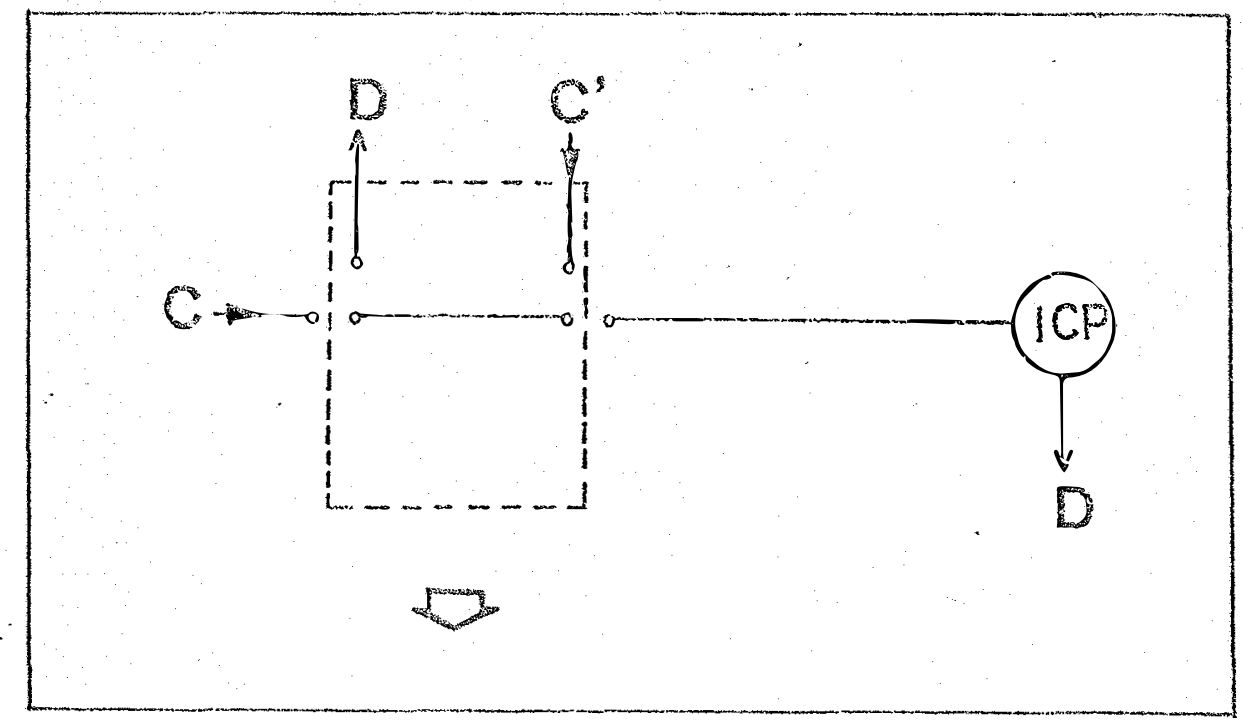

Figura 1. Sistema FIA que utidiza jnjegan per tampon

C*- rluxo utiljzado para entrada da emostra

C.- fluko que a transporta para o ICP.

D - descorte.

0 intervalo de tempo enire' a comutacto do injetor e o inicio de integratro do sin?, foi determinedo experi-.. mentalmente acionando" simultaneanente, o comendo de entrada da amostra o o inicio do registro. A derasagen entre o jnicio do registro e o aparenimento do sinal da amostra, e o intervalo de tempo T4 que deve ser introduzido no programan ( vide Apendice)

\subsection{Sistena FIA para automagzo do procedimento} das adiçes padrär.

\section{4.1 Frojeta do si stema}

Vari-s sistemas FIA tem sido utilizados para efen tuar, o procedimento das adicoses padrao. os sistemas em linha funca empregam a injega da solucto padra sobre a amostra, que flui continumente pelo detector. Aseim, uma serie de padross injetados sobre a amostra definem 
una curva de calibraga (Tyon e Idris.198i). A injectoo

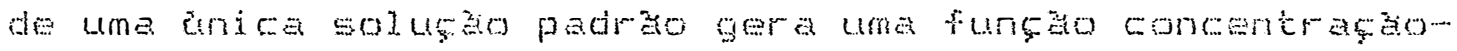
tempo, que quando injetade sobre a amotre define infinitos pontos de adiço (Arahjo et ajij, igewi). Entretento. a maior parte dos sistemes FIA descritos para efotuar adiçes, apresentam contiguraca en contubncia nos

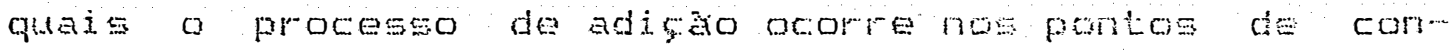
fluencia. No sistema FIA com zonas condesentes (zagatho, 1981), solugaes padrao, de diforentes conentra çós 520 injetadas simultanamente com a amostra. Tanbany soluçes padra podem ser geradas no istema com anostragem na zona dispersa (Gind et asidy 198\%? enpregando-se ume unidade programivel de controle de tempo A geraga He padroes a partir de uma urima solusa padra tentan a conseguida no sistema que utiliza injegro sequencial (Zagatto et alii, 1985). Este sistema na ubilia con trole de tempo, contudo o volume injetado da anostra deve ser suficientemente grande de forma que permita adicionar" por confluencias a zona resulcante contendo o padràेo.

Qs sistemas de adiço por injegto dis soluebes padräo sobre a amostra que flui continuamente pelo detector, nao sajo recomendaveis devido es elevadas concentraçaes se podem apresentar problemas de contaminaça e deposiça na tocha. o emprego da injeço sequencial, năo apresenta picos de adiço resolvidos quando a deteçąo है efetuada por integraga do sinal. 
Testos iniciais, com o sistema que explore o gra

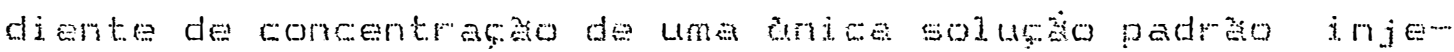
tada foram efetuados e os resubados apresentaram-se instaveis prejudicando a reprodutibilidece das medidas.

No presenter trabalhog o sistema em ronflubcia com zonas coalescentes e geraga das solubes padra pelo processo de amostragen da zona dispersa poi adotadon

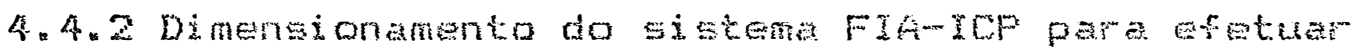
as adicoes

0 sistema FIA-ICF para eretuar adiches apresenta duas partes independentes, que sato nostradas na Figura 2. A reprodutibilidade das al iquotas selecionadas esta rela ci.onada com o formato da zona da amogora gereda En vista dissos o. sistema da Figura ga roi dimengionado de modo que o modelo da distribuifan seja aproximadamente gaussiana, a qual segundo Zagato st alis: 19905: apresenta resultados mas precisos. Fara o dimensionamento deste sistema foi utisizada a detera colorimetrica de uma solucato de verde de bromocresol preparada em solucalo de tetraborato de sadio 0.1 M. Esta solumo foj cambem empregada no lugar dos carregadores e em substituifan da amostra. Fara ná afetar a velocidade analiticas utili--

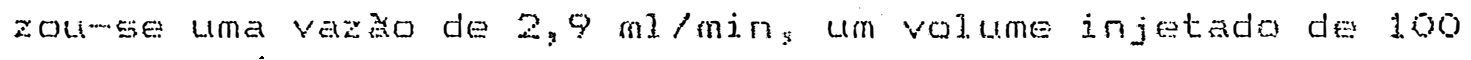
$\mu 1$ e a bobina de dispersato de 125 ma

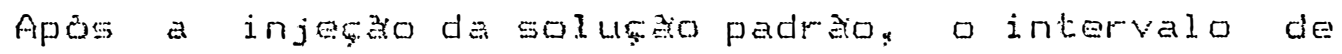
tempo ate a proxima comutecto define a adica e a to tempo de enchimento da alsa da amostra no sistema principal. 


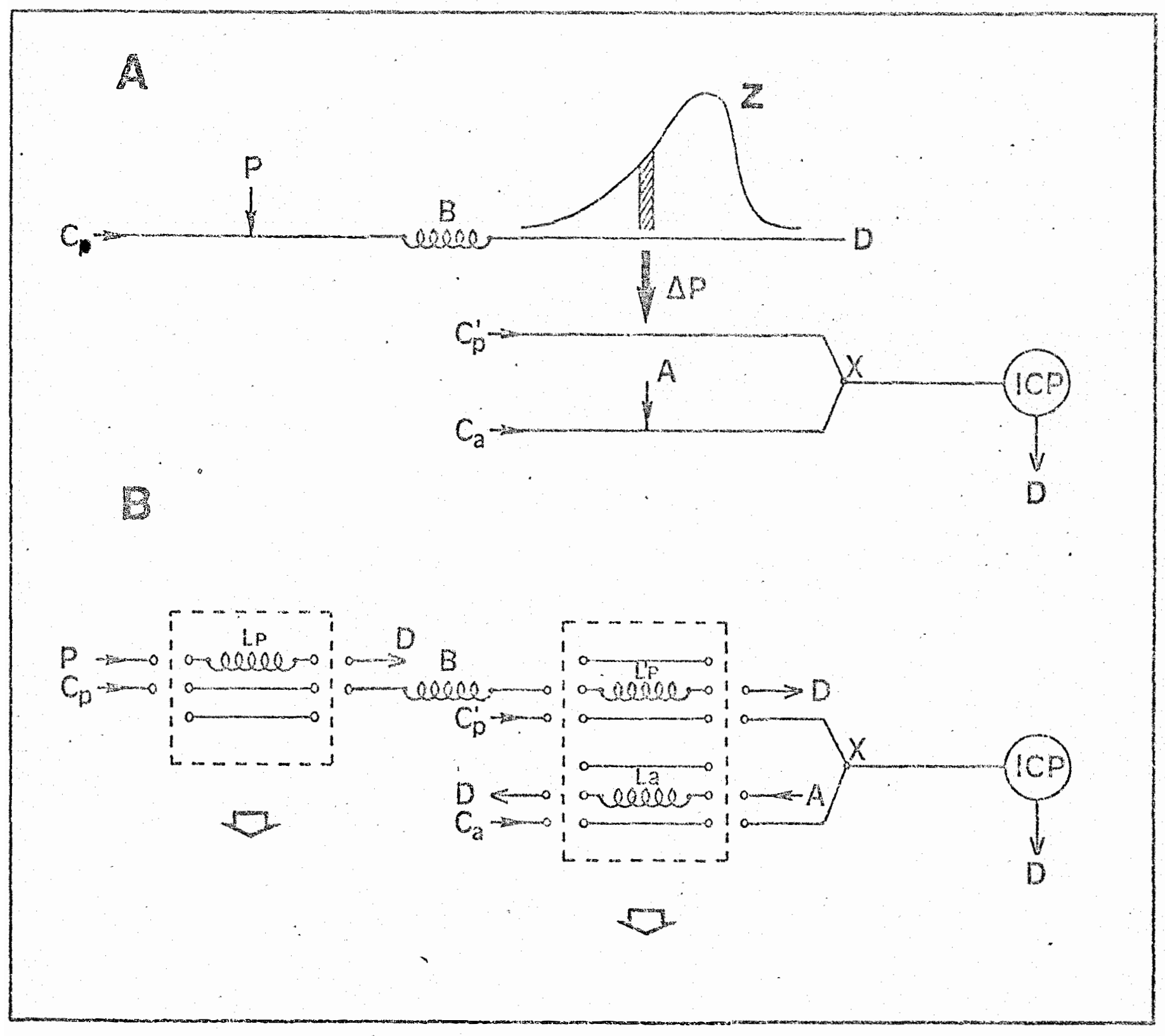

Figura 2. Sistema de anostragen na zona dispersa 2a esquema do processo e $2 b$ montagen do sistema. P- soluça pedrio original, $\triangle F-$ soluca padrao a adicioner a Z-zona dispersa do padrä. A -amostra, La,l.p e L."P sao as alcas gue de finem os volumes injetados ex Cay Cp e Cp as soluços carregadoras de $A, F$ e $\triangle P$ respectivamente. $D$ - descarte, $X$ ponto de confluenria. 
A Figura 2 a motira o esquema do processo de forma

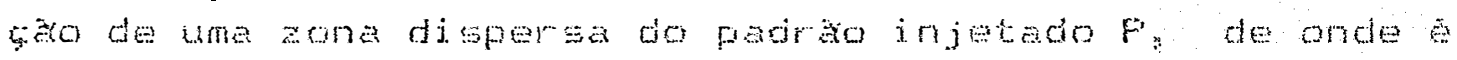
amotrade una porge ap que a injetada sobre oubm thuo carregador C". A montagem deste prosesso na undade de comutagas emcontra-se esquentizada na Figura $2 b$.

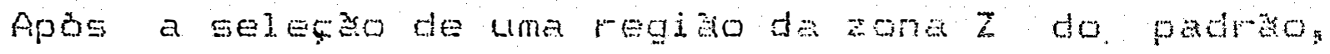
esta de injetada sinul taneamente con a jujega de anostra empregando a sistema de zonas coalesentes Este sistema foi dimensionado com varbes de 122 e 43 minin de foma

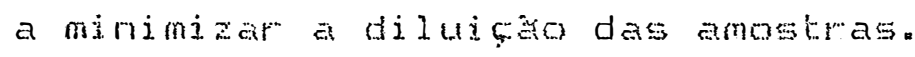

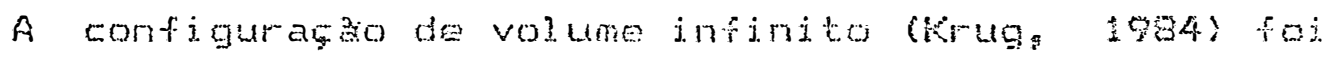
utilizada para deterninar a sithaga de minima dispersa para a amostrara.

Dado que foj escolbida una varas de entrada no ICF relativamen bajka $(1,5$ ml min), apresenta-ge o problena

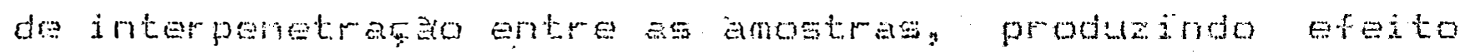
de menoria e afetando a frequencja anditica. Para contorna-10 foi lutilizado um rluxo intermitente de 4.5 milmin de HCl o, $5 \mathrm{M}_{4}$ que Java o sigtema (Figura 3 ) Este fluko entra no gisteme quando o comutador esta ne posiço de amostragema

\subsubsection{Funcionamento do sistena}

A 501 uscalo padráco $P$ e colocada para ser aspirada enchendo a alsa Lps como nostra a Figura zb. Na comutaça da unidade a esquerdas a soluczo contids em Lp e trans--

portada for Cos dispersando-se na passagen atraves de B e L’p e dirigindo-se zo descarte. A comutacaro da unidade á 
direita deve ocorrer" enguarto a zona disperea esta fluindo por L"pa o intervalo de tempo entre a conuteca destas unidades derire a regda da zona dispersa selew cionada en L"p. Foi elaborado un programa que relaciona o intervajo de tempo com a concentratao da aliguota anostradas em relasan a padrao original. os parametros de cortitole do programa estao descritos no Apendjce. 0 tempo por cicolo de operacao e constante, dado por ta th e funtiona por decrementos sucessivos deta nas undades

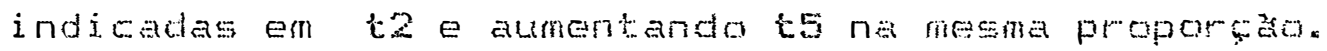

\subsection{0 sistene proposto}

O sistema proposto e constitudo por uma unidade de

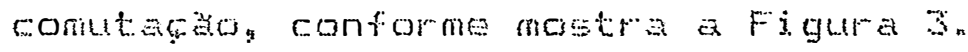

As vazes dos carregadores" as takas de aspirabon os comprimentos das alcas e dos reatores encontram-se espen cificados na Tabela 6 .

Tabela to Dimensires do sistema proposto

\begin{tabular}{|c|c|c|}
\hline Far ametro & sol पF 20 & dimengaio \\
\hline \multirow[t]{2}{*}{ Taxas de aspiraço } & amostra & $5.9 \mathrm{ml} / \mathrm{min}$ \\
\hline & solur ato padren & $2.9 \mathrm{ml} / \mathrm{min}$ \\
\hline Vazose carregadores & $\begin{array}{l}\text { amostra } \\
\text { adiço } \\
\text { padrào } \\
\text { intermitente }\end{array}$ & $\begin{array}{l}1,2 \mathrm{ml} / \mathrm{min} \\
0,5 \mathrm{ml} / \mathrm{min} \\
2,9 \mathrm{ml} / \mathrm{min} \\
4,5 \mathrm{ml} / \mathrm{min}\end{array}$ \\
\hline \multirow{3}{*}{$\begin{array}{l}\text { Comprimentos das } \\
\text { al cas }\end{array}$} & amostira & $100 \mathrm{~cm}$ \\
\hline & adj 6 a & $40 \mathrm{~cm}$ \\
\hline & padra ào & $40 \mathrm{~cm}$ \\
\hline \multirow[t]{4}{*}{ Featores } & disper $=30$ & $125 \mathrm{~cm}$ \\
\hline & $a-x$ & $7 \mathrm{~cm}$ \\
\hline & $b \cdots x$ & $2,5 \mathrm{~cm}$ \\
\hline & $\begin{array}{l}x-y \\
y-y \text { nebul } i z \dot{z} d o r\end{array}$ & $\begin{array}{l}3 \mathrm{~cm} \\
25 \mathrm{~cm}\end{array}$ \\
\hline
\end{tabular}




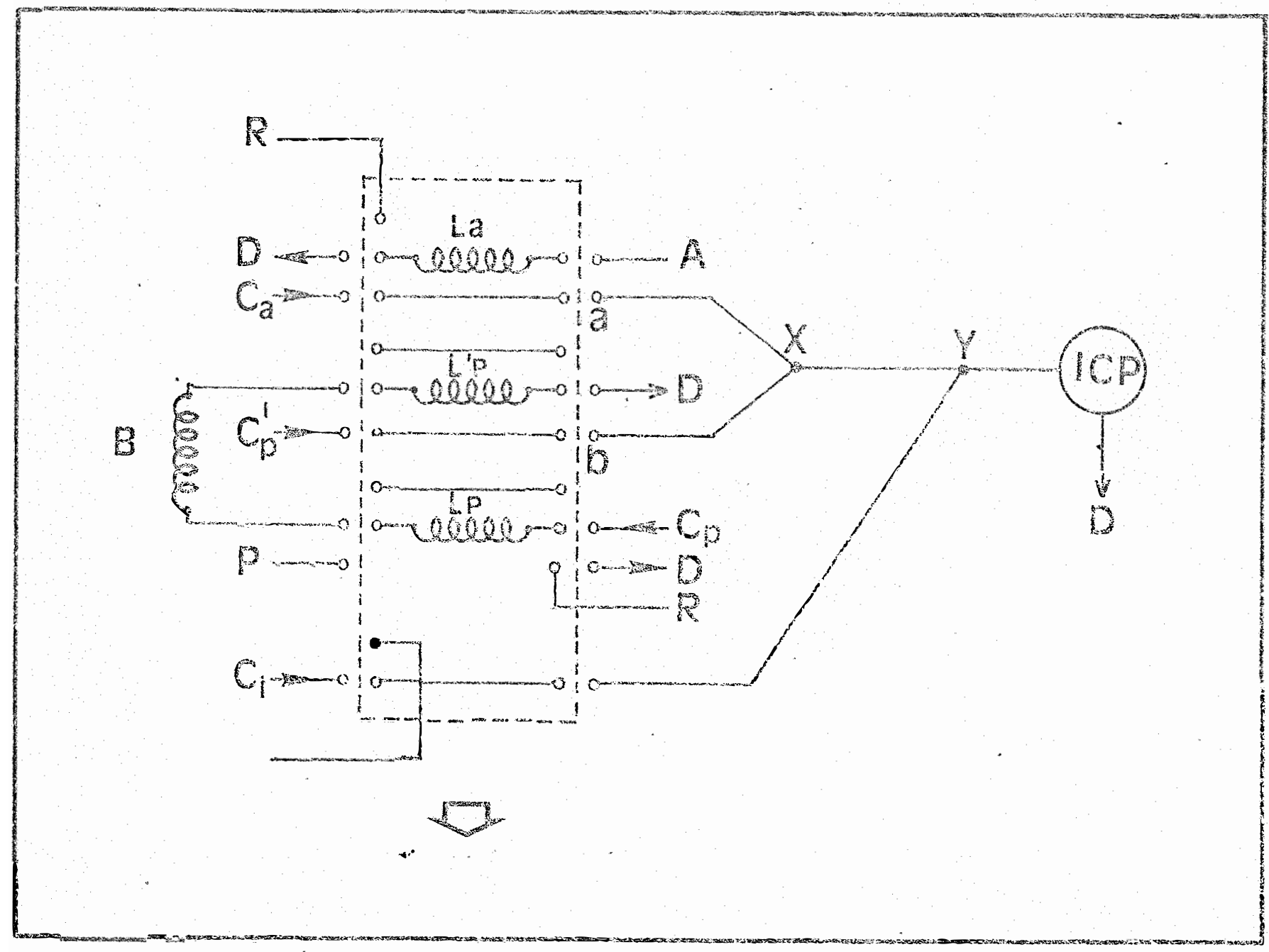

Figura 3. Esquena do sistema FiA-I fop proposto.A parte movel da unidade de comutecto corresponde 点 regia delinitada pela in inha tracejada.

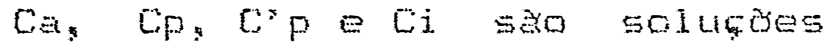
carregadomas: A 2 a amostra $E$ F o padra. La e l.p alcas que determinam os volunes de $A$ e F a serem injetados: L"P determina o voIune de adiço, Bd e o reator de dispersa $D$ o descartes $X$ e portos de confluencia E F reservatorio. 


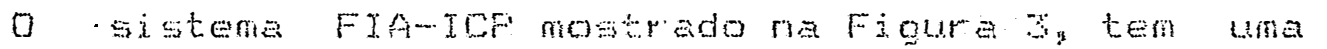

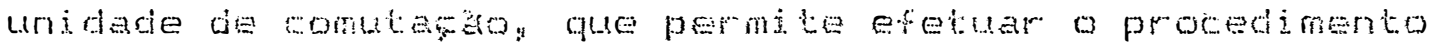

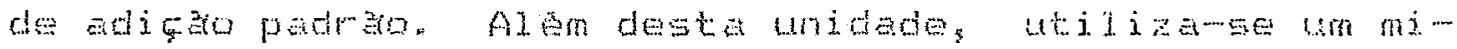
crocomputador que comanda a operacaso de comutaga ex a

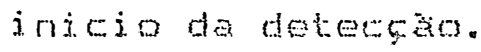

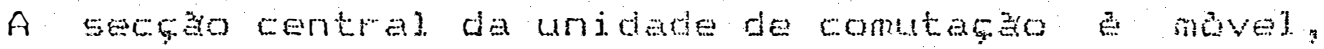
podendo ocupar duas posicoses Na posiga mostada ma

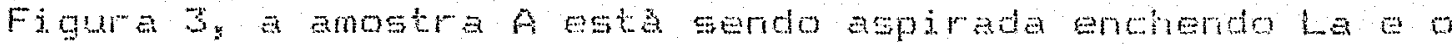

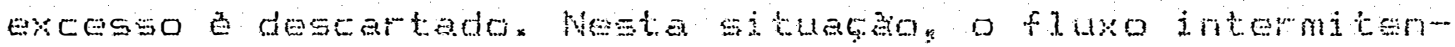
te Ci entra no sjstema por confluencia no pont:o $Y$ a Duando

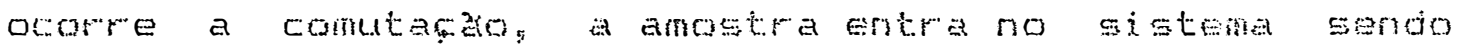
transportada por ca formando uma zona djepersa a que

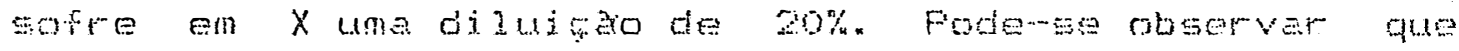

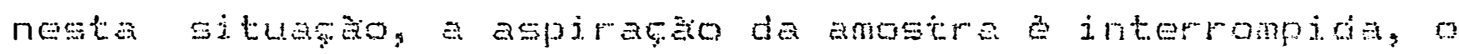
mesmo acontecerido com o padre na outra posiozo do comu $\operatorname{tadcor}$

A dijuga de zona da amostra no ponto de conflusncis, provoca um al argamento da zora dispersa a que conta

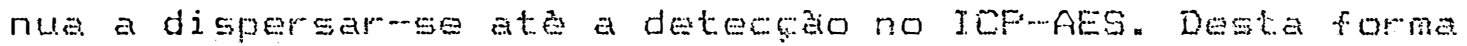
2 obtida a resposta correspondante a eada elemento na amostra. Estes valores permitem programar a concentrasa das adjges, que serao efetuadase a concentrecaso de

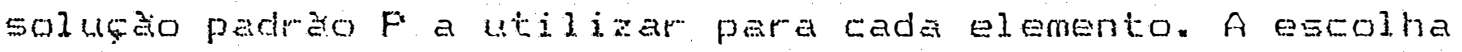
apropriada da duracto do ciclo da analises dos intevalos de tempo en tada posicáo da unidade de comulara e dos incrementos a adicionar, sato selecionados pelos dados de controle do programa. Fara este trabalho, roi fixado um 
ciclo de 30 s sendo tz variavel de 20 ate 12 sets de 10 ate 19 s com inerementos t2 de 1 ou 25 dependendo do elemento. Algumas restriçosexperimentais pera escow Tha dos tempos devem ser cons deradas:

- 0 cicho $t 5$ deve eer $y$ y s. dado que encre a

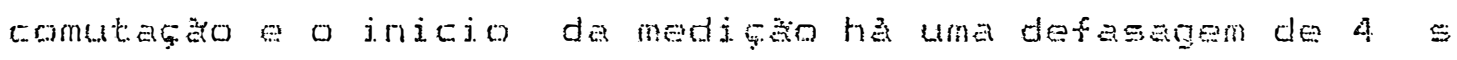
e o tempo de integraga è de $10 \mathrm{~s}$.

- to final deve ser 2 los de rorma que assegure o completo enchimento da al ca da amostra.

Foi utilizada una goluça colorida de verde de brow moresol no lugar de $F$ e soluba de tatraborato de sodio como soluges carregaciorss para testar o sistema de adiches. A medica toj efotuada en un espectrofotametro a 6. $17 \mathrm{~nm}_{4}$ com varjeges de tempo de 1.

Apes definitio dos tempos: efetuaram-se as adiches de todos os elementos na amostra.

Os dados requeridos pata processanento do GeAm sao: concentragbes adicionadas, pegposta inicial da anostra respostas apbs efetuar" as adjoges. 
5. RESLLTADOS E DISCUSGTO

5. 1 Otimizaça das condiçues de operatato

A varedura dos pardmetros de operacko do ICF-AEs.

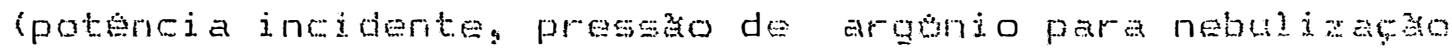
e altura de obstervagazol apresentou o Eomportamento nostrado na figha 4. Nesta Figura, so mostradas as intensidedes de emissan, obtidas no comprimento de onda de

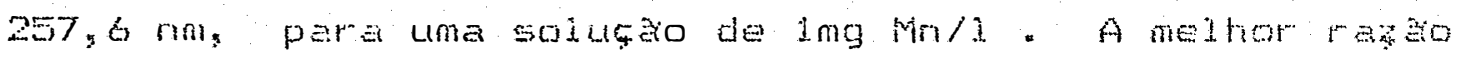
entre as intensidades foi obtida para potencia de 1.1 lw, altura de observaça do $15 \mathrm{~mm}$ e pressán de argonio de 17 1b/pol. Fara a obtenga cias curvas da Figure a a esquer da, a pressao de argonio foi mantida constante em 20 Ib/pol", e para as curvas a direita a potbroia incidente foi fixada em $1.1 \mathrm{~kW}$. Devense ressal tar que estes ajustes otimizan a recepsado do sinal liquido emitido para a maicria dos sensores considerados, ou sejas para todos os sensores que detectam linhas de emissab de atomos ioniardos extitados. Fara a detecka de elementos como Al, As. Cu, Ni e Fi cujos sensores detectam as linhas de emissuo de atomos excitados, a melhor razac de intensidades ocorre para luma al tura de observaço de 20 mim. 


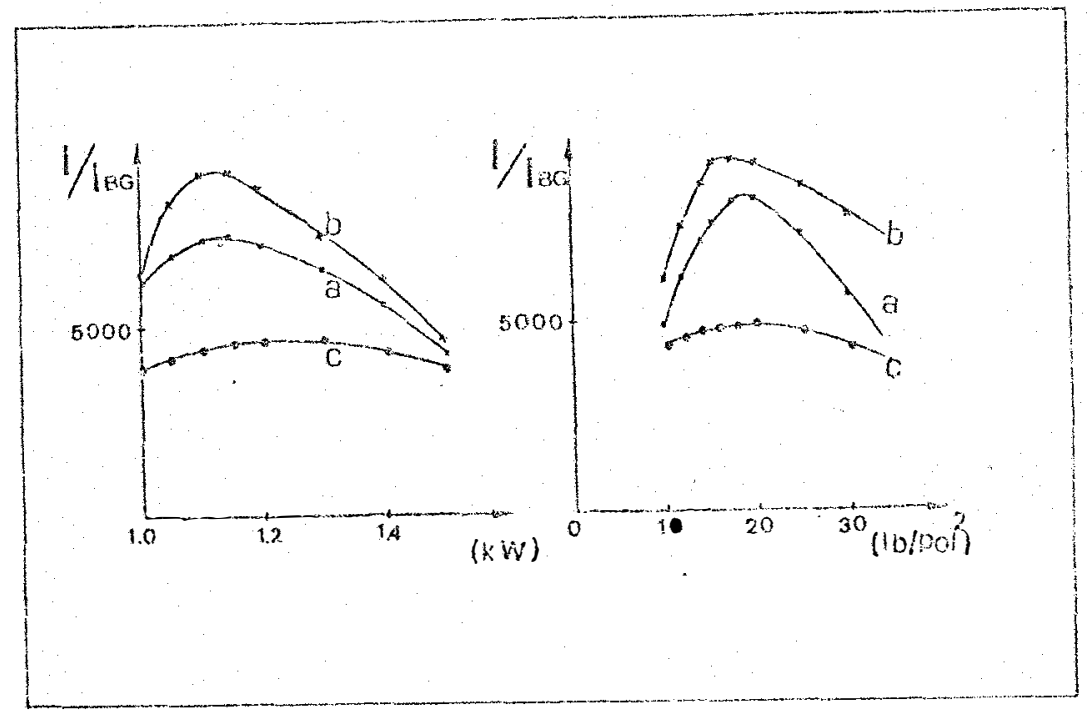

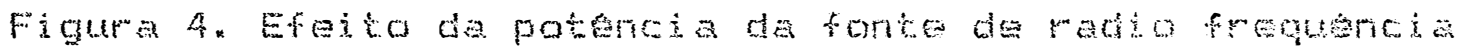

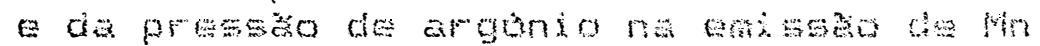

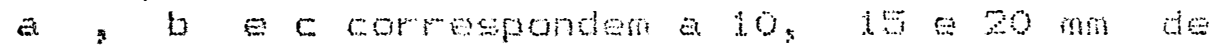

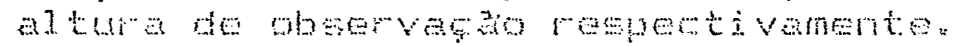

Ass rapes entre as intensidades sato extramenente seneiveis aos tres partatros, o que indica a relevonota

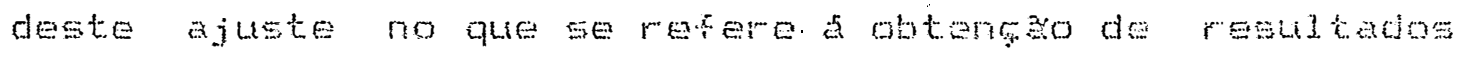
precisos

\section{2 Curvas de calibrasto}

A aralise mutielenentar das solucees padraconcen tradas e das soluçes geradas pelo sistema diluidor deserito no item 4.2.2. permite determinar a funsa regposte-concentraca para cada sensor. As curvas de padronizacho apresentadas na Tabela 7 , obtidas a partir de 7 medi -. das, näo epresenten luma resposta perfeitamente inear nas faikas de concentraço estudadas. 
Tabela 7. Curvas de caldorato

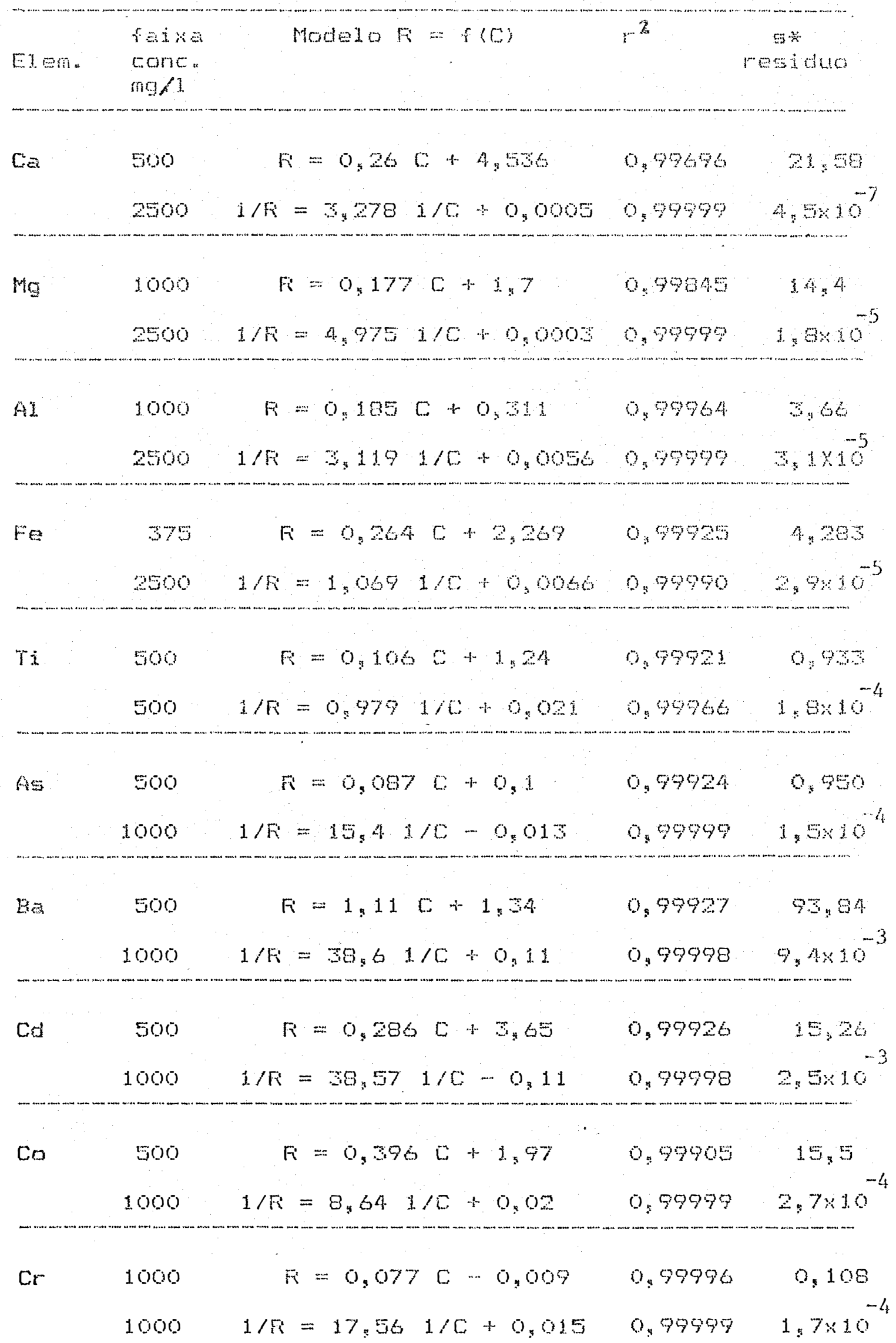


Tabela 7. Curvas de calibragao (contimugrao)

\begin{tabular}{|c|c|c|c|c|}
\hline$E 1=\pi$. & $\begin{array}{l}\text { faika } \\
\text { cont. } \\
\text { mg/l. }\end{array}$ & MoOEIO $F=f(C)$ & $r^{2}$ & 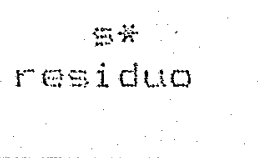 \\
\hline \multirow[t]{2}{*}{ Cus } & 250 & $F_{i}=0,350+0,47$ & 0.99955 & 3,3 \\
\hline & 1000 & $1 / F_{i}=30,4 \quad 1 / C \quad \cdots \quad 0,005$ & 0,99990 & $5.0 \times 10^{-3}$ \\
\hline \multirow[t]{2}{*}{$\mathrm{Mn}$} & 575 & $F_{i}=1,05 \%+10,35$ & 0.99753 & 212,4 \\
\hline & 1000 & $1 / F=9, n 61 / 0+0,027$ & 0,99998 & $5,0 \times 10^{-4}$ \\
\hline \multirow[t]{2}{*}{ Mo } & 500 & $F_{i}=0,255 c+1,25$ & 0,59927 & 11,9 \\
\hline & 1000 & $1 / F_{1}=30,391 / 0-0,021$ & 0,99998 & $\because 7 \times 10^{-4}$ \\
\hline \multirow[t]{2}{*}{$N i$} & 500 & $F_{i}=0,090 c+0,31$ & 097954 & 0,46 \\
\hline & 1000 & $1 / F=45,771 / C+0,11$ & 0.99999 & $8.5 \times 10^{-3}$ \\
\hline \multirow[t]{2}{*}{$F$} & 1000 & $F_{i}=0,15 \mathrm{C}+0,74$ & 0.97979 & 2,70 \\
\hline & 1000 & $1 / F=9,811 / C-0,01$ & 0,99959 & $8.2 \times 10^{-5}$ \\
\hline \multirow[t]{2}{*}{$\mathrm{Pb}$} & 1000 & $F=0.569 c+1.69$ & 0,99946 & 70,2 \\
\hline & 1000 & $1 / F^{\prime}=3,231 / C-5_{9} 0 \times 10$ & 0,97998 & $8,3 \times 10^{-5}$ \\
\hline \multirow[t]{2}{*}{$S i^{r}$} & 500 & $F_{i}=0,469 c+9,53$ & 0,99581 & 96,46 \\
\hline & 1000 & $1 / F=52,021 / C+0,28$ & 0,97998 & $5,4 \times 10^{-2}$ \\
\hline \multirow[t]{2}{*}{$v$} & 1000 & $F_{i}=0,170 c+0,58$ & 0,99998 & 0,69 \\
\hline & 1000 & $1 / F=4.161 / C+0,004$ & 0.99999 & $5,5 \times 10^{-6}$ \\
\hline \multirow[t]{2}{*}{ Zn } & 100 & $F_{i}=5,8 \mathrm{C}+6,80$ & 0.99887 & 171,8 \\
\hline & 1000 & $1 / F=5,641 / C+0,07$ & 0,99971 & $2,0 \times 10^{-3}$ \\
\hline \multirow[t]{2}{*}{$\mathrm{Zr}$} & 500 & $F=0,21 C+1,58$ & $0,9981.8$ & 8,23 \\
\hline & 1000 & $1 / F=15.91 / C+0,05$ & 0,99999 & $7,7 \times 1.0^{-4}$ \\
\hline
\end{tabular}


A substituibo des respostase das concentrabes pelos seus valores elevados f potencia $(-1\rangle$, apresentou

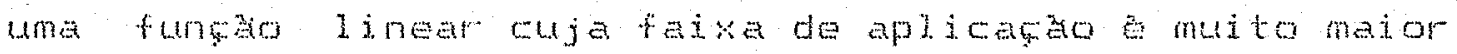
para a generalidade dos sansores.

Qs sinajs obtidos para as concentracbes mas slevedas sao responsaveis pela obtenga de lima curvas que nazo representa, adequadamente a melhor funcas innear para a majoria cios pontos obtidos, prejudiando principamente os Valores correspondentes as baisas concentrasos. A transformaca proposta, permite a obtengo de una curva que representa melhor a ma iom dos pontos dentro desta

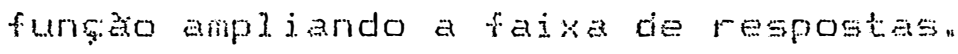

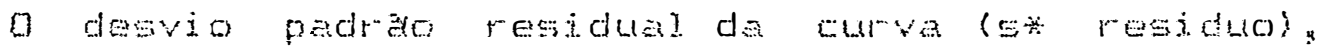
permite avaliar o espahamento dos pontos experimentats com refersncia acos pontos entimados. Dentre os elemertos estudados o que apresentou meihor ajuste no modelo R - C foi o eromo.

0 coeficiente de seneibilidade de Eada elemento am seu proprio sensor" $k_{i i}$ e dado pelo valor do coeficiente angular da reta $F i=f(C)$. Fode-se observar na Tabela 7 gue os sensores que apresentam melhor razào sinal/ruido são o do Zn, Ba E Mn.

As respostas dos elementos Ca. Mg, Al e Fe que se encontran em maiomes concentraçbes nos solubilizados de rochas, apresentam no modelo linearizado una al ba correlaço com as concentracoses, na faixa de ate $2500 \mathrm{mg} / \mathrm{l}$.

Na aplicaço do GSAM como ferramenta para Ealibraça interejementar, deve ser empregado o modelo linearizado 
para a aval iaga das interforencias entre os elementos majores da amostra e destes. nos elementoz trasos. Desde que neste trabaino, enrase foi dada as determinabes de elementos tracos sujeitos a interferencias, assumiurs uma resposta linear para os elementos maiores . Esta rondiço de contorno permite uma melhor avaliaca das interm ferencias sofridas pelos elementos tracos, mas nao por mite que atraves do BSAM se obtentam informages das interfertncias entre os elementos maiomes.

\subsection{Matriz de calibráca multielementar}

As regresobes lineares antre as concentrabes de un elemento i na sollcyo patra e as respostas nos diferentes sensoles j, produzem una matriz de calibraço multielementar. Atraves do procedimento de calculos gite utiIiza os diferenciais entre as concentrabes adicionadas de cada lum dos elementos, éposivel deteminar as coeficientes angulares das $i x j$ regresedes ou coesicientes de sensibilidade $k_{i j}$ arranjados na matriz de calituraçes K utlizando GSAM.

A Tabela 8 mostra a matriz $K_{s}$ obtida a partir do processamento das solufbes padia contendo 250 " 500 e $1000 \mathrm{mg} / \mathrm{l}$ de cada elemento. Algumas dessas soluçes apresentam concentrafues que ultrapassem a faixa linear de respostas dos proprics sensores, mas que permitem caracterizar melhor as respostas nos sensores interferidos. 
Tabela B. patriz K Og valores ki d dete matriz indican a detectán no sensor j da endssa produzide pelo elenento i. A primeira limh corresponde aos coerjcientes de sensibi.jidade do elemerito i nos sensomes Ca.Mg...... Mo e a segunds linhe nos sensores $\mathrm{Ni}, \mathrm{Mn}_{\mathrm{s}} . \ldots . . \mathrm{F}$.

\section{SENSOR}

\begin{tabular}{|c|c|c|c|c|c|c|c|c|c|c|}
\hline & $\begin{array}{l}\mathrm{Ca} \\
\mathrm{Ni}\end{array}$ & $\begin{array}{l}M s \\
K_{n}\end{array}$ & $\begin{array}{l}\text { AL } \\
Z n\end{array}$ & $\begin{array}{l}\text { Fe } \\
\text { Zr }\end{array}$ & $\begin{array}{l}\text { Ti } \\
\mathrm{Pb}\end{array}$ & $\begin{array}{l}\text { As } \\
v\end{array}$ & $\begin{array}{l}\mathrm{Co} \\
\mathrm{Ba}\end{array}$ & $\begin{array}{l}\mathrm{Cr} \\
\mathrm{Cd}\end{array}$ &. $\begin{array}{c}c .12 \\
.9 r\end{array}$ & $\stackrel{\text { Ho }}{8}$ \\
\hline $\mathrm{Ca}$ & $\begin{array}{l}.23233 \\
.00000\end{array}$ & $\begin{array}{l}.00002 \\
.00001\end{array}$ & $\begin{array}{l}.00025 \\
.00002\end{array}$ & $\begin{array}{l}.00003 \\
.00000\end{array}$ & $\begin{array}{l}.00001 \\
.00003\end{array}$ & $\begin{array}{l}-.00053 \\
\because .00002\end{array}$ & $\begin{array}{r}-.001323 \\
.00001\end{array}$ & $\begin{array}{r}.00001 \\
-.00000\end{array}$ & $\begin{array}{l}.00000 \\
.00003\end{array}$ & $\begin{array}{l}.00000 \\
.000033\end{array}$ \\
\hline $\mathrm{Mg}$ & $\begin{array}{l}.00002 \\
.00001\end{array}$ & $\begin{array}{l}.17390 \\
.00004\end{array}$ & $\begin{array}{l}.00002 \\
.00005\end{array}$ & $\begin{array}{l}.00005 \\
.03000\end{array}$ & $\begin{array}{l}.000000 \\
.00003\end{array}$ & $\begin{array}{r}-.00013 \\
.00012\end{array}$ & $\begin{array}{r}.0002 ? \\
.00000\end{array}$ & $\begin{array}{l}.00031 \\
.00002\end{array}$ & $\begin{array}{l}.0000\{ \\
.0001022\end{array}$ & $\begin{array}{l}.00005 \\
.00005\end{array}$ \\
\hline A1 & $\begin{array}{l}.00002 \\
.00000\end{array}$ & $\begin{array}{l}.00001 \\
.00116\end{array}$ & $\begin{array}{l}.18350 \\
.001311\end{array}$ & $\begin{array}{l}.00003 \\
.00000\end{array}$ & $\begin{array}{l}.00000 \\
.00019\end{array}$ & $\begin{array}{l}.00037 \\
.00002\end{array}$ & $\begin{array}{r}.000 ? 3 \\
.00000\end{array}$ & $\begin{array}{l}.00001 \\
.000002\end{array}$ & $\begin{array}{r}.00000 \\
-.000603\end{array}$ & $\begin{array}{l}.00016 \\
.00309\end{array}$ \\
\hline 5 & $\begin{array}{l}.00023 \\
.00002\end{array}$ & $\begin{array}{l}.00027 \\
.00072\end{array}$ & $\begin{array}{l}.0001 a \\
.00192\end{array}$ & $\begin{array}{l}.24050 \\
.00005\end{array}$ & $\begin{array}{l}.00300 \\
.0001 \%\end{array}$ & $\begin{array}{r}-.00003 \\
.06187\end{array}$ & $\begin{array}{r}-.00010 \\
.00001\end{array}$ & $\begin{array}{l}.00013 \\
.00505\end{array}$ & $\begin{array}{l}.00002 \\
.00000\end{array}$ & $\begin{array}{l}.00000 \\
.00025\end{array}$ \\
\hline $\mathbf{T i}$ & $\begin{array}{r}.00081 \\
-.00001\end{array}$ & $\begin{array}{r}.00006 \\
.00004\end{array}$ & $\begin{array}{l}.00448 \\
.00120\end{array}$ & $\begin{array}{l}.00043 \\
.00091\end{array}$ & $\begin{array}{l}.11130 \\
.00012\end{array}$ & $\begin{array}{r}\cdots .00095 \\
.00302\end{array}$ & $\begin{array}{l}.00035 \\
.00003\end{array}$ & $\begin{array}{r}.00005 \\
-.00001\end{array}$ & $\begin{array}{r}.00016 \\
-.00000\end{array}$ & $\begin{array}{r}.00050 \\
-.000 s\end{array}$ \\
\hline As & $\begin{array}{l}.00008 \\
.00001\end{array}$ & $\begin{array}{l}.00005 \\
.00052\end{array}$ & $\begin{array}{l}.00014 \\
.00030\end{array}$ & $\begin{array}{l}.00001 \\
.00301\end{array}$ & $\begin{array}{l}.00000 \\
.00015\end{array}$ & $\begin{array}{l}.00089 \\
.00005\end{array}$ & $\begin{array}{r}-.00102 \\
.00001\end{array}$ & $\begin{array}{l}.50001 \\
.00451\end{array}$ & $\begin{array}{r}.00001 \\
-.00000\end{array}$ & $\begin{array}{l}.00003 \\
.00003\end{array}$ \\
\hline Co & $\begin{array}{l}.00011 \\
.00019\end{array}$ & $\begin{array}{l}.00012 \\
.00029\end{array}$ & $\begin{array}{l}.00063 \\
.00027\end{array}$ & .000 & $\begin{array}{l}.00002 \\
.00049\end{array}$ & $\begin{array}{r}-.00059 \\
.00009\end{array}$ & $\begin{array}{l}.35930 \\
.00002\end{array}$ & $\begin{array}{l}.00004 \\
.00019\end{array}$ & $\begin{array}{r}.0000 \hat{4} \\
-.00000\end{array}$ & 008 \\
\hline$c_{r}$ & $\begin{array}{l}.00106 \\
.00001\end{array}$ & $\begin{array}{l}.00027 \\
.00014\end{array}$ & $\begin{array}{l}.00020 \\
.00059\end{array}$ & $\begin{array}{r}.00009 \\
.00008\end{array}$ & $\begin{array}{l}.03005 \\
.00009\end{array}$ & $\begin{array}{r}-.00059 \\
.00050\end{array}$ & $\begin{array}{r}-.36090 \\
.00002\end{array}$ & $\begin{array}{l}.03053 \\
.00000\end{array}$ & $\begin{array}{r}.00005 \\
-.00000\end{array}$ & \\
\hline $\mathrm{Cu}$ & $\begin{array}{l}.00002 \\
.00000\end{array}$ & $\begin{array}{l}.00000 \\
.00001\end{array}$ & $\begin{array}{r}.00003 \\
.02204\end{array}$ & $\begin{array}{r}-.00001 \\
.00000\end{array}$ & $\begin{array}{l}.00602 \\
.00103\end{array}$ & $\begin{array}{r}-.00065 \\
.00000\end{array}$ & $\begin{array}{r}-.00108 \\
.05004\end{array}$ & $\begin{array}{l}.00001 \\
.0000 ?\end{array}$ & $\begin{array}{l}.29731 \\
.00003\end{array}$ & $\begin{array}{l}.0000 ? \\
.00159\end{array}$ \\
\hline Ho & $\begin{array}{l}.00068 \\
.00001\end{array}$ & $\begin{array}{l}.00040 \\
.000: 4\end{array}$ & $\begin{array}{l}.00034 \\
.00051\end{array}$ & $\begin{array}{l}.50021 \\
.000314\end{array}$ & $\begin{array}{l}.00003 \\
.00043\end{array}$ & $\begin{array}{r}-.00053 \\
.01986\end{array}$ & $\begin{array}{r}.00 \leq 05 \\
.00033\end{array}$ & $\begin{array}{l}.00021 \\
.00001\end{array}$ & $\begin{array}{r}.00028 \\
-.00000\end{array}$ & $\begin{array}{l}.25603 \\
.00056\end{array}$ \\
\hline $\mathrm{Ni}$ & $\begin{array}{l}.00004 \\
.10012\end{array}$ & $\begin{array}{l}.00006 \\
.00001\end{array}$ & $\begin{array}{l}.00011 \\
.01184\end{array}$ & $\begin{array}{r}-.0000 ? \\
.00098\end{array}$ & $\begin{array}{l}.00017 \\
.00045\end{array}$ & $\begin{array}{r}-.00063 \\
.0000 ?\end{array}$ & $\begin{array}{r}-.00071 \\
.00000\end{array}$ & $\begin{array}{l}.00000 \\
.00008\end{array}$ & $\begin{array}{r}.000102 \\
0.00000\end{array}$ & $\begin{array}{l}.00003 \\
.00005\end{array}$ \\
\hline Mn & $\begin{array}{l}.00018 \\
.00001\end{array}$ & $\begin{array}{r}.00254 \\
1.01088\end{array}$ & $\begin{array}{l}.00032 \\
.00016\end{array}$ & $\begin{array}{r}.00 \\
-.00\end{array}$ & $\begin{array}{l}.00000 \\
.00012\end{array}$ & $\begin{array}{r}-.00063 \\
.00039\end{array}$ & $\begin{array}{r}-.00110 \\
.00001\end{array}$ & $\begin{array}{l}.00041 \\
.00000\end{array}$ & $\begin{array}{l}.00021 \\
.0000 *\end{array}$ & $\begin{array}{l}.00003 \\
.00005\end{array}$ \\
\hline $2 n$ & $\begin{array}{r}-.00000 \\
.00000\end{array}$ & $\begin{array}{r}.06000 \\
-.00000\end{array}$ & $\begin{array}{r}-.000105 \\
6.39970\end{array}$ & $\begin{array}{r}.00001 \\
-.00000\end{array}$ & $\begin{array}{l}.00001 \\
.00004\end{array}$ & $\begin{array}{l}-.00065 \\
-.00001\end{array}$ & $\begin{array}{r}-.00110 \\
.00000\end{array}$ & $\begin{array}{l}-.00000 \\
-.00001\end{array}$ & $\begin{array}{l}-.00000 \\
-.00000\end{array}$ & $\begin{array}{l}.00034 \\
.00025\end{array}$ \\
\hline $2 r$ & .00192 & $\begin{array}{l}.00058 \\
.00056\end{array}$ & $\begin{array}{l}.00081 \\
.00058\end{array}$ & & $\begin{array}{l}.00008 \\
.00016\end{array}$ & $\begin{array}{r}-.00061 \\
.00164\end{array}$ & $\begin{array}{r}-.00104 \\
.00024\end{array}$ & & $\begin{array}{l}.00008 \\
.00001\end{array}$ & $\begin{array}{l}.0000 \% \\
.000 \% 8\end{array}$ \\
\hline $\mathrm{Pb}$ & $\begin{array}{l}.00009 \\
.00001\end{array}$ & $\begin{array}{l}.00006 \\
.00005\end{array}$ & $\begin{array}{l}.00017 \\
.00015\end{array}$ & $\begin{array}{l}.00001 \\
.00001\end{array}$ & & $\begin{array}{r}-.00059 \\
.00006\end{array}$ & $\begin{array}{r}-.001 .08 \\
.00050\end{array}$ & $\begin{array}{l}.00001 \\
.0000 *\end{array}$ & $\begin{array}{r}.00001 \\
-.06000\end{array}$ & $\begin{array}{l}.00005 \\
.00003\end{array}$ \\
\hline v & $\begin{array}{l}.00358 \\
.03001\end{array}$ & $\begin{array}{l}.00037 \\
.00023\end{array}$ & $\begin{array}{l}.01235 \\
.00124\end{array}$ & $\begin{array}{l}.00022 \\
.00008\end{array}$ & & $\begin{array}{l}.00041 \\
.17037\end{array}$ & $\begin{array}{r}-.00108 \\
.00007\end{array}$ & $\begin{array}{l}.00105 \\
.00002\end{array}$ & $\begin{array}{l}.00006 \\
.00000\end{array}$ & $\begin{array}{l}.00007 \\
.00011\end{array}$ \\
\hline Ba & $\begin{array}{l}.00007 \\
.00001\end{array}$ & $\begin{array}{l}.00003 \\
.00001\end{array}$ & $\begin{array}{l}.00019 \\
.00012\end{array}$ & $\begin{array}{r}-.00000 \\
.00000\end{array}$ & $\begin{array}{l}.0500 k \\
.00005\end{array}$ & $\begin{array}{r}-.00064 \\
.00004\end{array}$ & $\begin{array}{r}-.00085 \\
1.15233\end{array}$ & $\begin{array}{l}.00000 \\
.00000\end{array}$ & $\begin{array}{r}.00001 \\
-.0000 *\end{array}$ & $\begin{array}{l}.0000 ? \\
.00032\end{array}$ \\
\hline$c d$ & $\begin{array}{l}.00012 \\
.00005\end{array}$ & $\begin{array}{l}.00006 \\
.00004\end{array}$ & $\begin{array}{l}.00019 \\
.00074\end{array}$ & $\begin{array}{l}.00002 \\
.00002\end{array}$ & $\begin{array}{l}.00001 \\
.00018\end{array}$ & $\begin{array}{r}-.00063 \\
.00007\end{array}$ & $\begin{array}{l}.00028 \\
.00001\end{array}$ & $\begin{array}{l}.00003 \\
.39279\end{array}$ & $\begin{array}{r}.00002 \\
-.03000\end{array}$ & $\begin{array}{l}.00004 \\
.00041\end{array}$ \\
\hline Sr & $\begin{array}{l}.00003 \\
.00000\end{array}$ & $\begin{array}{l}.00000 \\
.00001\end{array}$ & $\begin{array}{l}.00018 \\
.00010\end{array}$ & $\begin{array}{r}-.00000 \\
.00000\end{array}$ & $\begin{array}{l}.00000 \\
.00002\end{array}$ & $\begin{array}{r}-.00065 \\
.00002\end{array}$ & $\begin{array}{r}-.00110 \\
.00004\end{array}$ & $\begin{array}{r}.00000 \\
-.00000\end{array}$ & $\begin{array}{l}.00001 \\
.53102\end{array}$ & $\begin{array}{l}.00009 \\
.00006\end{array}$ \\
\hline$P$ & .00000 & .0000 ó & .0005 s & $\begin{array}{r}-.00000 \\
-.00000\end{array}$ & $\begin{array}{r}-.0000 * \\
.00001\end{array}$ & $\begin{array}{r}-.0000 .5 \\
-.00001\end{array}$ & $\begin{array}{r}-.00108 \\
.00001\end{array}$ & $\begin{array}{r}.00001 \\
-.00005\end{array}$ & $-.0000 *$ & $\begin{array}{l}.00008 \\
.15226\end{array}$ \\
\hline
\end{tabular}


Ds coeficientes bii y ou seja coeficientes de sencibilidade dos elementos nos seus sensores principeis, apresentam valores similares aos obtidos com as curvas

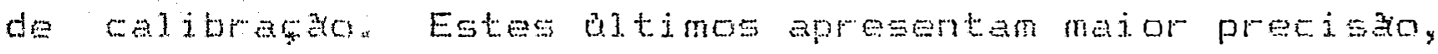
uma vez que os mesmos form obtidos com um numero maior de pontos e considerandomse somente a faja linear.

Os valores da Tabela e, permitem quantificar a inter feroncia de cada elemento sobre os principais sensores juterferidos: expressados romo $\% \dot{\mathrm{i}}_{\mathrm{i}}$. fassims pode-se observar que alguns valores indicam naves is significativos de interferenciasa por exemplo o kalas

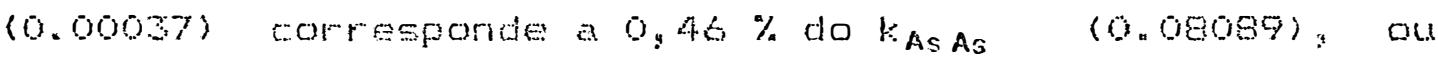
seja. 100 unidades de concentraga de A3, produzen uma interferencia no sensor do As: correspondente a o, 46 unidades de concentraga de As.

Qs valores da Tabela 8, apresentam-es livres do efeito do BG, correspondendo as interfertheias aspectrajs produzidas por coincidencia de linhas. f Tabela 9 resume as maiores interferencias expressas en $\% \mathrm{l}_{i \mathrm{i}}$. 


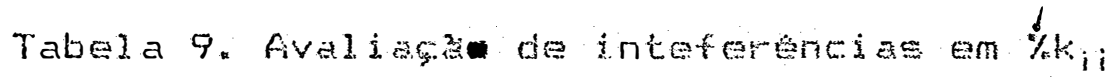

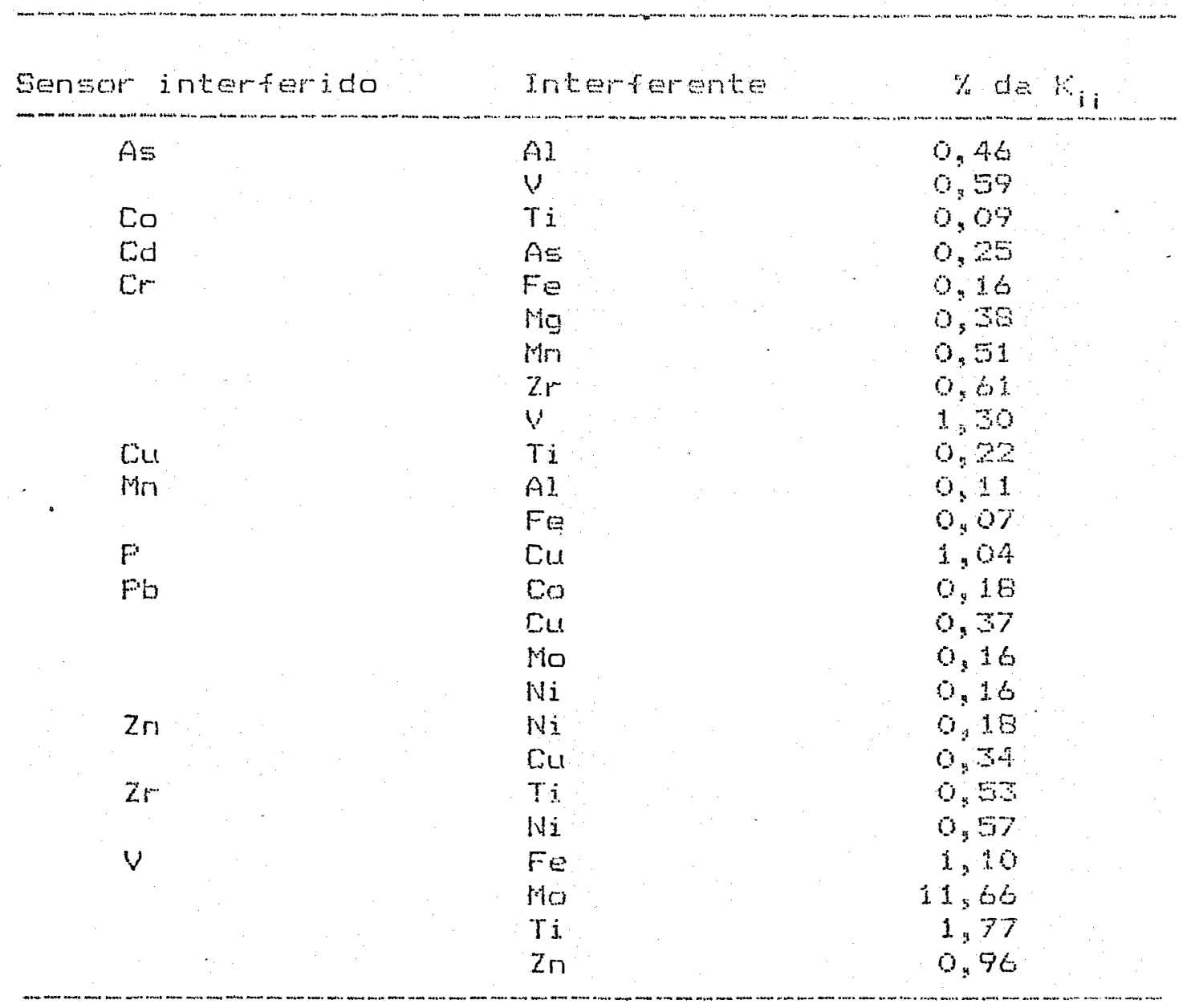

5.4 Correça de $\mathrm{BG}$

Na aplicaf̧o do GSAM, para determinar a matria utilizaça das diferensas entre as respostas, pela adicao incremental, faz com que seja dispensavel a correfäo de EG. For outro lado, o GSAM nzo fornece informaçes sobre as interferencias devidas a emissào de um "continuum" ou radiaçào de fundo produzida pelas emissòes dos estados ionizados I e IJ do argonio, as bandas espectrais dos radicais $\mathrm{OH}^{-}$. do $\mathrm{N}_{2}^{+}$e do No. Como foi salientado, os valores $\mathrm{i}_{i j}$ da Tabela 8 mostram apenas as interferencias 
causadas pela coincidencia de linhas.

Wo Jevantamento das interrerencias utidizanowoen o corretor EG disponivel, for am obtidos os resultados correspondentes ao sinal Ifquido e an sinal devido d o fr e emissto da matriz da amostra. Os valores do EEC expresw sos nas suas concentragos equivalentes, devidos ao efoito do aumento da concentrasto de Al e Mo sobre alguns sensores interferidos saso mostrados na Figura 5.

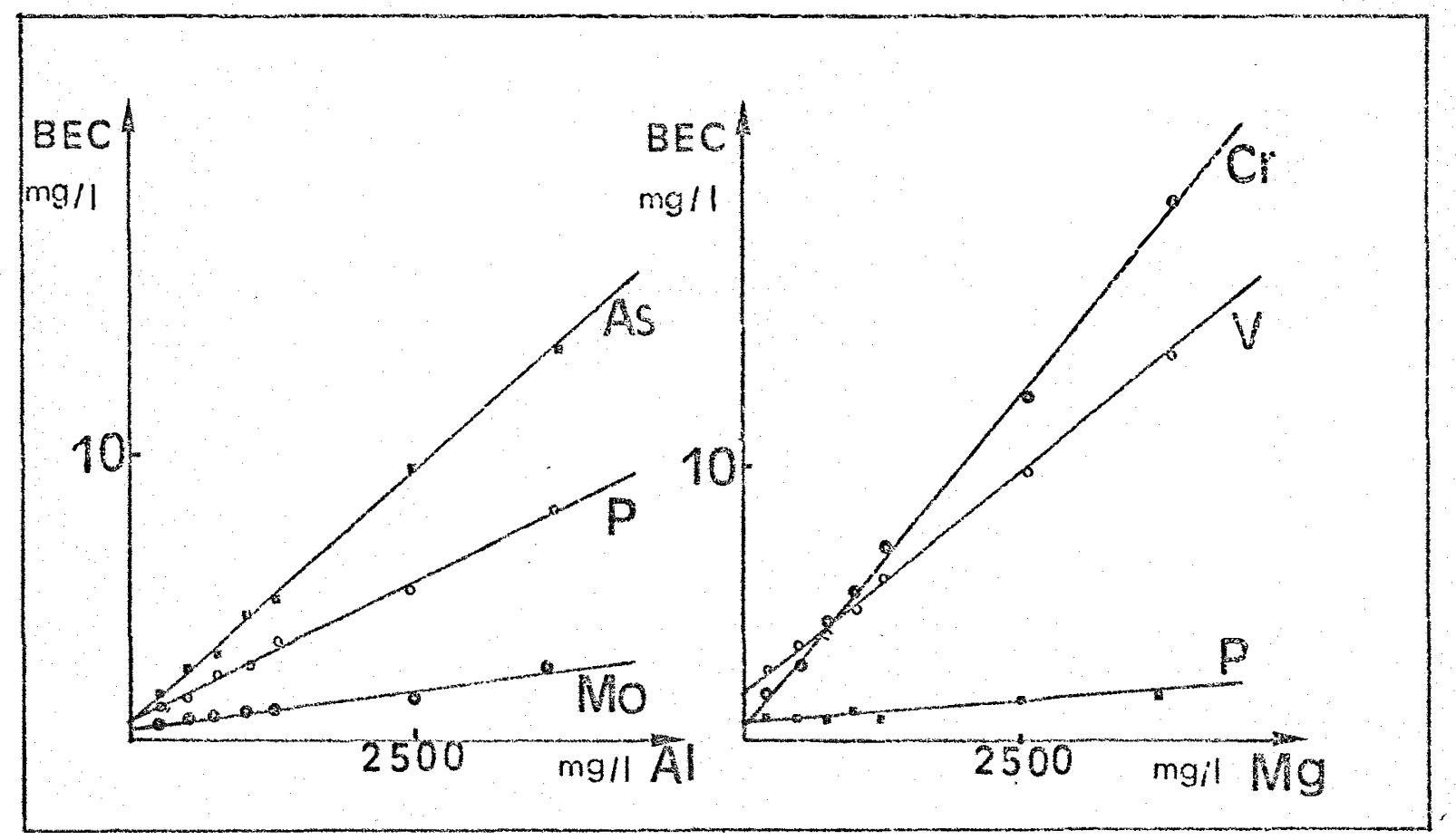

Figura 5. Efeito das concentraçes de Al no BeC do As, F e Mo e de Mg no BEC do $\mathrm{Cr}, \mathrm{V}$ e F

Dbserva-se na figura 5 , que hà uma correlatra linear entre a concentraça do elemento interferente o EEC clos sensores interferidos, o que viabiliza o gSAM. Em geral, na ausencia do analito, a majoria dos sensores apresenta resposta 1 iquida posjtiva, e estas se apresentam estaveis 
Sob as mesmas condigdes experimentais.

For outro lados os Valores do BEC dependen das condicos de operaca do ICF. A Figura b mostra o efeito da mudanca das condicases de operacto sobre o EEC para o sensor de thr no comprimente de onda de 257 , b nom.

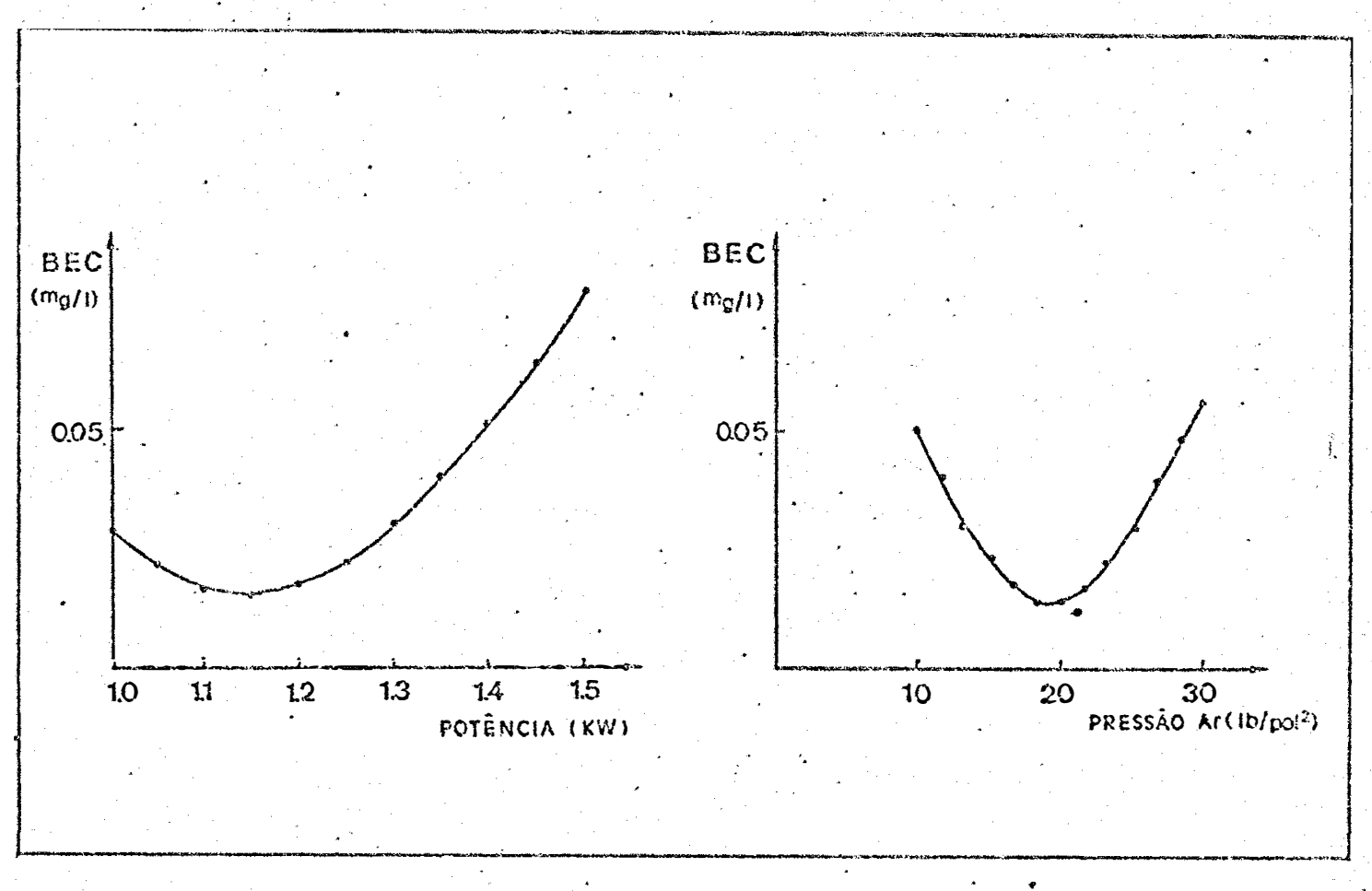

Figura b. Efeito da potencia da fonte de radiofrequencia a da pressazo de argonio sobre os valores do BEC do sensor de Mn em 257,6 $\mathrm{rm}$

A Figura to mostra que os valores de minimo BEC ocorren para potencia da radiofrequencia de 1,15 t: pressaco de argonio no nebulizador de aproximadamente 20 $1 b /[0])^{2}$.

A correço de EG, permite contornar as interferencias espectrais devidas d luz difusa, 
prejudicando no entretanto, os limites de detectio fere a maioria dos elementos.

De acordo com a teoria de propagata de erros a precisáo das medidas com correcalo de ge è prejudicaday visto que o sinal e resul tante da substraço de duas medidas experimentais. A corregaro de ro litilizando o GSA apresenta maior preciszo do que a ingsumental, uma vez que corrige as interferencias atreves das rempostas incrementadas pelas edicoes, considerando valores tolativos e efetuando extrapolaça de regressabo linear.

5.5 Efeito da matriz sobre as caracteristicas de dekectaso dos elemsntos tragcs

A analise das matrizes simujadas descritas na rabela 3. acusou a presenga de elementos trecos apesar dos mesmos estarem ausentes naj respectivas soiludes. Estas concentragties aparentes dos elementos tracoss constituen os valores da prova em "branco" para os respectivos sensores. A Tabela 10 mostra as medias é desviog padra das provas em "branco", obtidos a partir de 7 repeticoes das leituras no ICF. Cada matriz foi sjmalda conforme descrito no item 4.2.3, utilizando-se no lugar de 5 micro uma soluço HCl 0,5 M. Estas medias correspondem as concentraçues aparentes dos elementos tracos. As concentraças minimas detectaveis mostradas na Tabela 10 correspondem a valores experimentais apresentando desvio padra relativo da ordem de $10 \%$. 
Tabela 10. Concentracoss aparentes e minimas detectaves na presemea de diferentes matrizes simuladas de rochas. De valores correspondem a mg/l no wollbilizado. Matriz Ultrabasica Basalto Granito Sedimento Elem.

Concentractes aparentes ( mg/1)

\begin{tabular}{|c|c|c|c|c|}
\hline As & 3,0902020 & $9.950 \pm .200$ & $11,1201,210$ & $2,510 \mathrm{t}, 020$ \\
\hline $\mathrm{Co}$ & $0,610 \pm, 009$ & $0,590 \pm .012$ & $0,390,004$ & $0.410 \pm 007$ \\
\hline Crr & $6,0901,072$ & $3,600 \pm, 057$ & $2,380 \div 047$ & $3,280 \pm, 005$ \\
\hline $\mathrm{Cu}$ & $0.4001,011$ & $0,410 \pm .00 \%$ & $0,280 \pm, 003$ & $0,340 \pm, 006$ \\
\hline Mo & $0.520 \pm, 00 \%$ & $0,750+012$ & 0.7201 .014 & $0,300,005$ \\
\hline$F$ & $1,6201,020$ & $1,940 \pm, 053$ & $1,130 \neq 0,0 \%$ & $1,160 t, 005$ \\
\hline $\mathrm{Fb}$ & $0,660 \pm, 000$ & $0.950 \pm .013$ & $0,740.021$ & $0,530 \pm, 010$ \\
\hline$v$ & $5,820 \pm .059$ & $5,210 \pm, 079$ & $1,4701,024$ & $1,700=008$ \\
\hline $2 n$ & $0,220 \pm 001$ & $0,230 \pm .004$ & $0,1001,001$ & $0,080 \pm, 001$ \\
\hline $2 r$ & $0,850 \pm, 006$ & $0,860 \pm, 008$ & $0.480 \pm 005$ & $0.310 \pm .011$ \\
\hline \multicolumn{5}{|c|}{ Concentracbes minimas datectaveis (ng/1) } \\
\hline$A S$ & 0,05 & 0,20 & 0,25 & 0.05 \\
\hline Co & 0,03 & 0,03 & 0.02 & 0,03 \\
\hline $\mathrm{Cr}$ & 1,20 & 0,50 & 0,30 & 0,50 \\
\hline Cu & 0,02 & 0,02 & 0,02 & 0,02 \\
\hline Mo & 0,05 & 0,10 & 0,10 & 0,05 \\
\hline$F^{\prime}$ & 0,20 & 0,20 & 0,10 & 0,20 \\
\hline $\mathrm{Fb}$ & 1,00 & 0,50 & 0,50 & 0,50 \\
\hline$v$ & 0,20 & 0.20 & 0,05 & 0,05 \\
\hline $\operatorname{In}$ & 0.01 & 0,01 & 0,01 & 0,01 \\
\hline $\mathrm{Zr}$ & 0,05 & 0,05 & 0,05 & 0,05 \\
\hline
\end{tabular}


As conoentraçes minimas detectaveis foram determinadas sxperimentalmente, utilizando-se o sistema simulador descrito no item 4.2.3. e a adicad de concsntraçes decrescantes da soluga smicro.

$$
\text { Se apds a aplicaça do bsam os rer.itados }
$$

se apresentarem negativos, isto significa que os mesmos se situam abajo dos respectivos limitas de deteecato. Os valores negativos sabo explicados como devidos aos processos de substragào envolvidos no calculo do bSArt.

\section{6 o sistema FIA-ICP}

0 Sistema FIA-ICF proposto para este tratalho e mostrado na figura $x$, foi testedo iniala mente injetandose somente aś soluç̧es padräo do prograna Mage, no lugar da amostra. $0 s$ desvios padra relativos das medidas correspondentes aos elementos de interesse, obtidos a partir de 5 leituras das respectivas solucbes padrozo. foram sempre menores que $1 \%$. Ds valores confirnaram a precisào caracteristica dos sistemas FIA-ICF reportados por Jacintho et alii (1981).

As. condiços de dispersato dab amostras rieste sistema, pode ser considerada limitada havendo uma diminuiçă de $20 \%$ do sinal correspondente á amostra em volume de saturaçàio Deve-se observar que, normalinente nos sistemas FIA a \% de dispersảo da especie injekada no sistema è determinada a partir da raza entre o máximo valor do sinal transiente com o sinal am volume infinito. No sistema FIA-ICF, a $\%$ de dispersăo foi aivaliada 
comparando-se a resposta obtida pela integraga do sinal transiente durante 10 g com aguele dojdo em volume infinito. Ds resultados obtidor pela injega da solucato padrac contendo $100 \mathrm{mg} / \mathrm{l}$ de cas Mg: Al e Fe no lugar da amostra no sistema FIA-ICF da Figura 3 , foram de $59,09+0,64 \mathrm{mgCa} / 1$, $58,91+0,5 \mathrm{mgMg} / \mathrm{l}, 56,7610,42 \mathrm{mgAl} / 1$ e $59,76 \pm 0,56$ ingFe/1.

\subsection{Sistema FIA para efetuar adicoes . \\ Os testes realizedos com o sistema da Fiqura zi para} promover adiçbes padräo, preliminarmente realizados com soluça colorida de verde de bromotesoly conforne descrito em 4.4.2, permitiram una evaljaga previa das concentraçes a serem adicionadas.

A Figura 7 da uma ideia das concentraçeas que podem ser geradas com o sistema proposto. Se a partir de uma soluça padrầo contendo $100 \mathrm{mg} / 1$ do elementos for sels-cionada uma aliquota 125 apbs a injeçă sera gerada uma soluço padráa de aproximadamente. $3,5 \mathrm{mg} / \mathrm{l}$. $0 \mathrm{~s}$ maximos valores de concentraçă for am obtidos na regiäo do maximo do sinal transiente, ao passo que as concentraças menores foram selecionadas na regiào descendente da

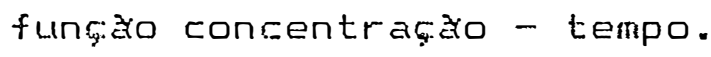

Na Figura 7 sä mostrados os picos correspondentes as aliquotas selecionadas pell a varredura dos tempos entre 32 e 75 , com varjaçes de 15. 


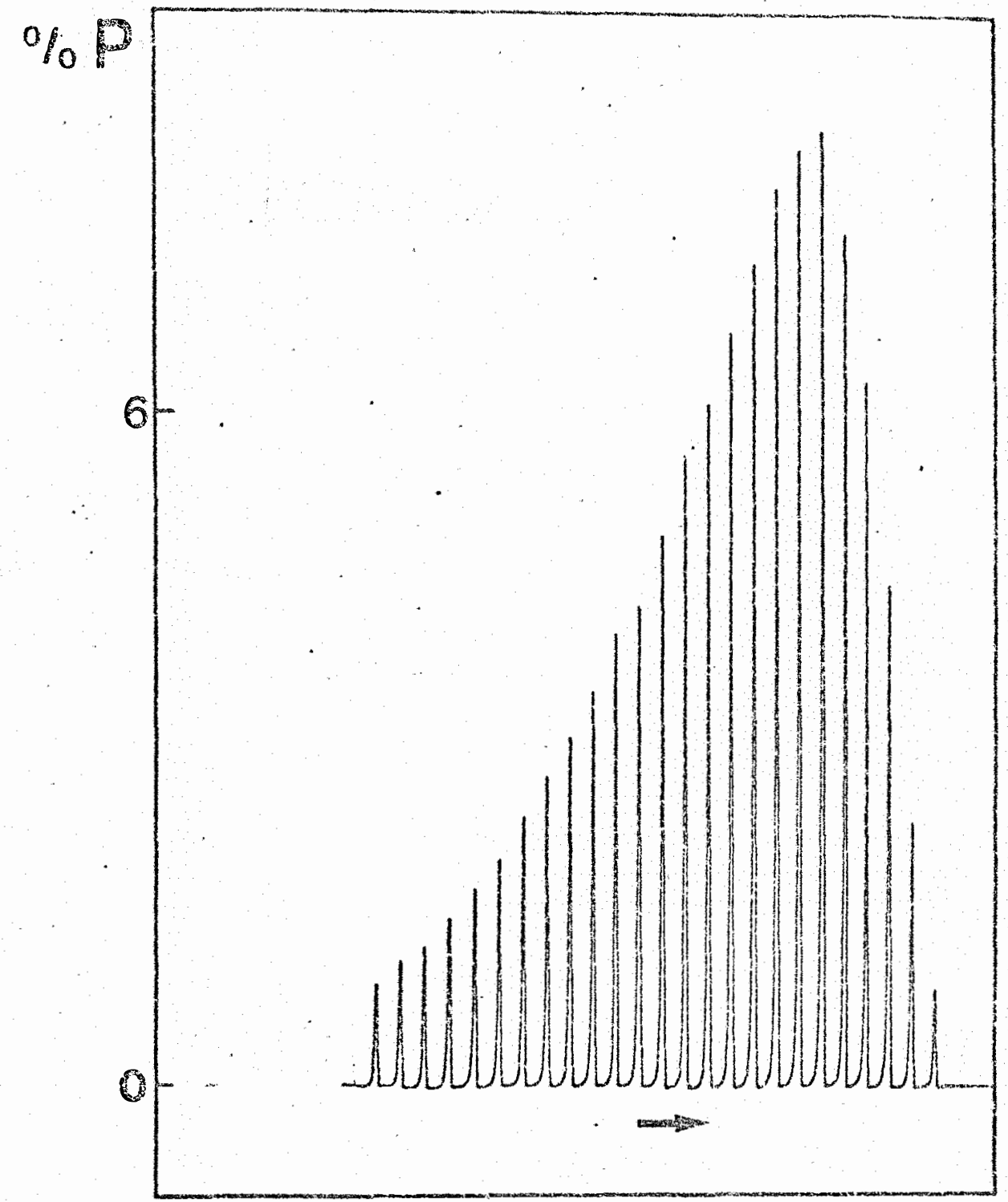

Figura 7 sequencia das soluçes padrăo geradas pela amostragem na zona dispersa de uma solucto de verde de bromocresol e detectäo colorimetries A seta indica a orden experimental com que foi efetlada a varredura dos tempos. F soluga padrac concentradat.

A precisào das necidas obtidas utilizando este sistema, depende das caracteristicas da zana disperses da regia amostrada e do sistema de controle eletronico. 
No sistema FIA-ICF, a partir de uma soluga padra contendo $100 \mathrm{mg} / 1$ de Ca, Mg. Al e Fe foram geradas as as soluçes padra mostradas na Tabela 11. para a varredura de tempos de 12 ate 16 com inomementos de 2

Tabela 11 Solucöes padräo geradas no sistema FIA-ICP. a partir de uma soluça padráde de $100 \mathrm{mg} / \mathrm{l}$ de Ca, Hgal e Fe e os desvios padra abtidos apos 7 repeticoes da sequencia completa

\begin{tabular}{|c|c|c|c|c|}
\hline $\begin{array}{l}\text { numero } \\
\text { da } \\
\text { Adi } 5=0\end{array}$ & Ca & $\mathrm{Mg}$ & $\begin{array}{l}\text { Elemento } \\
\text { Al } \\
\text { (mg/l) }\end{array}$ & $F_{E}$ \\
\hline 1 & $2,36510,060$ & $2,350 \pm 0,067$ & $2,550+0,050$ & $2,51,0,050$ \\
\hline 2 & $4,496 \pm 0,085$ & $4,290 \pm 0,097$ & $4,5750,069$ & $\because .586 \pm 0,096$ \\
\hline 3 & $6,510 \pm 0,087$ & 6.455150 , 094 & $5,996 \pm 0,092$ & $6, \pi \% \pm 0,000$ \\
\hline 4 & $8,56010,097$ & 8, $365 \pm 0,095$ & $3,489 \pm 0,083$ & $8.469 \pm 0.090$ \\
\hline
\end{tabular}

Na Tabela 11 sào apresentados os valores correspondentes ás ariçbes efetuadas com os elementos majores dos solubilizados de rochas. Estes resultados sä́ extensivas a todos ós elementos, dado que, a sequencia das adiches apresentara correlaça lo linear mültipla. Esta correlaça, indica a estabilidade do sistema com referencia ao proces-samento de adiçós de diferentes elementos e permite programar as concentraçes a serem adicionadas de cada elemento. 


\subsection{Aplicaço do GSAM}

o conjunto de didos dotido peid sistema FIA-ICF: contendo a matriz das concentmacos adicionadess o vectop da resposta inicial e a natriz das mopesas apos as adicbes, e nostrado na Tabela 12. Estes restitedos refen ren-we as solubilizado da amosta certificada de basaldo EHVO-1.

Na Tabela 12, a linha 1 contern o valor de NCod: o numero de elementos e a utilizeso (i) ou nao (o) da correca do branco. A linha 2 eerve pare identificar as amostras e indicar a sequencia dos elementos. A Lima indica o tipo de GSAM (valor ISEL no menu do programe no Apendice?" o ncinero total de deterninacres coumero de adifoses $x$ remero de elementos) en escalonkmento (1) ou nâ (o) ( ISCAL no prograna). Da Iinha 4 a 30530 colorados os valores das concentracoses adicionadas ou seja os dados das 1 inhas 4,5 e 6 corresporden a adiches de 207 $389(207+112)$ e $385,4(207+142+46,9)$ ng/1 de Ca, e assm sucessivamente. Isto pelor rato do GaAm incremental tersido utilizado. A linha 3 corresponde as respostes obtidas para a amostra antes das adiçes. De linha 02 a 58 sato apresentadas as respostas obtidas apos adicionar as concentracoses indicadas nas linhas 4 a 30 . Nao utilizou-se correcalo dos valores branco, no caso estes seriam indicados na 1 inhe 59. 
Tabela 12. Resultados ger"ados pelo sigtema FIA-ICP i

para aplicacádo do GSAM para amostra de basalto EHVO-1

$6,9,0$

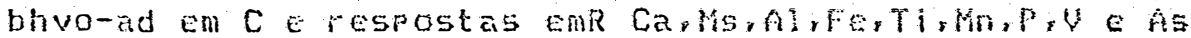

$4,27,9,0,0$

$207 \ldots$

$112 \times$,

46.4,

$0 ., 138.1$.

$0 ., 41.5$,

$0 ., 37.1$,

$0 ., 0 ., 189.7$,

$0 ., 0.774 .5 \%$

$0 ., 0 ., 84.8$,

$0,0,0,150.3, \quad$ CONC. AOKCTOKADAS

$0,0,0,86.4$,

$0 ., 0 ., 0 ., 46 .$,

$\left[\omega_{*}, 0,0 ., 0,43,59\right.$,

$0,0,0,0,0,13.68$,

$0 ., 0,0,0,0,1,5 i 5 y$

$0 ., 0 ., 0 ., 0,0 ., 22.83$,

$0,0 ., 0,0 \ldots, 0,7.87$,

$0 .>0 ., 0 ., 0,0 ., 6.53$,

$0,70,0 ., 0 ., 0,0 ., 4.083 r$

$0,0,0,0,0,0,0,2,25$,

$0 ., 0,0,0,0,0,0,1.97$,

$0,0,0,0,0,0,0,0 ., 4.087$,

$0,, 0_{*}, 0,0,0,0_{*}, 0,2.59$,

$0, \times 0,0, \times 0,0 ., 0 ., 0 ., 1.991$,

$0,0,0,0,0,0,0,0,0,1.877$,

$0 ., 0,0,0,0,0,0,0,8,0,1,149^{\circ}$

$0,, 0,0 ., 0,0 ., 0,0,0,0,1,119$,

$410 ., 59.4,89.3,394.7,41.5,43.5,2.63,2,9,0.72$

$617 ., 01.03,93 ., 398,42.2,44.02,2.83,2.97,0.94$,

RESP STA JNYCIAL.

$71.9 ., 61.1,94.3,404 ., 42.9,44.76,2.7,3.02,0.96$.

$780 ., 61.14,94.3,403,42.53,44.56,2.72,3.03,0.96$.

$410 ., 93.1,90,15,390 ., 41,42.9,2.59,2.95,0,92$,

$411,, 116 ., 93.9,401,42.3,44.46,2.7,3.06,0.96$,

$412,126.6,92.1,399, .41 .8,44.15,2.67,3.06,0.96$.

$411 ., 61.4 \times 150 \times 1,408,42.7,45.7,2.85,3.01,2.37$,

$411 ., 63.8 ; 177.8,407,42.2,46 ., 2.93,3,11.6$,

$410 ., 61.4,194.7,413,442.5,47.3 .07,3.02,1,74$,

$412.0,59.49,89.75,584.4,41.27,43.77,2.66,3.23,0.96$, AS ADICOES

$411.0 .60 .38,95.2,620 ., 42.79,45.7,2.82,3.5,1.01$,

$411.4,60.28,95.3,718 ., 42.71,45.87,2.93,3.6,1.02$.

$411 ., 59.6,93.8,396 ., 63.2,43.8,2.65,3.18,0.94$,

$410,59.6,93.1,397 ., 71.7,44.0,2.63,3.24,0.94$.

$411 ., 59.6,93.4,398,76.9,44.0,2.62,3.28,0.94$,

$410 ., 59.5,90,7395,41.6,73.6,2.64,2.92,0.92$,

$410.59 .4 .39 .6 .395 .+41.6,84.45,2.64,2.93,0.92$,

$411,59.5,89.6,395 \ldots, 41.6,94.6,2.64,2.94,0.92$,

$410.8,59.4,99.4,394.9,41.6,43.6,3.79,2.9,0.92$,

$410.1,59.5,39.4,394.8,41.6,43.6,4.41,2.9,0.92$,

$410.5,59.5,89.4,395 ., 41.6,43.5,4.94,2.9,0.92$,

$410 ., 59.4,89.3,394.7,41.5,43.5,2.63,6.25,0.92$,

$410,59.4,89.3,3,4.7,41.5,43.5,2.63,7.87,0.92$,

$410 ., 59.4,89.3,394.7,41.5,43.5,2.63,9.38,0.92$.

110.,59.4,89.3,394.7,41.5,43.5,2.63,2.92,1.20,

$410 ., 59.4,89.3,394.7,41.5,43.5,2.63,2.92,1.31$,

$410 ., 59.4,89.3,394.7,41.5,43.5,2.63,2.92,1.45$,

$-1$ 


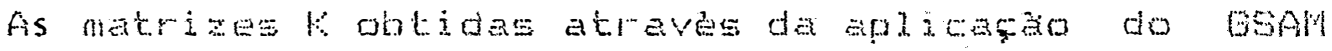
sobre os resultados de duas amostras de basalto (BCp-1 e

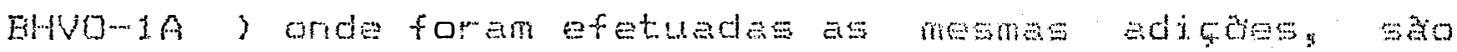
mostradas na Tabela 13.

Tabeia 13. Comparaço das matriag K obtidas pelo GSAM para as amostras EHVO-1 e ECR-1

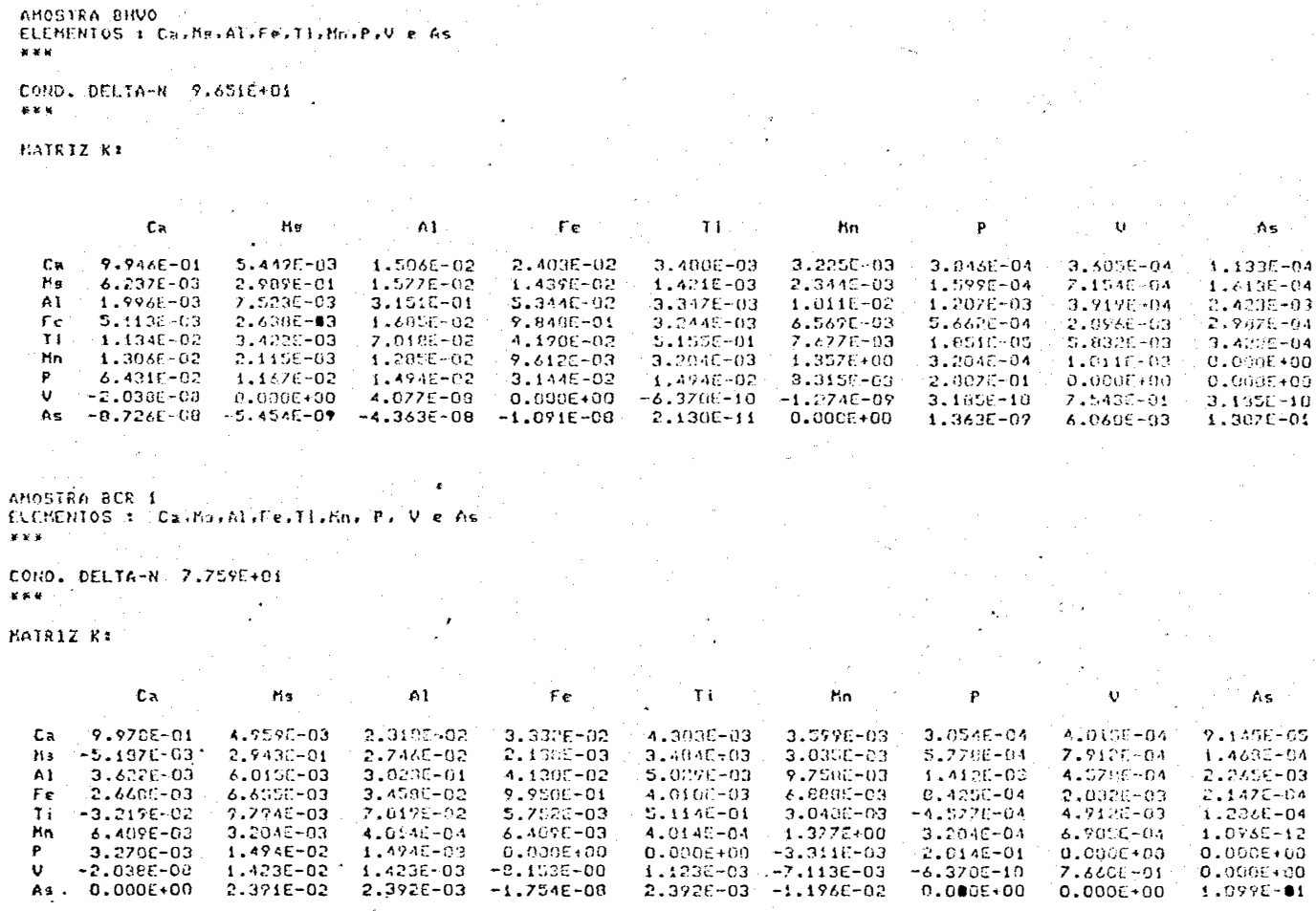

Observa-se que a maioria dos valores de ambas as matrizes nå apresentam variaçes significativas, o que permite simplificar a correça de interrerencias de amostras similares. O valor mais discrepante foi a do coeficiente KAsas , apresentando uma variacto da ordem de $30 \%$. Isto provavelmente deve- se ao fato do sensor do As apresentar respostas muito baixas e portanto sua precisào Ve-se comprometida. Outro fator a consicierar refere-se 5 
detergáa desce alemerto ser efetuda na regia do ultravioleta (195, $6 \mathrm{~m}$ ), onde segundo Seforadgr et alid (1981) ocorre un "continum" do Al, que apresenta al gumas bandas de grande intensidade devidas a recombinaca de ions.

Na Tabela 13 e mostrada a cond. delta-N ou condiga da metriz das adifoes totais. Este velor fomere lma indicaco do comportamento do projeto de adi toes e apresenta a mesma orden do grandeza que a variata entre o maior e o menor valor entre as adisos eretuadas interelementos. Idealmente, se es abtedes sato idanticas para todos o: analitos este velor è jgual a undaden

Fara andise de rotina de grupos de amostras simiI ares pode-se aplicar o GSAM sobre lima amostray romo etapa de calibraça e em seguida as comoramacoes iniciais dos analitos na amosme enten calculadas pela equa sato

5.8 Avaliagzo da preciszo e exatidáo dos resultados

Qsu resultados obtidos a pertir de dojs solubilizados independentes de cada amostra cujes medidis no lCF foram efetuadas com 5 repetiços, permitem determinar a precisåo das diferentes etapas envolvidas na anjise de rochass.

A Tabela 14 mostra os resultados da anjise estatistica aplitada sobre os resultados obtidos pela analise quimica proposta para os solubilizados de 7 amostras de rochias. o teste f foi empregado para comparar os resultados obtidos para solubilizados independentes. 
Tabela 14 Resultadoe partais de anostras de rochas, en mgll

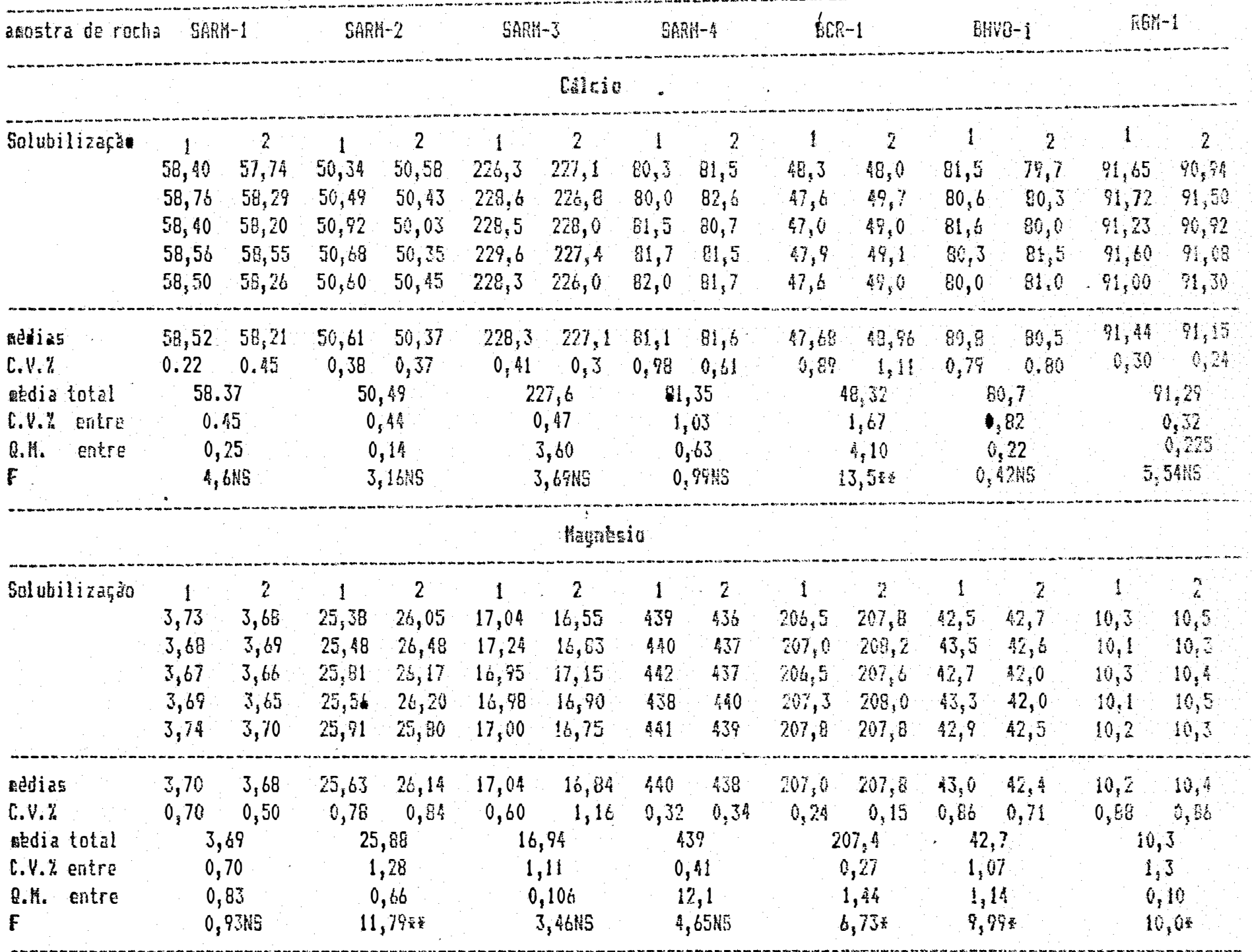

Alumio

\begin{tabular}{|c|c|c|c|c|c|c|c|c|c|c|c|c|c|c|}
\hline Sol uniliz z & $\begin{array}{c}1 \\
58,0 \\
59,2 \\
58,7 \\
59,7 \\
58,5\end{array}$ & $\begin{array}{c}2 \\
59,0 \\
59,8 \\
60,1 \\
60,0 \\
61,3\end{array}$ & $\begin{array}{c}1 \\
87,5 \\
88,0 \\
88,2 \\
88,0 \\
87,8\end{array}$ & $\begin{array}{c}2 \\
87,6 \\
86,8 \\
87,6 \\
87,4 \\
87,2\end{array}$ & $\begin{array}{c}1 \\
75,3 \\
74,8 \\
75,9 \\
73,6 \\
74,2\end{array}$ & $\begin{array}{c}2 \\
71,2 \\
71,2 \\
72,5 \\
72,8 \\
71,8\end{array}$ & $\begin{array}{c}1 \\
87,8 \\
88,5 \\
88,2 \\
88,9 \\
88,1\end{array}$ & $\begin{array}{c}2 \\
87,3 \\
87,5 \\
87,9 \\
87,6 \\
88,2\end{array}$ & $\begin{array}{c}1 \\
71,4 \\
70,6 \\
72,5 \\
71,8 \\
71,8\end{array}$ & $\begin{array}{r}2 \\
73,6 \\
72,0 \\
72,0 \\
72,9 \\
72,3\end{array}$ & $\begin{array}{c}1 \\
72,4 \\
72,6 \\
73,0 \\
73,2 \\
72,8\end{array}$ & $\begin{array}{c}2 \\
72,0 \\
71,8 \\
72,8 \\
72,8 \\
72,4\end{array}$ & $\begin{array}{c}1 \\
480 \\
481 \\
480 \\
481 \\
480\end{array}$ & $\begin{array}{l}2 \\
481 \\
460 \\
491 \\
482 \\
481 \\
441\end{array}$ \\
\hline $\begin{array}{l}\text { geddias } \\
\text { C.Y.\% }\end{array}$ & $\begin{array}{l}58,8 \\
0.99\end{array}$ & $\begin{array}{r}60,0 \\
1,2\end{array}$ & $\begin{array}{l}87,9 \\
0,27\end{array}$ & $\begin{array}{l}87,2 \\
0,32\end{array}$ & $\begin{array}{l}74,8 \\
1,07\end{array}$ & $\begin{array}{l}71,9 \\
0,91\end{array}$ & $\begin{array}{l}88,3 \\
0,42\end{array}$ & $\begin{array}{l}87,7 \\
0,36\end{array}$ & $\begin{array}{l}71,6 \\
0,74\end{array}$ & $\begin{array}{l}72,5 \\
0,84\end{array}$ & $\begin{array}{l}72,8 \\
0,39\end{array}$ & $\begin{array}{l}72,3 \\
0,48\end{array}$ & $\begin{array}{l}480 \\
0,1\end{array}$ & $\begin{array}{l}+51 \\
1,31\end{array}$ \\
\hline $\begin{array}{l}\text { sedia entre } \\
\text { C.V.\% entre } \\
\text { Q.M. entre } \\
\text { F }\end{array}$ & & $\begin{array}{l}43 \\
52 \\
72 \\
70+7\end{array}$ & $\begin{array}{l}87 \\
0,\end{array}$ & & & $\begin{array}{l}3 \\
0 \\
45 \\
22 \times 3\end{array}$ & $\begin{array}{r}8 \\
0, \\
0, \\
6\end{array}$ & & & $\begin{array}{l}08 \\
03 \\
3 \\
56 \div\end{array}$ & & & & \\
\hline
\end{tabular}

NS - năo significativo "zsignificativo a $1 \%$ signifirativo a $5 \%$ 
Tated a 14. Resultado parciais do amostras de rochas, en mgll

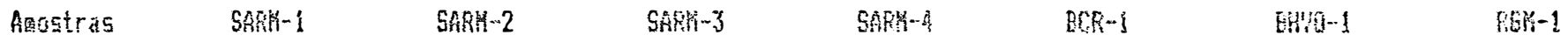

Ferra

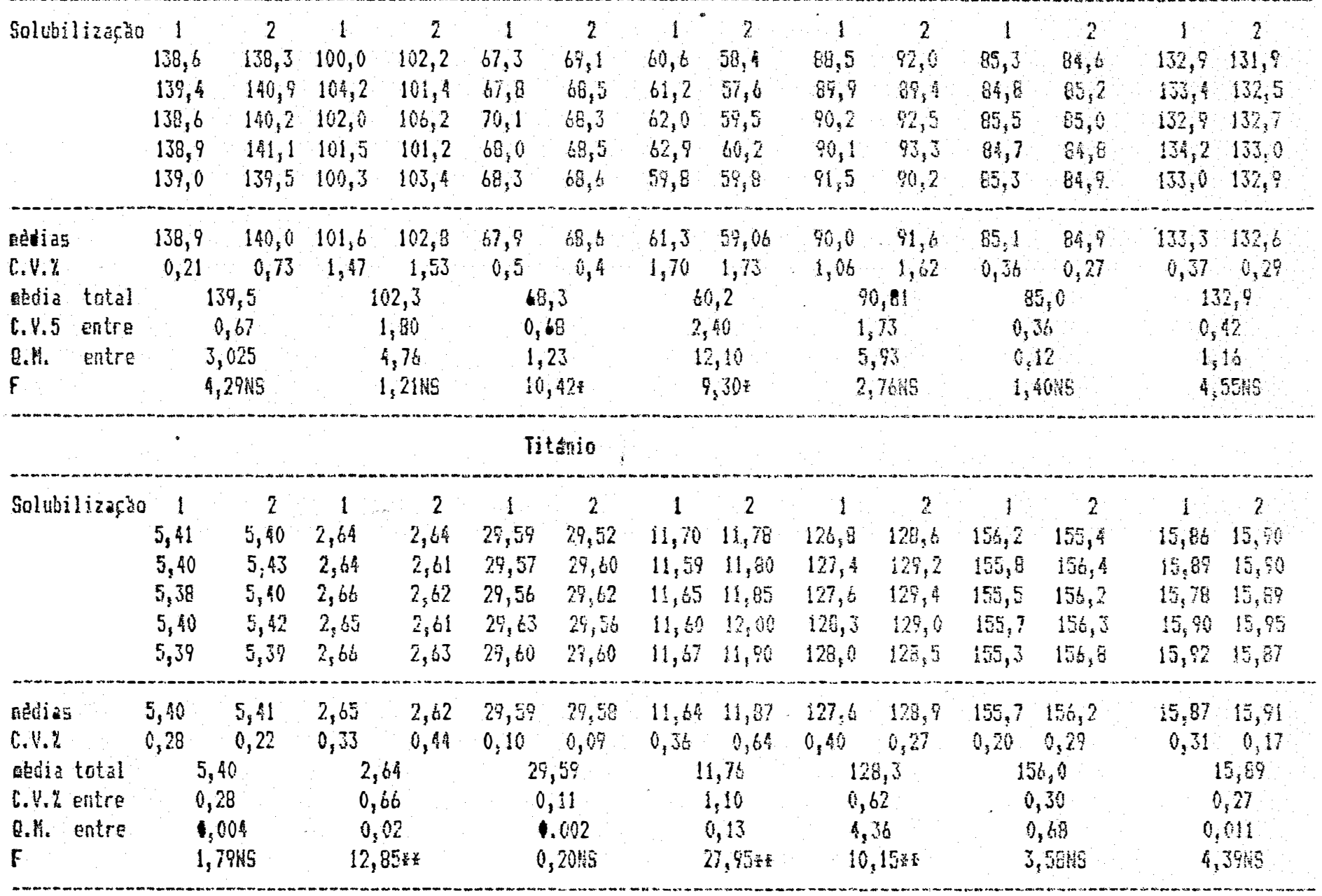

Tho significativo

significativo a 1\% de probatilidade

E significativo a $5 \%$ de provabilidade 
Na Tabela 14 pode-5s observar que os coeficientes de variaça para um mosmo solubilizado foi gemajmente menor que $1 \%$ com al gumas excegbes en que ultmapassou 1\%. Entre os solubjlizados; este cofficiente foi sempre menor que $2 \%$ o teste de significancia estatistice entre os solubilizados mostrou que seis delss naso apresentam diferença significativa para ca e para a amostra ECr-1 a variagâno entre os solubilizados foi signjicativa ao nivel de $1 \%$ de probabilidede. Fara o ceso do Mgs tres anostras apresentaram-se diferentes ao nivel de $5 \%$ e mesmo numero náro apresentou diferenta significativa. As determinases de Al apresentaran coeficientes de variaços mais altos ro botal dos resultados. no entanto entre os solubilizados somente una amostra apiesentou diferenç significativa de $5 \%$

En geral, os valopes nostram que a precisado das medidas do ICF forain concordantes com a obtida com solu-

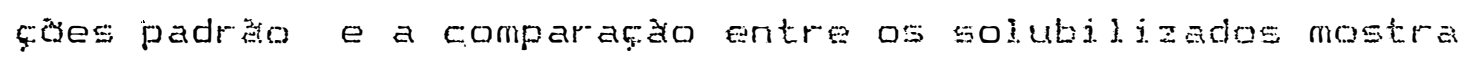
que o processamento das amostras foi bem conduzido.

A comparaço dos resultados finais obtidos: diretamente e apos a correçán de jnterferenciass para os meteriais de referencia com os valores certificados mostrada na. Tabela 15. Nesta Tabela säo reportados os valores encontrados e corrigidos dos 20 elementos de interesse, para os materiais de referencia descritos na Tabela 5 .

De um modo geral os valores encontrados para as 
Tamena 15. Fesultados obtidos pare materiads de referencia Lertificados

\begin{tabular}{|c|c|c|c|c|c|c|c|c|c|c|c|}
\hline \multicolumn{2}{|c|}{ Espacie } & C.. & $\operatorname{Mg} B$ & 81203 & Fends & 102 & tinn & $P 205$ & As & $\mathrm{Ba}$ & Co \\
\hline \multicolumn{4}{|l|}{ Anostra } & \multicolumn{2}{|c|}{$\%$} & & & & \multicolumn{3}{|c|}{ mig $/ 1$} \\
\hline \multirow{3}{*}{ reves } & elic. & 0,7 & 0,06 & 11,83 & 1,99 & $5,41 \pi$ & 1798 & $2 t 1$ & 120 & 118 & $25^{\circ}$ \\
\hline & cor. & 0,77 & 0,06 & 11,83 & 9,99 & 5,812 & 1635 & 254 & 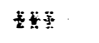 & 110 & 4 \\
\hline & cert. & 0,78 & 0,06 & 12,08 & 2,000 & 5,808 & $160 \overline{5}$ & $\sqrt{10}$ & $M C$ & 120 & $M C$ \\
\hline \multirow{3}{*}{ 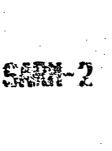 } & Enc.: & 0,72 & 0,43 & 17,52 & 1,51 & $25 \frac{85}{2}$ & 903 & 0,21 & 1113 & 0,20 & 10 \\
\hline & cor. & 0,72 & 0,93 & 17,52 & 1,51 & 254 & $01 \%$ & 0,13 & $x$ & 0,28 & 2 \\
\hline & rert. & 0,68 & 0,96 & 17,34 & 1,80 & $265 \%$ & $60 \bar{x}$ & 0,12 & $M C$ & 0,27 & $3 * x$ \\
\hline \multirow{3}{*}{ shas } & Enc. & 3,28 & 0,27 & 13,80 & 9,37 & 0,46 & 0,80 & 6198 & 947 & 433 & 21 \\
\hline & cor. & 3,28 & 0,27 & 13,48 & 9,37 & 0,46 & 0,76 & $27 !:$ & 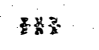 & 433 & 3 \\
\hline & rert. & 3,22 & 0,28 & 13,64 & 9,91 & 0,48 & 0,77 & 2008 & $\mathrm{HC}$ & 450 & $\mathrm{NC}$ \\
\hline \multirow{3}{*}{ 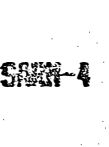 } & Enc. & 10,85 & 7,40 & 16,58 & 8,56 & $1180 x$ & $1550 \%$ & 450 & 1240 & 98 & $N D$ \\
\hline & cot. & 10,85 & 7,40 & 16,50 & $E_{1}: t$ & $1140=$ & $1300 x$ & 136 & 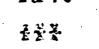 & 98 & $\mathrm{Wh}$ \\
\hline & sert. & 11,50 & 7,50 & 16,50 & $B, 57$ & 11997 & 13948 & 130 & $\mathrm{Mi}$ & $10 ?$ & \% \\
\hline \multirow{3}{*}{$25 e^{3}-1$} & enc. & 7,12 & 3,53 & 13,95 & 13,2 & 2,25 & 0,189 & 0,47 & 1127 & 678 & 72 \\
\hline & cor. & 7,12 & 3,53 & 13,95 & 13,2 & 2,23 & 0,182 & 0,35 & 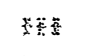 & 678 & 35 \\
\hline & cert. & 6,97 & 3,48 & 13,72 & 13,1 & 2,23 & $0,1 \in 0$ & 0,36 & $0, \bar{E} 2 x$ & 480 & 36 \\
\hline \multirow{3}{*}{ 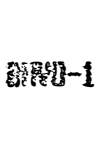 } & enc. & 10,65 & 4,87 & 13,84 & 11,3 & 2,67 & 0,170 & 0.38 & 1140 & 131 & 95 \\
\hline & cor. & 10,65 & 6,97 & 13,84 & 11,8 & 2,67 & 0,170 & 0,30 & $7 \cdot \frac{7}{2}$ & 131 & 50 \\
\hline & sert. & 11,40 & 7,242 & 13,70 & 12,00 & 2,70 & 0,170 & 0,28 & $M C$ & 130 & $4 i$ \\
\hline \multirow{3}{*}{ REE: } & Enc. & 1,12 & 0,27 & 13,85 & 1,85 & 0,26 & 0,007 & 0,106 & 271 & 696 & 10 \\
\hline & tar. & 1,12 & 6,27 & 13,85 & 1,95 & 0,26 & 0,037 & 0,05 & 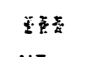 & 696 & 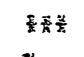 \\
\hline & cert. & 1,17 & 0,28 & 13,80 & 1,90 & 0,27 & 0,040 & $M$ & $\mathrm{NE}$ & 705 & 3 \\
\hline
\end{tabular}

\footnotetext{
* ug/g to Elenento

* กัด certificado

f* abaino in liaite de deteç范

HC ne consta

His no deter winado

enc. - valor encontrado

cor. - valor carrigido

cert. - valor certificado
} 
Tabela 15. Resultados abtidos para materiais de referencia certificados (continuaga)

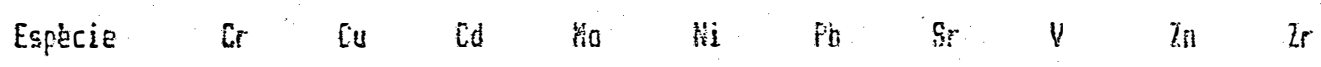

\begin{tabular}{|c|c|c|c|c|c|c|c|c|c|c|c|}
\hline Aarosti & & & & & & ag $/ \mathrm{l}$ & & & & & \\
\hline 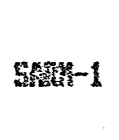 & $\begin{array}{l}\text { enc. } \\
\text { cor. } \\
\text { cert. }\end{array}$ & $\begin{array}{l}33 \\
15 \\
12\end{array}$ & $\begin{array}{l}20 \\
13 \\
12\end{array}$ & $\begin{array}{l}1,0 \\
1,0 \\
k C\end{array}$ & $\begin{array}{l}39 \\
12 \\
110\end{array}$ & $\begin{array}{l}4 \\
4 \\
8\end{array}$ & $\begin{array}{l}175 \\
43 \\
80\end{array}$ & $\begin{array}{l}10 \\
10 \\
10\end{array}$ & $\begin{array}{l}58 \\
6 \\
28\end{array}$ & $\begin{array}{l}52 \\
50 \\
50\end{array}$ & $\begin{array}{l}256 \\
296 \\
300\end{array}$ \\
\hline chish-2 & $\begin{array}{l}\text { enc. } \\
\text { cor. } \\
\text { cert. }\end{array}$ & $\begin{array}{l}67 \\
10 \\
12\end{array}$ & $\begin{array}{l}26 \\
15 \\
19\end{array}$ & $\begin{array}{l}1,5 \\
1,5 \\
4\end{array}$ & $\begin{array}{l}58 \\
8 \\
4 C\end{array}$ & $\begin{array}{l}10 \\
10 \\
7 \% 5\end{array}$ & $\begin{array}{l}199 \\
10 \\
58: 2\end{array}$ & $\begin{array}{l}57 \\
57 \\
82\end{array}$ & $\begin{array}{l}67 \\
13 \\
10\end{array}$ & $\begin{array}{l}12 \\
10 \\
10\end{array}$ & $\begin{array}{l}20 \\
20 \\
33\end{array}$ \\
\hline Sompats & $\begin{array}{l}\text { enc. } \\
\text { cor. } \\
\text { cert. }\end{array}$ & $\begin{array}{l}104 \\
15 \\
10 k\end{array}$ & $\begin{array}{l}63 \\
10 \\
13\end{array}$ & $\begin{array}{l}b \\
6 \\
i c\end{array}$ & $\begin{array}{l}30 \\
15 \\
k C\end{array}$ & $\begin{array}{r}15 \\
15 \\
15\end{array}$ & $\begin{array}{l}400 \\
50 \\
83\end{array}$ & $\begin{array}{l}1260 \\
4260 \\
4525\end{array}$ & $\begin{array}{l}130 \\
77 \\
81\end{array}$ & $\begin{array}{l}409 \\
402 \\
395\end{array}$ & $\begin{array}{l}11100 \\
11100 \\
1102\end{array}$ \\
\hline SEM- & $\begin{array}{l}\text { enc. } \\
\text { cor. } \\
\text { cert. }\end{array}$ & $\begin{array}{l}370 \\
32 \\
30\end{array}$ & $\begin{array}{l}27 \\
15 \\
14\end{array}$ & $\begin{array}{l}5 \\
5 \\
N C\end{array}$ & $\begin{array}{l}\text { ND } \\
k 2 \\
M C\end{array}$ & $\begin{array}{l}120 \\
120 \\
120\end{array}$ & $\begin{array}{l}190 \\
10 \\
10\end{array}$ & $\begin{array}{l}260 \\
280 \\
260\end{array}$ & $\begin{array}{l}360 \\
215 \\
220\end{array}$ & $\begin{array}{l}75 \\
66 \\
68\end{array}$ & $\begin{array}{l}26 \\
26 \\
23\end{array}$ \\
\hline $60-1$ & $\begin{array}{l}\text { enc. } \\
\text { cor. } \\
\text { eert. }\end{array}$ & $\begin{array}{c}359 \\
10 \\
15\end{array}$ & $\begin{array}{c}188 \\
15 \\
16\end{array}$ & $7_{k C}^{7}$ & $\begin{array}{c}68 \\
428 \\
1,5\end{array}$ & $\begin{array}{c}13 \\
13 \\
10\end{array}$ & $\begin{array}{c}359 \\
10 \\
14\end{array}$ & $\begin{array}{l}314 \\
314 \\
330\end{array}$ & $\begin{array}{c}700 \\
410 \\
920\end{array}$ & $\begin{array}{l}138 \\
122 \\
125\end{array}$ & $\begin{array}{c}200 \\
200 \\
185\end{array}$ \\
\hline BHW & $\begin{array}{l}\text { ene. } \\
\text { cor. } \\
\text { cert. }\end{array}$ & $\begin{array}{l}750 \\
300 \\
320\end{array}$ & $\begin{array}{l}335 \\
120 \\
135\end{array}$ & $\begin{array}{l}8 \\
8 \\
n C\end{array}$ & $\begin{array}{l}6 b \\
12 \\
k C\end{array}$ & $\begin{array}{l}137 \\
137 \\
140\end{array}$ & $\begin{array}{l}222 \\
5 \\
4,23\end{array}$ & $\begin{array}{l}380 \\
390 \\
560 \%\end{array}$ & $\begin{array}{l}610 \\
300 \\
326\end{array}$ & $\begin{array}{l}112 \\
103 \\
102,6\end{array}$ & $\begin{array}{l}150 \\
150 \\
145\end{array}$ \\
\hline 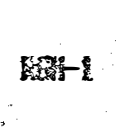 & $\begin{array}{l}\text { enc. } \\
\text { cor. } \\
\text { cert. }\end{array}$ & $\begin{array}{l}43 \\
4 \\
3\end{array}$ & $\begin{array}{l}35 \\
10 \\
11\end{array}$ & $\begin{array}{l}2 \\
2 \\
11 C\end{array}$ & $\begin{array}{l}42 \\
6 \\
k C\end{array}$ & $\begin{array}{l}6 \\
b \\
6\end{array}$ & $\begin{array}{l}158 \\
23 \\
2.1\end{array}$ & $\begin{array}{l}87 \\
87 \\
100\end{array}$ & $\begin{array}{l}79 \\
13 \\
15\end{array}$ & $\begin{array}{l}37 \\
33 \\
22\end{array}$ & $\begin{array}{l}212 \\
212 \\
280\end{array}$ \\
\hline
\end{tabular}

* ug/g do eleaento

+ nào certificado

tí abaixo do liaita de deterçato

MC nako consta

NII no deter

ene. - valor encontrado

cor. - valor corrigido

cert. - valor certificado 
especies matores tais como caO, $\mathrm{MgO}_{4} \mathrm{Al}_{2} \mathrm{O}_{3}, \mathrm{Fe}_{2} \mathrm{O}_{3}$ e $\mathrm{TiO}_{2}$ apresentaram-se bastante concordantes tom os valores certificados, a teste de correlacko entre todo os resultados corrigido e os certificados para cada anostra apresentou os valores de correl agho e os desvios mostrados na Tabela 16. A correlacajo entre os valores encontrados $E$ os valores certificados foi efetuada primejramente dentros de cada amostra para os el ementos reportados como axidos e en seguida foi analisada a correlacar de cada oxido considerando-se todas as amostras.

Tabela 16. Correlaço entre resultados obtidos e certificedos para as oxidos dos elenentos $C a, M g, A l, F E, T i, M \cap F$

\begin{tabular}{|c|c|c|c|c|c|}
\hline Anostra & $r^{2}$ & $S_{n} Q_{*} *$ & Especie & $r^{2}$ & $8.0 . *$ \\
\hline SAFM- 1 & 0,9999 & 0,148 & $\mathrm{CaO}$ & 0.9992 & 0,22 \\
\hline SAFIN- 2 & 0.7999 & 0,009 & Mgo & 0.9996 & 9,051 \\
\hline SAFH-Z & 0.7989 & 0,500 & A120Z & 0.9969 & 0,120 \\
\hline SAFIN1-4 & 0.9991 & 0,450 & FezOB & 0,9994 & $0,20$. \\
\hline ECFi-1 & 0,9997 & 0,110 & $\mathrm{TiO}$ & 0.9999 & 3900 \\
\hline EHVO-1 & 0,9998 & 0.067 & $\operatorname{mnO}$ & 0.9999 & 18,77 \\
\hline FIGIM-1 & 0.9999 & 0,002 & $\mathrm{~F} 205$ & 0.9999 & $0.17 \mathrm{~A}$ \\
\hline
\end{tabular}

* S. Q. soma de quadrados dos emros

o $\mathrm{Al}_{2} \mathrm{O}_{3}$ foi a especie que apresentou menos correla5ao e o $\mathrm{F}_{2} \mathrm{O}_{5}$ apesar de seus valores teren sido corrigidos : apresentou melhor correlaço. Entre as amostrass, os valores mais exatos foram os obtidos para fibly-1 e os mais discordantes correpondem a SAFH-4.

A compensaça das interferencias levou a obtença de resultados corrigidos bastante proximos dos valores certificados o que comprova a eficiencia do GSAM. Fara os 
elenemtos tracos au apresentam baxas concentregoes

eram esperadas as variages pncontradas devido as concentracbes serem proximas das mandmas detectaveis.

Doserva-se que o GGAM apresentou-se muito eficiente pare corrigir intem ferencias axtremanonte eignificativas

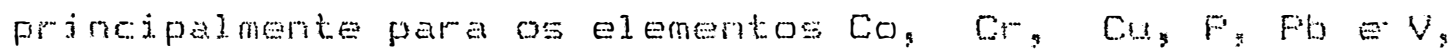
assim tanben, para os elementos menos incerferidos caso do Mre zh. Os elementos tracos que nao sorren inter..

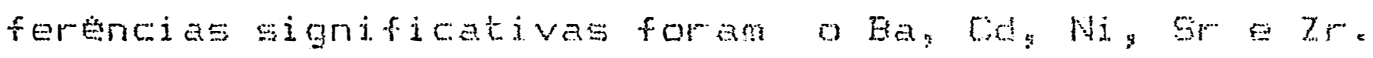

Deveme salientar que os elemertó As co e Ma foram incluidos na Tabela 15 , mesno eles ná terem sido certificados de forma a permitir una forte de informaço dos teores possivelmante presentes. Entre eles. pade-se observar que o cd nao apresentame fromuneiadamente in-

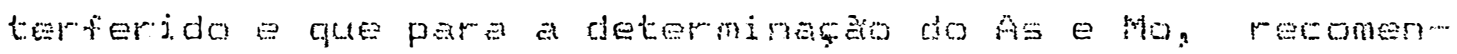
da-se a utilizaça do metodo de correcbes proposto. No caso da determinato de As, de valores corridios sempre Se foram abaixo das concentracoes minimes detectaveis, o que ja era esperado fase as perdes deste. elemento por volatilizaço durante a decomposicào das amostras. Apesar do GSAM ter corrigido os valores obtidos para As, o metodo mais recomendado par a determinazato tem sido o que utiliza a geraça do hidreto.

Apesar dos elementos Na e K nảo aparecerem ra Tabela 15. Lma ves que o espectremetro lutidizado ná apresenta sensores adequados para os mesmos, estes elenentos quando determinados por espectrometria de absorcto atomica nos 
.80 .

mesmos solubiliados mostr"aram valores concordantexs com os Valores certificados de todas es amostras. Desta fornax 0 metodo utilizado para decomposiza das amostras apresentou-se adequado permitindo a solubilazapa completa dos eiementos majores da mostra s sencio o $5 j$ o enico elemento maior nà determinado. No entertos esta sol hibi1. ocorrem en baikas concentracoes devido a minimizar problemate de contaminasa e dimanuir as perdas.

Os resultados das amostras de rochas rejacionadas ra Tabela 4, foram obtidos sen e com eorrectä de interferencias e säo apresentados na Tabela i. . Una ver que estas amostras foram andisadas em conjunto com os materiats certificados" os resultados obtidos apresentam precisajo e exatidào da mesma ordem. 
Tabela 17. Resultados obtidos para amostwas de rochea

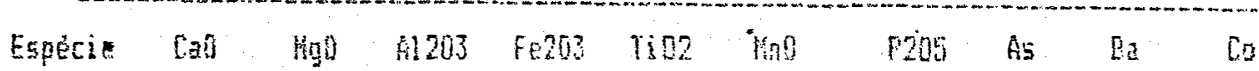

foschers "3.

解h

\begin{tabular}{|c|c|c|c|c|c|c|c|c|c|c|c|}
\hline 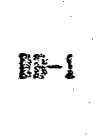 & $\begin{array}{l}\text { ent. } \\
\text { cor. } \\
\text { ref. }\end{array}$ & $\begin{array}{l}7,65 \\
7,65 \\
7,50\end{array}$ & $\begin{array}{l}4,25 \\
4,25 \\
4,36\end{array}$ & $\begin{array}{l}15,30 \\
15,30 \\
15,48\end{array}$ & $\begin{array}{l}9,58 \\
9,58 \\
9,72\end{array}$ & $\begin{array}{l}1,14 \\
1,14 \\
1,11\end{array}$ & $\begin{array}{l}0,14 \\
0,14 \\
0,18\end{array}$ & $\begin{array}{l}0,36 \\
0.20 \\
0,25\end{array}$ & $\begin{array}{c}119 ? \\
5 \times 2 \\
40\end{array}$ & $\begin{array}{l}530 \\
530 \\
\mathrm{No}\end{array}$ & $\begin{array}{l}55 \\
21 \\
4 \mathrm{C}\end{array}$ \\
\hline $68-1$ & $\begin{array}{l}\text { enc. } \\
\text { rot. } \\
\text { ref. }\end{array}$ & $\begin{array}{l}1,26 \\
1,26 \\
1,21\end{array}$ & $\begin{array}{l}0,50 \\
0,5 \\
0,50\end{array}$ & $\begin{array}{l}14,75 \\
14,75 \\
15,06\end{array}$ & $\begin{array}{l}1,69 \\
1,69 \\
1,62\end{array}$ & $\begin{array}{l}0,25 \\
0,25 \\
0,26\end{array}$ & $\begin{array}{l}0,02 \\
0,02 \\
0,02\end{array}$ & $\begin{array}{l}0,23 \\
0,20 \\
0,16\end{array}$ & 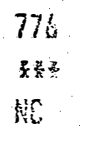 & $\begin{array}{l}450 \\
250 \\
250 \\
M 0\end{array}$ & $\begin{array}{l}7 \\
3 \\
3\end{array}$ \\
\hline GISE & $\begin{array}{l}\text { enc } \\
\text { ear. }\end{array}$ & $\begin{array}{r}2,53 \\
2,53\end{array}$ & $\begin{array}{l}1,63 \\
1,63\end{array}$ & $\begin{array}{l}12,95 \\
12,95\end{array}$ & $\begin{array}{l}3,59 \\
3,59\end{array}$ & $\begin{array}{l}0,30 \\
0,09\end{array}$ & $\begin{array}{l}0,06 \\
0,06\end{array}$ & $\begin{array}{l}0,22 \\
0,21\end{array}$ & $\begin{array}{r}645 \\
345 \\
3528\end{array}$ & $\begin{array}{l}\mathrm{Mi} \\
\mathrm{Wi}\end{array}$ & $\begin{array}{l}30 \\
12\end{array}$ \\
\hline 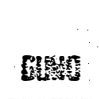 & $\begin{array}{l}\text { ent } \\
\text { tor. }\end{array}$ & $\begin{array}{l}2,34 \\
2,34\end{array}$ & $\begin{array}{l}0,80 \\
0,80\end{array}$ & $\begin{array}{c}13,30 \\
13,30\end{array}$ & $\begin{array}{l}2,80 \\
2,80\end{array}$ & $\begin{array}{l}0,84 \\
0,4.4\end{array}$ & $\begin{array}{l}0,00 \\
0,00\end{array}$ & $\begin{array}{l}0,2 \\
0,28\end{array}$ & $\begin{array}{r}755 \\
4848\end{array}$ & $\begin{array}{l}434 \\
434\end{array}$ & $\begin{array}{l}32 \\
18\end{array}$ \\
\hline
\end{tabular}

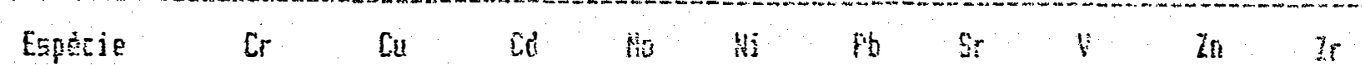

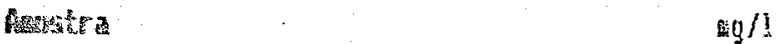

\begin{tabular}{|c|c|c|c|c|c|c|c|c|c|c|c|}
\hline 艧-1 & $\begin{array}{l}\text { enc. } \\
\text { sor. }\end{array}$ & $\begin{array}{l}397 \\
16\end{array}$ & $\begin{array}{l}129 \\
10\end{array}$ & $\begin{array}{l}6 \\
6\end{array}$ & $\begin{array}{l}64 \\
54\end{array}$ & $\begin{array}{l}40 \\
40\end{array}$ & $\begin{array}{l}21 i \\
26\end{array}$ & $\begin{array}{l}245 \\
285\end{array}$ & $\begin{array}{l}430 \\
160\end{array}$ & $\begin{array}{l}99 \\
.90\end{array}$ & $\begin{array}{l}245 \\
245\end{array}$ \\
\hline$a-1$ & $\begin{array}{l}\text { ens. } \\
\text { enr. }\end{array}$ & $\begin{array}{l}46 \\
15\end{array}$ & $\begin{array}{l}34 \\
17\end{array}$ & $\begin{array}{l}2 \\
2\end{array}$ & $\begin{array}{l}38 \\
\text { EF }\end{array}$ & $t$ & $\begin{array}{l}166 \\
35\end{array}$ & $\begin{array}{l}92 \\
92\end{array}$ & $\begin{array}{l}74 \\
10\end{array}$ & $\begin{array}{l}59 \\
58\end{array}$ & $\begin{array}{l}206 \\
206\end{array}$ \\
\hline $610 \%$ & $\begin{array}{l}\text { enc. } \\
\text { cot, }\end{array}$ & $\begin{array}{l}225 \\
44\end{array}$ & $\begin{array}{l}161 \\
18\end{array}$ & $\begin{array}{l}\mathrm{ND} \\
\mathrm{HD}\end{array}$ & $\begin{array}{l}72 \\
1\end{array}$ & $\begin{array}{l}26 \\
26\end{array}$ & $\begin{array}{l}37 \\
12\end{array}$ & $\begin{array}{l}2 \\
8\end{array}$ & $\begin{array}{l}112 \\
10\end{array}$ & $\begin{array}{l}52 \\
50\end{array}$ & $\begin{array}{l}300 \\
300\end{array}$ \\
\hline Gif & $\begin{array}{l}\text { ent. } \\
\text { cor. }\end{array}$ & $\begin{array}{l}118 \\
52\end{array}$ & $\begin{array}{l}43 \\
10\end{array}$ & $\begin{array}{l}2 \\
2\end{array}$ & $\begin{array}{l}48 \\
385\end{array}$ & $\begin{array}{l}11 \\
11\end{array}$ & $\begin{array}{l}189 \\
85\end{array}$ & $\begin{array}{l}126 \\
126\end{array}$ & $\begin{array}{l}116 \\
10\end{array}$ & $\begin{array}{l}52 \\
52\end{array}$ & $\begin{array}{l}256 \\
256\end{array}$ \\
\hline
\end{tabular}

2. ug̣/g do elemerito

* naco certificato

It ahaixo do liaite de deteçato

NC nalo consta

No nè detersinado

enc. - valor encontraúo

cor. - valor currigido

ref. - valor de referencia êedia de 10 laborastrios. 
G. CONCLUSOES

A determinaço simultanea dos elementos maiores a tracos en un mesmo solubilizado de roche utilizando-se espectrometria de emisso atomica com pjasme induzido (dCF-AES), e visvel com respeito d deteminato de Cas Mg. Al, Fe, Ti, Ba, Cd, Ni, gr e Zr.

0 Gom nostrou-ge nuto ariciente fara taraterizar e compenser as interferencias espectras s devidas a matriz.

A aplicaca do $69 \mathrm{AM}$ para contornar as interferencias pernitiu que, al don dos elenemtos actma s sejan determinados com exatidao e precisà Co, Cr, Dus Ho No, $\mathrm{Fr} P \mathrm{~PB}, \mathrm{~V} \mathrm{Zn}$.

A viabilidade da aplicasao do bSAM foi conseguida

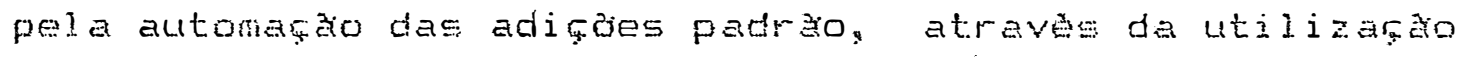
de um sistema de injeçäo en fluko con amostragem na zona dispersa. Este procedimento automatizedo, alen de apresentar luma boa precisäo com referencia as adiçoes, mostrou-se eficiente no que djiz respeito do consumo de amostra e velocidade analitica, conseguindo-se 120 adicbes e medidas por hora. 
Fodewe recomendar a a icama do osam para efetur

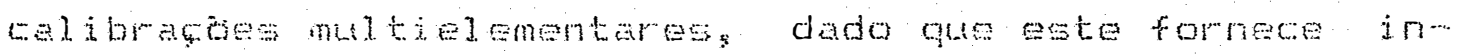
formatses mais completses ecome o comportanento dos sen-

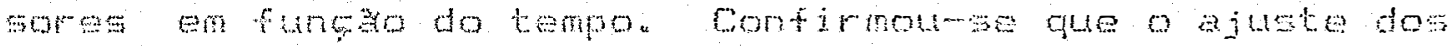
parametros de operega do TrF AES é fundamental pare a obtencto da melhor raza de intensidades. Este ajuste depende da linh de eniseso considerada. Feconenda-se Utilizar abenes uno matriz to como ferrenenta para

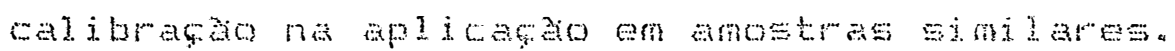

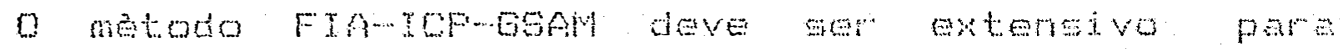

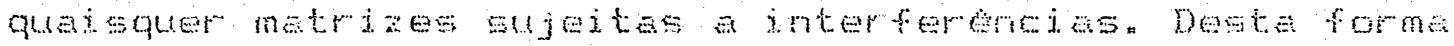
escudos envolvendo elementos tratos en drerentes

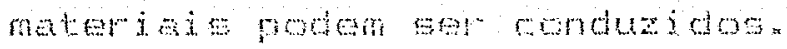

Este trabalto, sen nenhuma dovida abre perspectaves

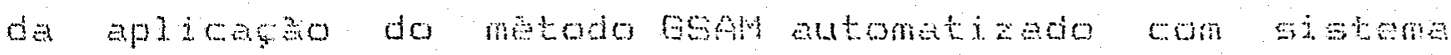

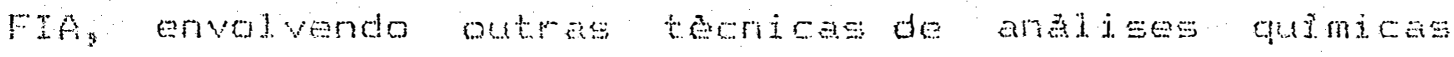
semelhentros 


\section{BIEL IOGFAFIA}

APFLETON, J.MEH, TYSON, F.J. 1906. Flow injection stomi absorption spectrmetry" the himetics of instruent response. J. Anal. At. Spec. Lomdon; i: 6574.

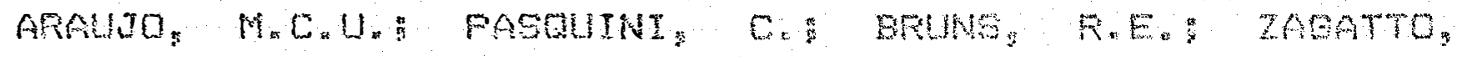
E.A.G. 1905. A fast procedure for standard adohtons

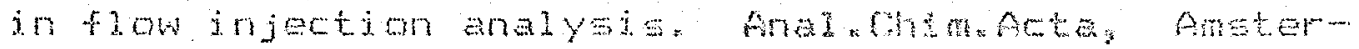
dan, $171: 57-245$

DARNES, R.M. 1978. Fecent advances in emission spectoscopy: inductive] y coupled plesma discherges fot

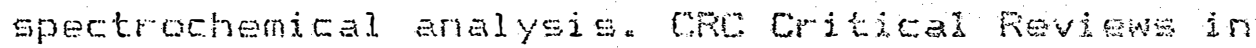
Anal. Chen. New York, 7: 203-285.

BEFGAMIN FILHO, H.; ZAGATTO, E.A.G. KFUE, F.J. REYS, B.F. 1978. Werging zones in flow injection atialy 5is. Fart Is Double proportional injector and reagent consumption. Anal. Chin. Aeta, Amsterdam, 101: 17-23.

DERGAMIN FILHO, H. REIS, B.F." JACINTHO, A.O.: TAGATrO, E.A.G. 1980. Ion exchange in flow injection analysis. Determination of amoritum ions at the Mgll level in netural waters with pulsed reagent. Anal. 
Chime Acta, Amsterdam, 117: 81-89.

BERMAN, S.9. MELAREN, J.W. 2775. EGtaLlishment of

compromise conditions for multielement andiys by indutively coupled plasma emiseion spectronetry. A preliminary report. Appl. Spees fredericl: $82(4):$ $372-377$

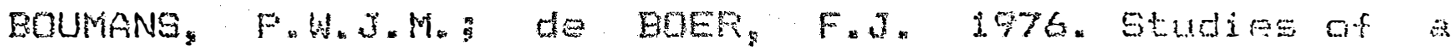
radiofrequency inductively coupled argon plasma for optical emj.sion spectrometry II a Inter rersence effects under compromise conditions for simutareous multicomponent analysis. Spentrochin. Actas New Yowt; $\quad 318: \quad 35,36$

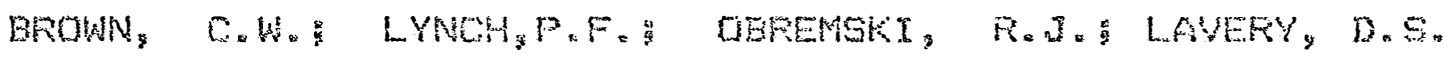
iga2. Matrix representations and criteria ror selecting analytical wevelengthe for multicomponent

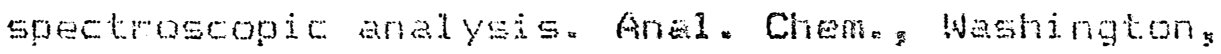
$54(9):+472-1479$.

BYSOUTH, E.R.: TYSOM, J.F. 4985. SAngle Etandard continuous flow and flow injection methods for nowem and extended range calibration for fjeme atomic abisorption spectronetry. Flew Analysis III Conference, Eirmingham.

IICKINSON, E.W.: FASSEL, V.A. 1967. Enission Epectrome.. tric detection of the elements at the nanogram per milliliter levei using induction-coupled plaema excitation. Anal. Chem., Wastington, 41 (8): $1021-1024$. 
plasma optical enission spectroscopy. Anal a Chem. Watnington $46(13): 11+0 \%-1120 A$

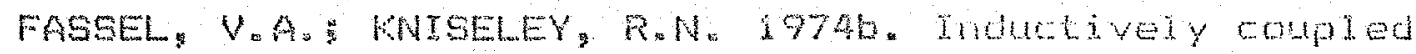

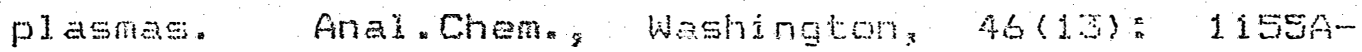
1. 1649

FRANK, T.E. KALTUAS, \%.H. KOWALBCI, D.F. 1903.

Fartial least squares esutions for mulicomonent andyeis. Anal. Chen w Whington, ss (1):

- $\quad 1800 \cdots 180 \%$

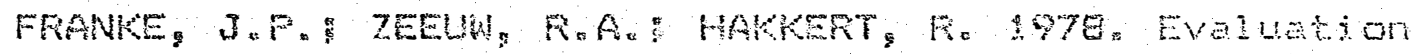
and optinization of the standard adition method for absorpton spectometry and anodic stoppang

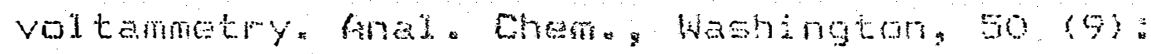
$1.74 \cdots 1300$

GINE, MF: REIS, D.F. ZAOATTO, EA.G. KRUB, F.J JACINTH, A.0. 1983. A simple protedure for standard additions in fiow injection analysis. Spectrophotonew tric determanation of nitrete in plant extracts. Anal. Chim. Acta. Amsterdan, 155: $131-138$. GREENFIELD, S.: JONES, I.L. BERFY' C.T. I964. High pressures plasmas as spectroscopic entssion sources. Analyet, Londons 89: 713-720.

GREENFIELD, S." JONES, I.L.W.: BERFY, C.T.: SPASH, D.I. 1969 Eritish patent. 1.109 .602$.

GREENFIELD, S. JONES, I.L,W.: MEGEACHTM, H.MCD.: SMITH, P.B. 1975 Automatic multi-semple Simultaneous multielement analycis with a H.F. plasma toreh and 
direter pading spectrometer".Anal. Chtma Aeta Amsterdan: 74: 225-24s.

HARROW, J.J. JANATA, I. 1505. Heterogeneous gamples in flow injertion systens "Fart 2 " standard addition. Anal. Chim. Acta, Amsteidam, 174: 12v-12.

HIRAI, Y. TOMOKUNI, K.190S. Flow injection anilyis with Standard adedtion. Flow Analys II Conferences Birmingham.

ISRAEL, Y. BARNES, R.1904. Standard additop method in flow injection analysis with inductively combed plasma atomit emission spectrometry. Anal. Coman. Washington: $56(7): 1100-1192$

JAEINTHO, A.O. ZABATTO, E.A.G. SEROAMM FMLHO, H. KRUE, F.J. REIS, E.F, BRUNG, R.E KOWGLE, D.F. 1981. Fiow injection systems with inductively-oupled argon plasme atomic endseion spectronetry Fart I. Fundamental considerations n Anel " Cham. Acta. Amstertam, 130: 245-255.

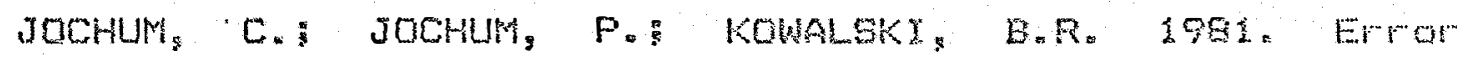
propagation and optimal performance in multicomponent analysjs. Anal. Chem, Washington, 5s (1): 85-92.

JORGENSEN, S.5. FETERSEN, K.M. HANSEN, E.H. 1985. A simple multifunctional valve for flow injection analysis. Anal. Chim. Acta. Amsterdam, 169: 51-5\%.

KALIVAS, J.H. 1983. FreEision and stability for the generalized standard addition method. Anad. Chem. Washington, 55 (3): 565-567.

KALIVAS, J.H. KOWALSKi, B.R. 1982. Compensation for 
drift and interferences in multicomponent analysis.

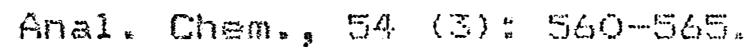

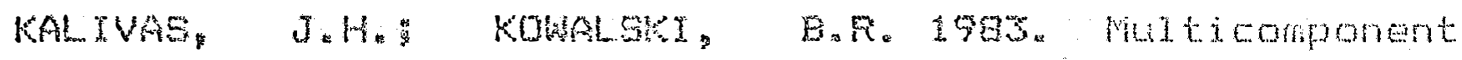
analysis with corrections for interferences and matrix effects. Anas. Ehen. Washington, 5 $5-35$

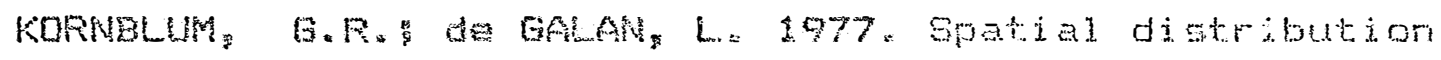
of the temperature and the number densities of electrons and atomie and ionde species in an induetively coupled FF

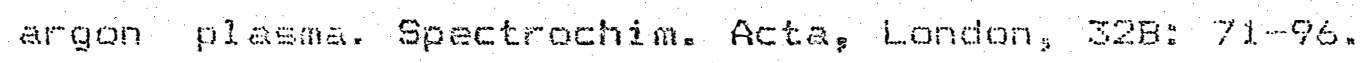

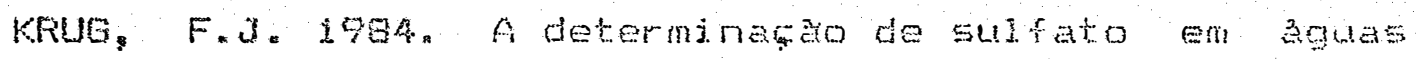
naturas a digeridos vegete por turbidimetria

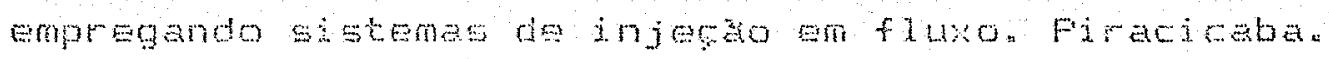
ESALG-USF. ATtese de Dower anento :P. 97.

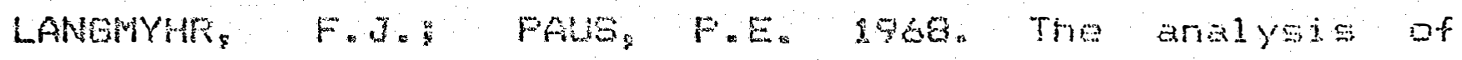

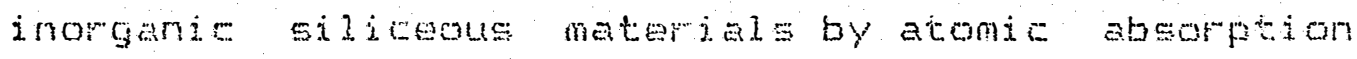
spectrophotometry and the hydrotluoric acid dewomposition technique. part $t$. The andysis of sili cate rocks. Anal. Chim. Actas AnEterdam, 4s: $397-$ A. 08.

LARSEN, I.L. HARTMAN, N.A. WAGMER, J.J. 1973. Estimating precision for the nethod of ctandard additions. Aral. Whem., Washington, 45 (8): 15111515

LARSUN, G.F.: FASSEL, V.A. GCOTT, R.H. KNISELEY, R.N. 1975. ICF optimal emission analytical spectrometry. A study of some interelement effects. Anal. Chen. 
Wathington, 47 (2): $250-243$.

LARSON, D.F. FASGEL, V.A. WINGE, R.K. KNIGELEY, R.N.

1976. Uitratrace analysis by optical amiseson spectroscopy: the stray litht potolem. Appl "spec.: Fredericle, $30: 384-386$

LEIRITIE, M. MATTSSON, E. 1970, A new approeth to the standard addition technique in atomic absorption spectroswopy. Anal. Letters, New Yort: y (6): $315-322$

LORBER, A. GULDART, Z. HAREL, A. LOBS. Compensetion for background variation by generalized backgound

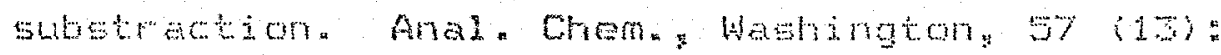
$2537-2540$

MAESGEN, F.J.M.J. HALKE, J.S CE BOER, J.L.M. 1982.

Preservation or accuracy and precisson jir the maly tical practice of low power ICF-bEs. Spectrochime Acts: New Yoll: 79B (6): $517-526$.

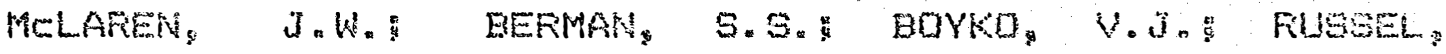
D.5.1981. Simultaneous determination of major " minor and trase elements in marine sediments by inductively coupled atonic: enission spectrometry. Anal "Chen. Waghington, 5y (12): 1802-1806.

MERMET, J.M. 1975 Comparaison des temperatures $t$ des densites eletroniques mesurees sur le gaz plasmagkne et sur les elements excites dans un plasma h.f. Spectrochima Acta, New Yort: $308: 305-396$.

DSTEN, D.H. KOWALSK, B.R. 1985: Bachground detectjon 
and correction in multicomponent analysis. Anal. Chem., Washington, $57\left(A_{1}\right): 909-\cdots 17$.

PAINTON, C.C.: MoTTOLA, H.A. 1982. Chemical kinetic contributions to practical difpersion in thow injection analysis. Anal. Chem, Weshington. 5s (11): $1715-1715$.

PAINTON, C.C.: MOTTOLA, H.A. 19B8. Gimetics in continuous flow sample processing. Chemical contributions to dispersion in flow-injection techniques. Anel. Chim. Acta, Ansterdam, 158: 67-.84.

PHILLIFE: G.R. EVRINGs E.M. 1983. Compatison of conventional and robust regression in analysis of chenical data. Anal. Chem., Washingtong 55 (7): $1134 \cdots 138$

PINTA, M. 1980. Espectrometrite d'absorption atomique. Ed. Masson ORSTOM, Tomo II. Fariss P. RATZLAFF, KoL. 1979. Optimizing precigion in standard condition measurements. Anal. Chem. Washington, $51(2): 232-235$.

REED, T.B. 1961a. Induction-coulped plasma. J. Appl. Physics: Lancaster, 52 (5): 821-822.

REED, T.E. 1961b. Growth of refractory crystals using the induction plasma torch. J. Appl. Physics, Lancester: 32 (12): 2584-2535.

REIS, B.F.: JACINTHO, A.O.; MORTATTI, J.; KFUG, F.J.: ZAGATTO, E. G.: BEFGAMIN FILHO, H. PESSENDA, L.C.R. 1981. Zone-.sampling processes in flow injection 
analysis. Anal. Chim. Acta, Ansterdan, 125: 221-220. RUZICKA, J.' HANGEN, E.H. 1975. FlOW injection aralysis. fert I. A new concept of fast continuous analysis. Anal. Chim. Actas Amsterdam, 78: 145-157.

RYBARCZYK, J.P.: JESTER, E.F. Y YATES, D.A.: KOIRTYOMAN, 5.F. 2582. Spatial profiles of interelement effects in the inductively coupled plasme. Anal. Chem: Wastington: 54 (15):2162-2170.

SAXEERG, B.E.H. KOAALSKT, B.R. 1979. GEnERaIized standard addition method. Anal. Chen., Wastington, 51 (7): $1031-10.88$

SCHIMDT: G.J.: SLAVIN, W.1982. Inductively coupled piasina emission spectrometry uith internal standarization and substraction of plasma background fructuations. Anad. Chem. Washington, 54 (j4): 2451-2495. SCHRADER, W. GROBENSKI, Z." SCHULZE, H. 1981. Einfuhrung in die AES nit dem induktivgetoppelten FIasma (ICF). Appl. At. Spec. , Uberlingen, $28: 10-58$.

TYSON, J.F. 1984. A critical look at calibration procedures for flame atomic-absorption spectrometry. Analyst: London, 109 (3): $313-317$.

TYSON, J.F.: IDFIS, A.B. 1981. Injection sample introduction for atomic absorption spectrometry : applications of a simplified model for dispersion. Aralyst, London, 106: 1125-1129.

TYSON, J.F.: IDRIS, A.B. 1984 Determination of chromium in steel by flame atomic-mborption spectrometry using a flow injection standard adoitions method. 
Analyst, 109: 25-26.

VALCARCEL, M.C. LUOUE DE CASTRO, M.D. 1984. Andisis por inyeccion en flujo. Imprenta San Pablos Còrdoba, p. 449.

VANDEGINSTE, B.: KLAESSENS, J. KATEMAN, G.19E3. Interattive calibration by a recursive generaliaed standard addition method. Anal. Chim. Actas Ansterdam, 150:71-86.

VANDERSLICE, J.T. STEWART: K.K. FOSEMFEL, A.E. H HGG D.J. 1981. Laminar dispersion in flow injection analysis. Talanta, London, 28: 11-18.

WARNER, I. D.: DAVTDGON, E.R. CHRISTIAN, G.D. 2977.

Quantitative analysis of muticomponent fiuomesence data by the methods of least squares and nonnegative least sum of errors. Anal. Chem. Washington: 49 (11): 2155-2159.

WENDT: R.H. FASSEL, V.A. 1965. Induction-coupled plasna spectrometric excitation source. Anal . Chem., Washington, $37: 920-922$.

zAGATTO, E.A.G.:1981. Anajises quìmicas multielementares en sistemas FIA-ICF-GSAM. UNICAMF, CTESE de Doutoramento, Campinas, p.102.

ZAGATTO, E.A.G.: JACINTHO, A.D.: KRUG, F.J. REIS, B.F.: BFUNS, F.E.: ARAUJO, M.C.U. 1783. Flow injection systems with inductively-coupled argon plasma atomic enission spectrometry. Part 2 The generalized standard addition method. Anal. Chim. Acta, Amsterdam, 145: 
$169-178$

ZAGATTO, E.A.G.: GINE, M.F. FEFNAKDES, E.A.N. REIS, B.F.: KFillag FoJ. 1985. Sequential injection in flow systems as an alternative to gradient exploitation. AnaI. Chim. Actas Amsterdam, 173: 289-297. ZSCHETLE IF" F." MURFAY, G.A. BAKEH, G.A.: PEDDTCORD, R.6. 1962. Instability of 2inear gyetems derived from spectrophotometric amelysis of muticomponent systems. Anal. Chem.s Hashington: 34 (13): 1776-1780. 


\section{APENNDICE}

Parânetros de controle do programs

Eaderę̧o no micropro

cessador

2000

01

02

03

04

05

06

07

08

09

$O A$

$O B$

OC

OD
Valor do parámetro

em hexadecional

OBS: os dados desta coluna são preenchidos pelo pesquisador antes da operação do sistema.
Comentário

I - define a duração do solenójde A ligado.

$\mathrm{T}_{2}$ - define o interva

lo de tempo para encher o "loop" L $s$.

$\mathrm{T}_{3}$ - define a duraçäo do solenóide $B$ ligado.

${ }^{T_{4}}$ - define o interva lo de tempo entre is introdução da amostra no percurso analítico e a inicialização do PDP-8.

$T_{5}$ - define o interva lo de tempo para com pletar o ciclo.

$T_{1}$ define 0 incremento de $\mathrm{T}_{4}$ en cada ci clo.

\footnotetext{
' $T_{2}$ define 0 incremento de $\mathrm{T}_{5}$ e o decre mento de $\mathrm{T}_{2}$ en cada ci clo.
} 


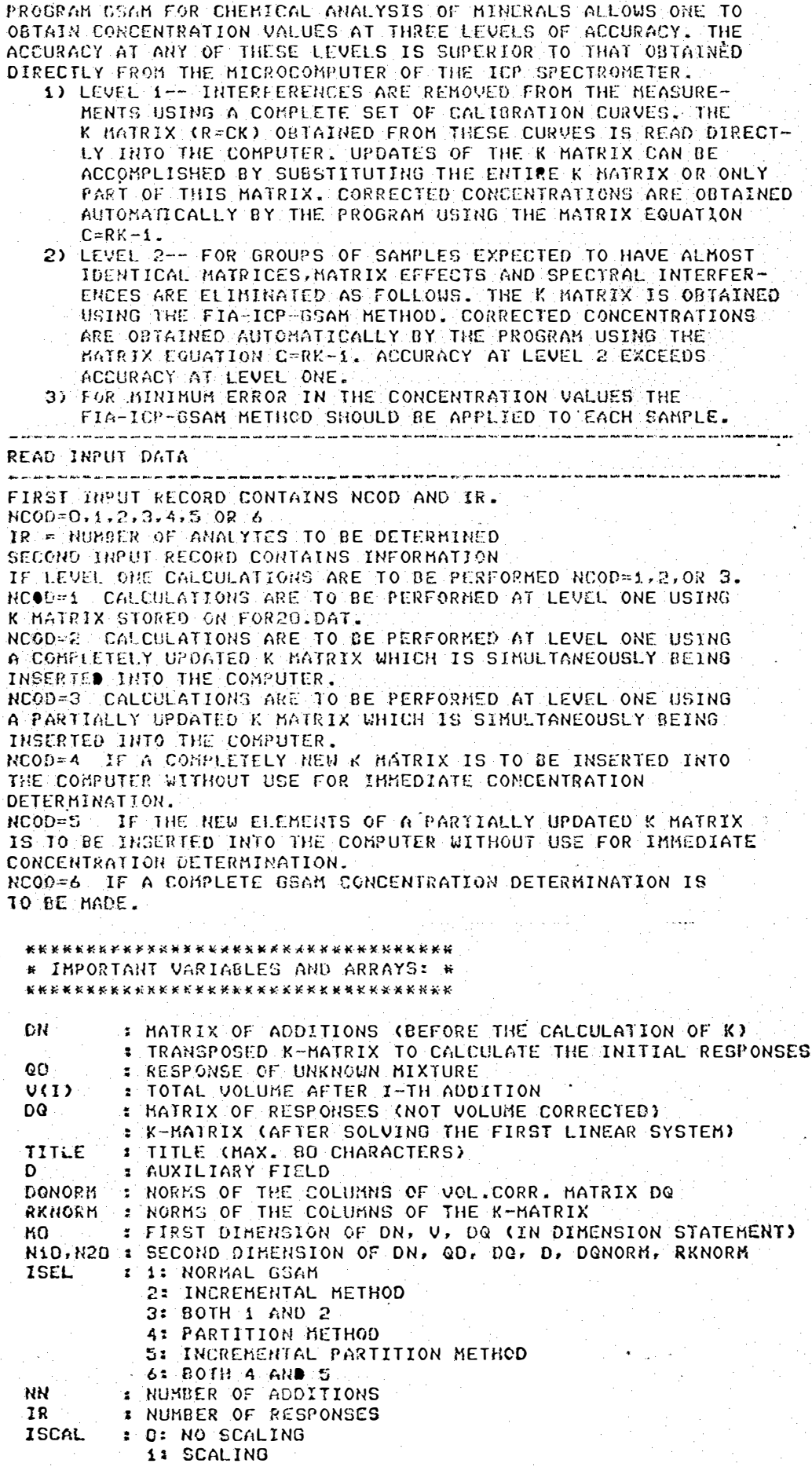

2) LEVEL 2- - FOR GROU?S OF SAMPLES EXPECTED TO HAVE ALMOST IUEMTICAL MATR ICES, HATRIX EFFECTS AND SPECTRAL INTERFEREHEES GRE ELIMIHATED AS FOLLOWS. THE K KATRTX IS OBTAINED USING THE FIA ICP TSSAM METHOD. CORRECTED CONCENTRATIONS ARE ORTAINED RUTOMATICALLY BY THE PROGRAM USTRG THE MAYPIX RGUATION C $=$ RK - 1. ACCURACY AT LEVEL a EXCEEDS ACCURACY AT LEVEL ONE.

3) FIR KINIMUM EREOR IN THE CONCENTRATION VALUES THE FIG-IOP-OSAM METHCD SHOULD RE APPLIED TO EACH SAHPLE.

REAO INPUT DRTA

FIRST THOUT KECORD CONTAYNS NCOD ANO 5 F $N C O O=0,1,2,3,4,5$ O2 6

$Y R$ : WUYORR OF ANALYTES TO BE DETERMTMED

SECCHO MHPUT RECORE COMTAINS TNFORMATJON

IF LEUET OHE CALCULATICRES ARE TO BE PERIOPMED NCOD $=9$, E, OR 3 HCOLE: 1 CALCULAYTOHS ARE TO BE PERFORHED AT LEVEL ONE USTME K MATPIX STORED ON FORZO.DAT.

NCGD F CALCHLATYOHS ARE TO DE PERFORHED AT LEVEL ONE USING A COHFIETELY UIPSTEO K BATRYX WHICH IS SIMULTANEOUSLY BEING INSERTED IH!TO THE COMUUTER

NCOD=3 CALCULATIONS AKE TO BE PERFOMHED AT LEVEL ONE USING A PAKITALLY LPDATEO $K$ MATRIX WHICH IS SIMULTANEOUSLY BEING IMSERTEO IHTO THE COMPUTER.

MCOS $=A$ IF A COHWLTELY MEW K HATRIX IS TO BE INSERTED TNTO THE COMPUTER WTTHOUT USE FOR IMHEDIATE CONCENTRATION DETERMINATTON

HCOD $=\Xi$ IF THE HEW EIEMEATS OF G PARTIALLY UPDATED K MATRIX IS TO BE YHAERTEO IMTO THE COMPUTER WITHOUT USE FOR IMMEOTATE CONCENTKAYIOH UETERMINATION.

RCOD=6. IF A COKSPLETE GSAM ECNCENTRATION DETERMINATION IS

TO BE MADE. 